\title{
FRACTURE OF HARDENED CEMENT PASTE
}

\section{SEPTEMBER 1968}

NO. 20
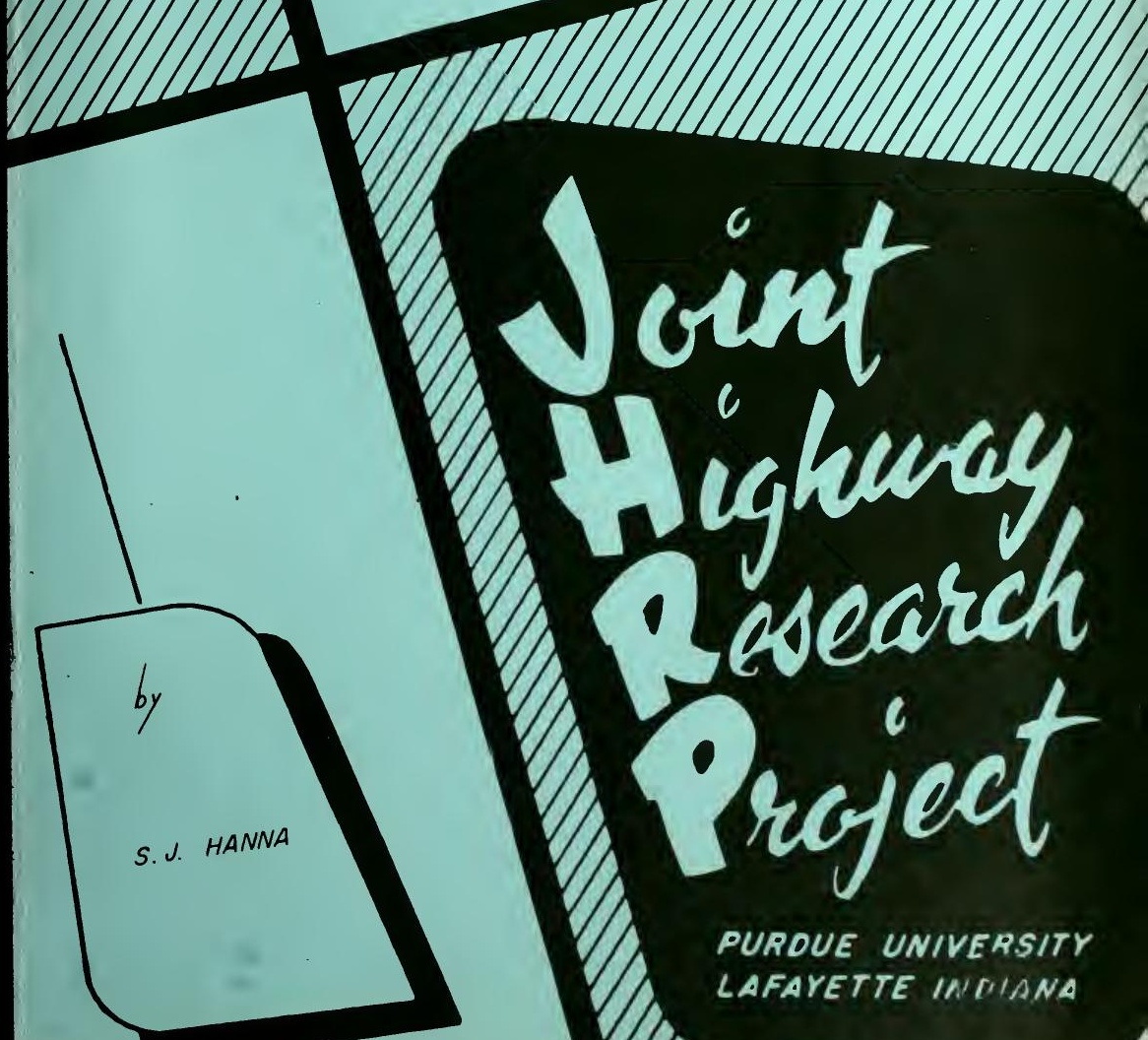
Final Report

FRACTURE OF HARDENED CEMETIT PASTE

To: J. F. Mclaughlin, Director

Joint Highway Research Project

From: H. I. Michael, Associate Director Joint Highway Research Project
September 12, 1968

File No.: $5-14-4$

Project No.: C-36-61D

The Final Report attached is titled "Frecture of Hardened Cement

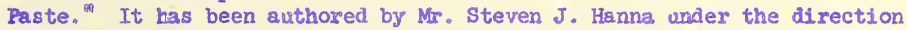
of Professor W. L. Dolch. The research was performed under a Plan of Study approved by the Board on May 10, 1966. Mr. Hanna also used the report as his thesis in partial fulfillment for the $\mathrm{Ph} . \mathrm{D}$. degree.

The research was concerned with the tensile fracture phenomena in hardened portiland cement paste. A modification of brittle fracture equations was suggested for cement paste and existing brittle fracture theories were evaluated.

The report is submitted to the Boerd for the record and for review and comment.

Respectrully submitted,

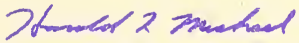

Harold L. Hichael

Associate Director

\section{HIM: $:$ me}

\author{
ce: F. L. Ashbaucher \\ W. L. Dolch \\ W. H. Goetz \\ W. L. Grecco \\ G. K. He.2lock \\ M. E. Hax \\ R. H. Harrell
}

J. A. Havers

V. E. Harvey

G. A. Leonards

F. B. Mendenhall

R. D. Miles

J. C. Oppenlander
C. F. Scholer

M. B. Scott

W. T. Spencer

H. R. J. Walsh

K. B. Woods

E. J. Yoder 
FIna1 Report

FRACTURE OF HARDENED CEMENT PASTE

by

Steven J. Fanna

Gradisate Instructor in Research

Joint Highway Research Project

Project: C-36-62D

File: $5-14 \times 4$

Purdue University

Lafayette, Indiana

September 12, 1968 


\section{ACKNOWIEDGEMENTS}

This investigation was sponsored by the Indiana State Highway Department. The writer is grateful to this organization for providing the necessary financial support.

The writer wishes to express his sincere appreciation to his major professor, W. L. Dolch, for his assistance during the course of the research and in the preparation and review of this thesis.

The writer also wishes to thank the many persons who provided advice, suggestions and encouragement on portions of this investigation. 
Digitized by the Internet Archive in 2011 with funding from

LYRASIS members and Sloan Foundation; Indiana Department of Transportation 
TABLE OF CONTEIVTS

Page

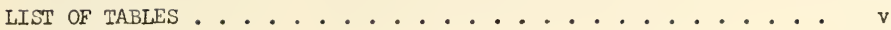

LIST OF FIGURES ....................... vi

ABSTRACT . . . . . . . . . . . . . . . . . viii

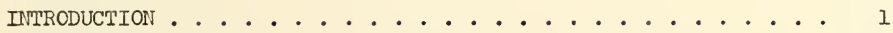

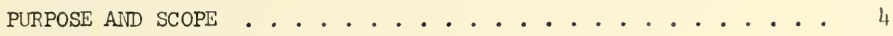

REVIEW OF PREVIOUS WORK ................. 5

FRACTURE OF CERIEITT PASTE ................... . . . 24

Experimental Considerations ............. . 24

Haterials ..................... 30

Mixing of Cement Paste . . . . . . . . . . . . 30

Casting Specimens ................. 36

Removal of Specimens from Molds . . . . . . . . . . . 37

Curing ......................... 39

Testing ......................... 39

Compression Testing ................. 41

Diametral-Compression Testing ............ 41

Theta Specimen Testing ............. 43

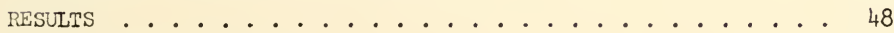

Density Determinations .............. . . 48

Results of Compression and Modulus of Elasticity Tests . . . . 49

Results of Tests on Theta specimens ........... 53

Results of Diametral-Compression Tests . . . . . . . . 57

Results of Tests on Cylinders with Artificial Flaws . . . . . 73

DISCUSSION OF RESULTS . . . . . . . . . . 78

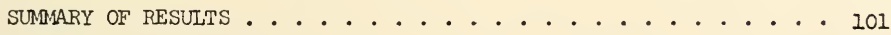

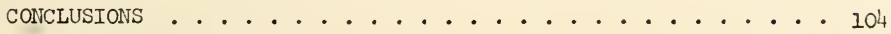

BIBLIOGRAPIY . . . . . . . . . . . . . 106

APPENDIX A: DATA SUMMARIES ...................... 115 
TABLE OF CONTENTS, continued

Page

APPENDIX B.............................. I40

Statistical Analysis of Theta Test Results for $\mathrm{W} / \mathrm{C}=0.4$. . . 140 Statistical Analysis of Theta Test Results for $\mathrm{W} / \mathrm{C}=0.5$. . . . 141 Statistical Analysis of Theta Test Results for $\mathrm{W} / \mathrm{C}=0.6$. . . 142 Statistical Analysis of Diametral-Compression Results

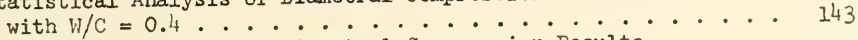

Statistical Analysis of Diametral-Compression Results

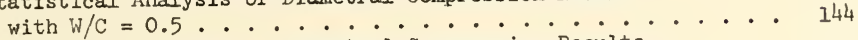
Statistical Analysis of Diametral-Compression Results with $\mathrm{W} / \mathrm{C}=0.6 \ldots . . . . . . . . .145$ Statistical Analysis of Mixing Techniques . . . . . . . . . 146 Statistical Evaluation of the Effect of Artificial Flaws . . . . 147 ANOVA Table for Diametral-Compression Results . . . . . . . I48 Regression Analysis of Theta Specimen - Flaw Data . . . . . . 149

APPENDIX C . . . . . . . . . . . 150

APPENDIX D . . . . . . . . . . . . . . . 152

VITA . . . . . . . . . . . . . . . . 154 


\section{LIST OF TABLES}

Table

1. Physical and Chemical Properties of Cement 317 . . . . . 31

2. Density Determinations of Cylinarical Specimens . . . . . 50

3. Density of One Inch by Two Inch Cylindrical Specimens . . . 51

4. Compression Test Results ............... . 51

5. Moduli of Elasticity of hardened Pastes . . . . . . . 52

6. Results of Tests on Theta Specimens Vacuum Mixed

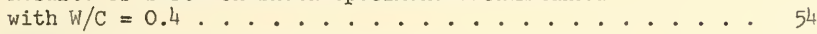

7. Results of Tests on Theta Specimens Vacuum Mixed

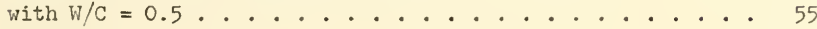

8. Results of Tests on Theta Specimens Vacuum Mixed with $\mathrm{W} / \mathrm{C}=0.6$................ 56

9. Results of Diametral-Compression Tests for $\mathrm{W} / \mathrm{C}=0.4$... 64

10. Results of Diametral-Compression Tests for $\mathrm{W} / \mathrm{C}=0.5 . . .65$

11. Results of Diametral-Compression Tests for $\mathrm{W} / \mathrm{C}=0.6 . . .66$

12. Summary of Failure Stresses From DiametralCompression Tests ................ 67

13. Summary of Diametral-Compression Tests for Specimens with Teflon Inserts . . . . . . . . . . . . 77

14. Compression Test Results . . . . . . . . . . . 115

15. Results of Modulus of Elasticity Tests . . . . . . . . . 117

16. Summary of Tests on Theta Specimens ........... 119

17. Summary of Microscopic Study of Theta Specimens . . . . . 123

18. Summary of Diametral-Compression Tests . . . . . . . 127

19. ANOVA Table for Diametral-Compression Test Results . . . . 148 
LIST OF FIGURES

Figure

Page

1. Theta Specimen Geometry ... . . . . . . . . 26

2. Hobart Mixer Hodel N-50 . . . . . . . . . 32

3. Plexiglass Vacuum Mixing Cylinder . . . . . . . . . 33

4. Mixing Cylinder in Position on Roller Mill . . . . . . 35

5. Teflon Theta Specimen Mold ............ . 40

6. Compression Testing Arrangement ............ . 42

7. Diametral-Compression Specimen Holder . . . . . . . . 44

8. Diametral-Compression Testing Arrangenent ....... . 45

9. Theta Specimen Testing Arrangement . . . . . . . 46

10. Theta Specimen No. 17-5 . . . . . . . . . . 58

11. Theta Specimen No. 29-2 . . . . . . . . . . 59

12. Theta Specimen No. 31-1............ . . 60

13. Relationship of Failure Stress to Cross-Section Area of Diametral-Compression Specinens with $\mathrm{W} / \mathrm{C}=0.4$. . . 62

14. Diametral-Compression Specimen No. 1-1 . . . . . . 69

15. Diametral-Compression Specimen No. 16-1 . . . . . . . 70

16. Triple-Cleft Failure .............. . . 71

17. Shear-Type Failure . . . . . . . . . . . . 72

18. Diametral-Compression Specimen with Air Void . . . . . 74

19. Diametral-Compression Specimen with Drilled Iole . . . 75

20. Diametral-Compression Specimen with Teflon Disk . . . . 76

21. Relationship of Flaw Size to Theta Specimen Failure Stress,

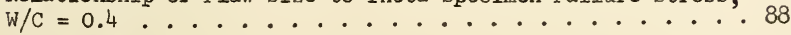


22. Temperature Dependence of Tensile Failure Stress for

0.4 W/C Diametral-Compression Specimens . . . . . . . 95

23. Temperature Dependence of Tensile Failure Stress for $0.5 \mathrm{~W} / \mathrm{C}$ Diametral-Compression Specimens . . . . . . . 9 96

24. Temperature Depenrence of Tensile Failure Stress for $0.6 \mathrm{~W} / \mathrm{C}$ Diametral-Compression Specimens . . . . . . . 97 


\section{ABSTRACT}

Hanna, Steven John. Ph. D., Purdue University, August, 1968. Fracture of Hardened Cement Paste. Major Professor: W. L. Dolch.

This investigation was concerned with tensile fracture phenomena in hardened portland cement paste. The origin of critical cracks and subsequent fracture under the influence of compositional and environmental variables were studied. The results were viewed in light of existing brittle fracture theories and an additional modification of brittle fracture equations was suggested for cement paste.

Two types of tensile tests, diametral-compression tests on cylindrical specimens and tests on theta shaped specimens, were used to evaluate the tensile strengths of the hardened cement pastes. Pastes were mace with type I portland cement and water-cement ratios of $0.4,0.5$ and 0.6. They were tested in a saturated condition after curing 28 days or longer.

In some specimens, small discs of teflon were inserted to serve as crack origins; in others existing air bubbles served the same purpose. Patterns on the fractured faces indicated that these flaws were the source of the final fracture. If no large flaw was present, a size effect on tensile strength was obtained.

Evaluation of the test data for the lower water-cement ratio paste specimens showed good agreement between the failure stress-rlaw size data and the form of the Griffith Theory and its modifications. Calculations of strain-energy-release rates gave values about the same as 
have been obtained by others using other means and support the assumption that the measured flaw sizes were the initial values from which the cracks propagated rapidiy.

The data showed that more energy was required for fracture than could be explained by the creation of new surface. The ratio of this "plastic work" to the energy to create surface during the onset of fracture was estimated to be about 3 .

Data for diametral-compression specimens tested at different temperatures showed a relatively high influence of temperature on the tensile strength of the low water-cement ratio pastes and a decreasing dependence with increasing water-cement ratios. Analysis of these data and the observation of free water on the fracture surfaces suggest water movement in the pores of the paste to be the extra energy-consuming process. 


\section{INTRODUCTION}

Portland cement concrete is widely used as a structural building material. In the area of highway transportation, portland cement concrete is used in the pavement and in its attendant structures. If the concrete fails by fracture, there is a resulting loss in load-carrying ability and in smoothness. Such failures result in increased maintenance and repair costs. If these failure mechanisms are well-understood, steps can be taken in the design of the concrete mixture and in the structural design to reduce the probability of failure. It is, therefore, important from both an economic and safety standpoint to have a better understanding of the failure mechanisms in portland cement concrete.

Much interest has been generated in recent years concerning the fracture mechanics of concrete and other ceramic materials. Early work was concentrated in the area of glasses and metals. The Griffith theory of brittle fracture $(34)^{*}$ and the Orowan modification of it (71) have been used to explain the process of fracture in glasses and metals. Kaplan (51) has applied the Griffith theory, as modified by Irwin (47), to concrete.

Concrete is a mixture of cement paste and aggregate, a complex and inhomogeneous system. Cement paste itself is inhomogeneous owing to the presence of unhydrated cement particles, capillary pores, gel pores and

\footnotetext{
phy.

Numbers in parentheses refer to references listed in the Bibliogra-
} 
microcracks formed by thermal and shrinkage stresses. But in comparison with concrete the cement paste can be considered a relatively homogeneous material.

The water-cement ratio is the primary factor controlling the strength of the paste through its controlling effect on the porosity. The lower the water-cement ratio, the lower the porosity and the higher the strength. Other variables, such as aggregate properties, affect the strength of portland cement concrete to a somewhat lesser degree. With a number of interrelated variables present, the effects of any single variable are masked by the action of the others. Any investigation of the fracture of concrete is thus extremely complex. The complexity of the system is reduced when only the hardened cement paste component is considered.

There are several specific questions to which satisfactory answers are lacking. One is, where do cracks in concrete come from? The existence of microcracks in concrete prior to any external loading has been established (97), but the cause of fatal flaws is not understood. In cement paste, the origins of such critical flaws are even more obscure than in concrete. Rough calculations, based on the theory of brittle fracture, indicate that flaws much larger than the capillary pores present in the cement paste must exist in order to explain its low tensile strength.

Still more complex is the problem of the propagation of existing microcracks in relation to their orientation within the mass. The problem of how cracks propagate through a material such as concrete, where there are numerous microcracks of various sizes and orientations, is 
formidable.

Another obvious problem is that of determining what corrective measures can be taken, either to prevent the formation of critical cracks or to control the propagation of existing microcracks. 
PURPOSE AND SCOPE

The purpose of this research was to examine tensile fracture phenomena in hardened portland cement paste, including crack origin and crack growth, under the effects of compositional and environmental variables. The results were interpreted by means of the modified Griffith and strain-energy-release-rate theories to test their applicability and to derive more acceptable models for fracture of this material.

The primary factor controlling the strength of the paste, and therefore, of the concrete, is the water-cement ratio. A range of watercement ratios from 0.3 (by weight) for a dense structure to 0.6 for a paste with an open caplllary structure was selected. The tensile strength of the paste was determined by the diametral-compression test on cylindrical specimens and tests on theta-shaped tensile specimens.

Both specimen size and test temperature are known to affect the behavior of stressed materials and were included as variables in this investigation. Factors such as curing conditions and mixing procedures were controlled at constant levels.

Based on the information gained by testing the cement pastes at the varlous levels of the controlled variables, and based on current brittle Practure theories, a hypothesis is presented for the failure mechanism in portland cement pastes under tensile stress. 
REVIEW OF PREVIOUS WORK

Much of the early work in the study of fracture mechanisms in materials was directed towards the development of failure theories based on the observed behavior of the materials. As the study of fracture mechanics proceded, new methods of analysis were used and the theory of elasticity was applied to more complex systems. Failure theories were developed based on theoretical analyses. It was observed, however, that the strength of materials is much lower than that predicted by the fracture theories. In 1920, A. A. Griffith $(34,35)$ developed a theory of fracture for brittle materials in which he attempted to reconcile the differences between the estimated strengths and those actually observed in testing.

Griffith's theory considered that cracks were formed in the material due to the action of stresses or that there were pre-existing cracks already present in the material prior to external loading. Using the result of Inglis's mathematical stress analysis (45) for the stress at the tip of an eliptical crack, Griffith developed his theory of brittle fracture.

"Just as in a liquid, so in a solid the bounding surfaces possess a surface tension which implies the existence of a corresponding amount of potential energy. If owing to the action of a stress a crack is formed, or a pre-existing crack is caused to extend, therefore, a quantity of energy proportional to the area of the new surface must be added, and the condition that this shall be possible is that such addition of energy shall take place without any increase in the total potential energy of the system. This means that the increase of potential energy due to the surface tension of the 
crack must be balanced by the decrease in the potential of the strain energy and the applied forces." (35)

Griffith concluded that since the average strain energy in a specimen is small compared to the theoretical energy required for rupture there must be a non-uniform distribution of the energy within the test specimen. In other words, there must be high stress concentrations at the points where cracks originate. Griffitb further concluded that there are only three possible ways in which these high stress concentrations can occur. These are:

(1) If the material is heterogeneous, there may exist a mutual surface tension, of sufficient magnitude, between different constituents.

(2) The material may contain severe initial stresses.

(3) The material may contain small cracks formed during manufacture or in the course of subsequent treatment.

Griffith proceeded to analyze a system based upon the third possible cause. Griffith's original analysis was limited to two-dimensional problems and to materials which obey Hooke's law. Using the mathematical results of Inglis (45) applied to a flat plate with an eliptical crack in the interior, Griffith (34) arrived at his familiar equation:

$$
\sigma^{2}=\frac{2 E y}{\pi c}
$$

where:

$$
\begin{aligned}
& \sigma= \text { the average tensile stress existing normal to the crack's } \\
& \text { long axis. } \\
& 2 c=\text { crack length } \\
& E=\text { Young's modulus of the material }
\end{aligned}
$$




$$
\gamma=\text { surface free energy of the material }
$$

The thermodynamic basis for this equation is that spontaneous crack extension can occur only when the total free energy of the system is thereby lowered. When the crack extends, the system uses strain energy that was stored elastically in the region relieved by the crack. Energy is consumed by the creation of new surface (and frequently in other ways). The critical crack size given by equation $l$ is that for a balance between the changes of these energies with incremental crack extension. The Griffith theory deals with elastic cracks and hence there are atomic bonds at the crack tip in every stage of elongation and fracture (22). There are, therefore, no additional criteria to satisfy for crack propagation.

As pointed out by Cottrell (22), most of the experiments on Griffith's theory have been on noncrystalline materlals. Griffith's work in experimental verification of his theory was primarily concentrated on glasses. He noted that as the glass was drawn to thin fibres, the observed strength approached that of the calculated strength. Griffith further noted that if glass rods were handled so that the surfaces were protected, high strength values were obtained, but if two such rods were even lightly touched together, the observed strengths were reduced drastically.

Sack (90) extended Griffith's theory to three dimensions using a disk shaped crack, of radius $c$, as the model. Sack derived the following expression for the plane strain condition:

$$
\sigma^{2}=\frac{\pi E y}{2 c\left(1-\mu^{2}\right)}
$$


Orowan (71) demonstrated that for fully brittle materials Equation (1) was a necessary and a sufficient condition of fracture. Orowan considered the variation in molecular forces as the molecules are pulled apart. The variation is zero when there is no stress applied to a material, and the molecular spacing at zero stress is b. The force rises to a maximum of $\sigma_{m}$ when the material is pulled apart and falls to zero as the fragments separate. The area under the curve is $2 \alpha$, which is the work of fracture per unit area. One half the area, $\alpha$, is estimated as $b_{\frac{m}{2 E}}^{2}$, and therefore:

$$
\sigma_{m}^{2} \cong \frac{2 E \alpha}{b}
$$

From Inglis's work it is shown that the stress concentration of a surface crack of depth $c$ is:

$$
\sigma=2 \sqrt{\frac{c}{\rho}}
$$

where $\rho$ is the radius of the root of the crack. "Thus, the value $\sigma$ of the applied tensile stress at which the molecular strength is reached at the tip of the crack is given by $\sigma_{m}=\sigma \cdot 2 \sqrt{\frac{c}{\rho}} "(71)$. And when substituted in the above equation for $\sigma_{m}$, the value of $\sigma^{2}$ is, within the accuracy of the estimate, identical to Griffith's.

If, however, there is plastic deformation associated with the crack propagation, then the surface energy used by Griffith must be replaced with the "plastic surface work". The stress required for crack propagation would then be proportional to the plastic surface work, p, rather than to the surface tension $\gamma$. 
Irwin (47) in analyzing the problem of crack propagation and the stresses in the vicinity of the leading edge of the crack developed a relationship for the crack extension force. He called this the strain energy release rate, $\mathrm{G}$ :

$$
G=\frac{K^{2}}{E}\left(1-\mu^{2}\right)
$$

where :

$$
\begin{aligned}
& K=\text { stress intensity factor }(47) \\
& E=\text { Young's modulus } \\
& \mu=\text { Poisson's ratio }
\end{aligned}
$$

The critical strain energy release rate, $G_{c}$, occurs at the onset of rapid fracture.

Recent investigators $(27,47,51,31$ ) have noted a slow crack growth prior to spontaneous fracture. This phenomenon is explained by Glucklich (31) as the result of the required increase in stress level to make the crack grow (perhaps due to stress redistribution in a nonhomogeneous material). When the crack reaches its critical size rapid fracture will occur, i.e., the crack will run spontaneously. At this point the critical strain-energy-release rate, $G_{c}$, occurs. Griffith assumed $G_{c}$ to be twice the surface free energy of the material, while more general considerations involve all other energy consuming mechanisms, such as plastic flow.

It is pointed out by Glucklich that $G_{c}$ is a material property.

"G is thus the resistance of metals to brittle fracture. When the third dimension is considered, $G$ has the dimension of a force and is sometimes referred to as the 'driving force'. In actual fact, it is the energy released for the formation of a unit new surface; and since it is measured at the onset of instability it includes the total requirement of energy. G replaces $E$ in Griffith's 
equation and it can be seen that in tension $G_{c}=\frac{2 \pi c \sigma^{2} \text { tens }}{E} "$.

In the work so far described, the crack is assumed to be plane and so to propagate across the section. But inspection of any fractured surface shows that it contains a great deal of irregularity, or hackle. Irwin (47) pointed out that in the fracturing of a brittle material there are two points of abrupt change in the process. The first of these is the transition from slow to fast crack propagation and the second is the point where the crack velocity reaches a critical value and forking of the crack or the development of hackle occurs.

"Once a crack approaches its terminal velocity, the kinetic energy associated with fast crack extension also approaches a constant maximum value. Beyond this point the released elastic strain energy increases with crack length. To dissipate the additional energy, the crack 'forks' or divides into two cracks, each of which propagates at a small angle to the original crack" (2l).

Clausing (18) in 1959 demonstrated that the Griffith theory and Mohr's theory are mathematically related. "... Only two theories known to the author show any hope of agreeing with experimental data on brittle materials. They are Griffith's Crack Propagation Theory, and Mohr's Theory. It will be shown that these two theories, although based on entirely different physical concepts are mathematically related. However, Griffith's theory is far more comprehensive than that of Mohr... Here we have a strange anomaly. Both Mohr and Griffith agree that Mohr's envelope is a valid representation of failure conditions. Both agree that the angle of failure is determined by the point of tangency of the envelope with a Mohr's circle. However, they have entirely different physical explanations for the failure that occurs at this angle. Mohr says it is due to shear, while Griffith explains it by tension at the tip of a crack. Their different physical reasonings lead to contradiction in the expected shape of Mohr's envelope" (18).

It should be noted that both Griffith's theory and Mohr's theory predict infinitely large triaxial compressive stress without failure. In this region Mohr's envelope is a valid representation of Griffith's theory.

Robinson (85) in his work with confining pressures on sedimentary 
rocks noted that Mohr's diagrams showed a change in the angle with high effective stresses. Robinson further noted that brittle failure always occurred in the sedimentary rocks when the confining pressures and the pore pressures were equal and that mode of failure gradually changed from brittle to ductile as the differential between the confining and pore pressures increases the transition pressure.

Glucklich (29) mentioned that the strain-energy-release rate $G$ is a function of the crack length in both tension and corpression. For the compression state the equation for $\mathrm{G}$ becomes:

$$
G=\frac{\pi \sigma^{2} \sin ^{2} \phi \cos ^{2} \phi}{E}
$$

where:

$$
\begin{aligned}
c= & \text { crack length } \\
\sigma= & \text { compressive stress } \\
\phi= & \text { angle between the plane of the crack and the direction of } \\
& \text { the compressive stress. }
\end{aligned}
$$

For concretes, mortars, and pastes there is evidence that cracks exist within the mass before the application of any external loading at all. Hsu $(42,43)$ and Slate and Olsefski (97) have shown by the use of thin sections and $X$-ray techniques the presence of such cracks in concrete. Presumably they are due to temperature changes, moisture changes, etc. Most of the studies of bond between aggregates and paste have also indicated that microcracks exist at the aggregate-paste interface due to bond failure $(20,42,43,97)$. A logical conclusion is that a concrete specimen fails by the extension of these microcracks under loading (51).

Savin (92) has shown that stress concentrations at the edge of a circular hole positioned at the center of a strip of finite width carries 
from 3 to 4 times the applied stress for hole diameters up to one-half the width of the strip. Thus a brittle material loaded in tension may crack at average stress levels below the ultimate strength of the material if voids or other stress risers are present.

Since concrete is a heterogeneous material made up of components with different physical properties, stress concentrations would be expected. Various investigators $(43,44,48,50,51,84,97)$ have shown that micro-cracks appear at forty to sixty percent of the ultimate load. Based on the knowledge that stress concentrations exist in concrete, it is quite reasonable to expect that in areas of these high stress concentration localized fallure occurs, microcracking results, these cracks grow, and ultimate failure occurs. Once the crack reaches a critical size it presumably propagates to failure without any increase in load in accord with Griffith's theory.

Griffith, in his analysis, used the surface tension of the material and based his hypothesis on the assumption that all the released strain energy in the system went into the formation of new surfaces. His theory neglects other energy absorbing processes such as heat generation and plastic flow. Neglecting these factors poses a problem in applying the Griffith theory to cement pastes - the magnitude of the surface energy. Investigations by electron microscopy and permeability measurements $(19,82)$ have indicated that the cement gel is made up of "slender ribbons and crumpled sheets or foils." The bonding forces that hold these gel particles together are not understood. Brunauer's (14) work indicates that a tobermorlte-like gel makes up most of the colloidal fraction of hardened portland cement paste, and that its surface free energy 
is approximately $390 \mathrm{ergs} / \mathrm{cm}^{2}$.

The strength of concrete is usually less than that of either the paste or the aggregate. The water-cement ratio basically controls the strength of the paste. This effect is primarily ascribed to the gelspace ratio (66) or, in other words, the ratio of solid to the total space; the more empty space, the weaker the paste. Research on ceramics (52) has shown that strength decreases exponentially with porosity,

$$
\sigma=\sigma_{0} e^{-n p}
$$

where :

$$
\begin{aligned}
& \sigma=\text { observed strength } \\
& \sigma_{0}=\text { strength at zero porosity } \\
& \mathrm{n}=\text { coefficient with range of } 4 \text { to } 7 \\
& \mathrm{p}=\text { volume porosity }
\end{aligned}
$$

Schiller (93) has suggested other relationships between strength and porosity. Passmore, et al (74), in studies of polycrystalline alumina, have developed relationships between porosity and grain size and strength. The relationship to porosity is given by:

$$
\mathrm{S}=B \mathrm{e}^{-\mathrm{bp}}
$$

where :

$$
\begin{aligned}
& S=\text { observed strength } \\
& B=\text { constant } \\
& b=\text { constant } \\
& p=\text { volume porosity }
\end{aligned}
$$

The relationship to grain size is given by:

$$
S=A G^{-a}
$$


where:

$$
\begin{aligned}
& S=\text { observed strength } \\
& A=\text { constant } \\
& G=\text { grain size } \\
& a=\text { constant }
\end{aligned}
$$

When aggregates and cement are combined with water to form concrete other factors, such as gradation and shape and surface texture of the aggregates, as well as porosity influence the strength of the concrete $(8,20,38,41,66,77,81,87,70,110)$. Hirsch (41) demonstrated that the modulus of elasticity of concrete is a function of the moduli of the cement paste matrix and of the aggregate. "The degree to which the elastic properties of one of the ingredients affects the modulus is a function of the quantity present in the batch" (41).

To complicate the picture still more, the hydration of portland cement to form cement gel is an exothermic reaction and considerable heat is generated. After the final set the heat generated, which reaches a maximum at about 16 hours (99), is reduced as the reaction slows. This reduction causes a temperature change in the concrete and hence some thermal stressing. As mentioned previously, thermal change, moisture loss, etc., could result in microcracking.

Glucklich (31) pointed out that an analogy can be found between concrete and metals. There are highly stressed zones in metals in which secondary cracks are formed that do not link to the main crack. Other investigations (63) have shown that failure in fractured rock samples is a multicrack action due to the polyphase nature of the rock samples. Heterogeneity is a factor also in concrete. 
"Aside from being controlled due to increase in energy demand for microcracking, the growth is also often checked by encountering an obstruction such as an aggregate. In most aggregates the surface tension is higher than in the cement paste so that when the crack penetrates an aggregate the demand of energy is suddenly increased. If the crack deviates around the aggregate, then the demand is also appreciably increased for the actual surface formed is much greater than the effective surface" (31).

In work with concretes and mortars, Kaplan (51) noted that microcracks occurred in notched beams at loads considerably less than the ultimate fracture load. Irwin (47) and Glucklich (27, 30) have called this "slow crack growth." This effect may be due to localized high stress concentrations that result in crack propagation in small increments as the stress increases, until a critical crack size is reached, at which point the crack will propagate rapidly and spontaneously.

Kaplan (51) used the Irwin modification of the Griffith equation and checked its applicability by means of tests on notched beams in flexure. The notches were used as stress risers to precipitate a failure at the notch root. For such a beam Kaplan developed an expression for the strain-energy-release rate when the notch depth to beam depth ratio is greater than 50 percent,

$$
G=0.52 \frac{\left(1-\mu^{2}\right) \sigma_{n}{ }^{2} h}{E}
$$

where:

$$
\begin{aligned}
& \mu=\text { Poisson's ratio } \\
& \sigma_{n}=\text { nominal bending stress at notch root } \\
& \mathrm{h}=\text { depth of the beam to notch root } \\
& \mathrm{E}=\text { Young's modulus }
\end{aligned}
$$

For notch depth to beam depth ratios less than 15 percent, Equation (10) must be modified by a function of that ratio. Kaplan calculated $G_{c}$ and 
found that it did not vary greatly for beams of different notch depths, indicating that $G_{c}$ was a property of the material. Ile stated:

"In determining $G_{C}$, the depth of the crack at instability was assumed to be the depth of the notch. This assumption may be incorrect in that the notch depth may increase prior to instability due to slow crack growth at the tip of the notch as the load is increased. The effect of this would be to increase the $G_{c}$ values which have been calculated." (51)

Kaplan concluded that strain-energy-release rate values could be ob-

tained for concrete using these procedures.

"Further research is necessary, particularly in regard to the question of slow crack growth prior to fast fracture. The results of this investigation nevertheless indicate that the Griffith concept of a critical strain-energy-release rate being a condition for rapid crack propagation and consequent fracture, is applicable to concrete. The critical strain-energy-release rate may be ascertained by suitable analytical and experimental procedures, and it is possible that the fracture strength of concrete containing cracks may thereby be predicted." (51)

Blakey and Beresford (7) did not see that a case had been made by Kaplan for the application of the Griffith theory to concrete.

"It now appears to the writers that it will be extremely difficult to escape from such a situation in studies of the fracture of concrete in view of the difficulty of measuring the energy dissipated in heat." (7)

It would appear that this problem was overcome by the use of the concept of strain-energy-release rate G. As pointed out by Glucklich (28) the strain-energy-release rate takes into consideration not only surface energy but every other form of energy into which the elastic energy may be converted during the process of crack extension.

There are problems in the measurement of the critical crack length, i.e., the length at which the crack will propagate spontaneously. Techniques of ink straining have been used with some success to determine the length (51) of the crack during slow growth. Robinson (84) discussed various methods, such as sound emission, ultrasonic pulse velocity 
and $x$-ray techniques of detecting the formation and propagation of microcracks in concrete.

It is pointed out by Glucklich $(27,28)$ that the type of testing machine, i.e., "hard" versus "live loads", will influence the crack length. The "live load" would probably produce a shorter "slow" crack.

Lott and Kesler (56) investigated crack propagation in plain concrete. Using the fracture toughness concept of Irwin (47) they developed a pseudo-fracture toughness for concrete when it is considered a homogeneous material. "The pseudo-fracture toughness of concrete is the summation of the fracture toughness of the cement paste and an arresting action developed by the aggregates" (56). Using Glucklich's suggestion that microcracks form in a region near the crack tip and thus increase the required stress over that for only the formation of new surfaces, Lott and Kesler hypothesized that the stress intensity factor $\mathrm{K}_{\mathrm{c}}$ at the start of rapid crack propagation is a function of the limiting size of the microcrack region and the surface energy of the material, cement paste. They further noted that if the microcrack region and surface energy were properties of the material then the critical stress intensity $\mathrm{K}_{c}$ would also be a material property. Since concrete is not homogeneous the fracture toughness of concrete depends not only on the energy required to propagate a crack in the matrix but also on the heterogeneity of the concrete. Lott and Kesler (56) used a model of an infinite plate containing a bonded disk to illustrate the effects of aggregates on crack propagation. Criteria for crack propagation were presented for various conditions. The stress intensity factor $\mathrm{K}$ for the disk and plate were used to show when failure will occur. This analogy is 


$$
K_{c}^{\prime}=K_{p c}+f(A R R)
$$

where :

$$
\begin{aligned}
K_{c}^{\prime} & =\text { pseudo-fracture toughness } \\
K_{p c} & =\text { stress intensity factor in paste } \\
f(A R R) & =\text { arresting function }
\end{aligned}
$$

The stress intensity factor in the paste is that at the onset of rapid crack propagation. The arresting function represents the modification of the elastic fields near the crack tip caused by the concrete aggregates .

"The fracture toughness of cement paste might be affected by the water-cement ratio and the curing of the paste. The factors that might affect the crack arrest are numerous and interrelated. The maximum size and the gradation of the aggregates and the aggregate percentage influence the body geometry of the polyphase concrete. Material properties of the cement paste and aggregates affect the modular ratio and the premature failure of the aggregates." (56)

Lott and Kesler used flexural tests on notched mortar and concrete specimens to test their hypothesis. They found the mean pseudo-fracture toughness varied from $0.265 \mathrm{Kips}$ per inch $3 / 2$ for one of the mortars to $0.356 \mathrm{Kips}$ per inch $3 / 2$ for one of the concretes. Using an expression developed by H. F. Bueckner in "Some Stress Singularities and Their Computation by Means of Integral Equations," in Boundary Problems in Differential Equations, 1960, they were able to compute $\mathrm{K}_{\mathrm{c}}^{\prime}$.

Charles (16) pointed out that for silicate glasses, failure was time dependent. With decreasing load the time to failure increased. Charles also pointed out that the environment influences both the breaking strength and the time to failure. The effect of environment was demonstrated by Orowan (73) by testing mica in a vacuum and moist air. 
Charles explains the concept of lowering the surface energy as

follows :

"It is instructive to examine the surface energy lowering concept of failure as proposed by Orowan (1944) and others (Rehbinder, 1943; Sato, 1954). According to this interpretation, if the surface energy of a solid is lowered, say by the absorption, of a surface active species, then failure for a given flaw geometry may occur at a lowered applied stress. This conclusion demands, however, that the relatively slow flaw growth occur prior to spontaneous rupture. The situation may be more closely described as follows:

The surface energy lowering occurs due to a damping action of the physically or chemically absorbed molecules (or their dissociation products) on the various vibrational modes of the substrate atoms. Neighboring substrate atoms will lose some attraction for one another since they now share some attraction for the relatively mobile absorbed species and their density of packing will be decreased to approach more nearly that of the atoms within the interior of the solid. The mechanical stress necessary to pull them apart will thus be lowered. The bond muture which occurs at lowered stress uncovers underlying atoms that are stable until further absorption permits separation. This cyclic process can continue until the stress concentration, arising from the extension of the flaw, builds up stresses sufficient to part original atoms of the solid and the spontaneous failure, envisioned by Griffith, results. It is evident that failure by this process implies a time effect which is associated with molecular transport of material to an interface. The time effect may be small but it exists nevertheless.

Let us now consider that the interaction of the absorbed species on the surface atoms of the solid is such that an effective 'negative' surface energy results. The tendency, in this case, is to produce rather than conserve surface and the surface atoms enter into combination with the absorbed molecules such that, if the resultant products do not prevent access of further adsorbate to fresh surfaces, a continuing corrosion reaction will occur. A time effect is again indicated but one cannot say, a priori, what the slow process might be that determines the time effect. It may be transport to the interface, or, on the other hand, it may be a reaction at the interface.

The surface energy lowering concept has a built-in mechanism that leads to crack extension in the direction of the maximum tensile stress gradient. The corrosion concept, on the other hand, requires a stress dependency of corrosion rate in order that a flaw might arrive at a critical geometry for crack propagation. Both concepts, however, predict a fatigue limit, an instantaneous high strength independent of atmosphere and conditions for a time effect in failure" (16). 
Brace (10) noted the work of McClintock and Walsh (59) on the extension of the Griffith theory of fracture to include the closing of Griffith cracks with the development of frictional forces along crack surfaces. "Both the original Griffith theory and the McClintock-Walsh modification prescribe limiting stress states for failure. These limiting stresses can be shown in the Mohr diagram to facilitate comparison with experimentally determined fallure conditions such as the Coulomb law" (10). Brace further pointed out that the Griffith theory predicts the orientation of the most severely stressed crack, in a material with a variety of cracks of different length and orientation. It does not predict how this crack will propagate" (10).

McClintock and Walsh (59) in order to explain the discrepancy between the Griffith theory and experimental results of tests on rocks assumed that in compression the cracks closed. It would then be possible for frictional forces to develop at the contact surfaces to influence (retard) the crack growth and hence the failure of the material. The modified theory written as a Mohr envelope

$$
\pm \tau=2 K-\mu \sigma
$$

where:

$$
\begin{aligned}
& \tau=\text { shear stress } \\
& K=\text { tensile strength } \\
& \sigma=\text { normal stress } \\
& \mu=\text { coefficient of friction }
\end{aligned}
$$

The Griffith theory written as a Mohr envelope is

$$
\tau^{2}+4 K \sigma-4 K^{2}=0
$$


The value of $\mu$ is assumed to be 0.8 to 1.0 , "the predicted pressure dependence of strength agrees well with that experimentally determined, for tests of low pressure" (10). The modified Griffith theory and the Coulomb law are identical in the region of compression (10).

Walsh and Brace (106) considered the fracture of brittle anisotropic rocks and extended the McClintock-Walsh modification of the Griffith theory to this case. Criteria were developed for both tension and compression, based on a mathematical model with long cracks of preferred orientation superimposed on a field of randomly oriented small cracks.

Paulding (75) used partially fractured rock and plots of volumetric strains to determine the growth of cracks during brittle fracture.

"The onset of crack growth and the work expended against confining pressure were found with the aid of plots of volumetric strain versus stress. Measurements of linear compressibility indicated the predominate direction of crack growth and the increase in porosity" (75).

Paulding further stated that the plots of volumetric strain versus stress provided a convenient means for determining the start of crack growth without any interruption of the test. Based upon the procedure which he used, Paulding estimated that the stress at the start of crack growth could be determined with about $10 \%$ accuracy.

Walsh (105) noted that during uniaxial elastic compression of rocks there is nonlinearity of the stress strain behavior and of the hysteresis. The cause was attributed to the existence of cracks that closed under the uniaxial compression, and the nonlinear hysteresis to friction between the crack faces, since the cracks are flat. The problem that arises is the determination of Young's modulus, Poisson's ratio, and the compressibility of such materials. Walsh (105) suggested that Young's 
modulus for an uncracked solid could be found by using the initial slope of the unloading curve. Walsh (105) presented a theoretical analysis of the stress conditions with cracks that close under uniaxial elastic compression. The analysis requires knowing the average crack concentration. Work by Brace (1965) supported the hypothesis that a certain amount of porosity occurs in crystalline rocks along grain boundaries and the decrease in porosity during the compression is due to the closure of these crack-like openings.

Brace and Bombolakis (11) found that under compression loading the most severely stressed crack is inclined at about 30 degrees to the axis of compression. Photoelastic studies showed that an inclined "crack" will grow in a manner such that the branches become parallel to the load and at the point of farthest advance the tension at the tip of the crack had dropped to the magnitude of the applied compression. They also noted that the tension at each crack tip was altered considerably for certain arrays. Therefore, the stresses to cause failure would be different than for the case of a single crack for certain of these arrays.

Phillips (76) pointed out that glass usually breaks at less than one percent of its theoretical ultimate strength. The imperfections that reduce the strength of glasses are thought to be confined to the surface. Griffith (34) noted that strength was reduced when glass rods carefully handled to prevent any surface defects were touched together lightly. In other materials, however, the imperfections are not necessarily limited to the material's external surface.

"In crystals, on the other hand, imperfection may include dislocations, interstitials, vacancies, stacking faults, and impurity atoms. For polycrystalline materials, we must add internal cavities and grain boundaries" (76). 
Detection and measurements of internal microscopic flaws is at the present time not possible for most materials. There are other problems also.

"Another question mark is the surface energy S. Data on surface energies of solids are meagre. Only recently has reliable information been obtained for copper. With nonmetallic solids, and particularly those with mixed ionic-covalent bonding, as in glasses, the problem becomes extremely complex. Yet Griffith extrapolated from $2000^{\circ} \mathrm{F}$ to room temperature: Bikerman $(1963$, 1964) offers an even more serious objection. He does not believe that the surface energy $S$ is involved at all in fracture phenomena. He argues that work is done, not on rupture as such, but on the deformations leading to rupture. Whereas the Griffith theory considered a competition between strain energy and surface energy, the Bikerman concept requires only a redistribution of strain energy... The experimental results (Kuznetsov, 1957; Schellinger, 1950) appear to be in better agreement with the new than with the old hypothesis. The specific fracture work $\mathrm{F}$, to produce one $\mathrm{cm}^{2}$ of new crack surface, then becomes several times greater than the $S$ value of Griffith. Shand (1964) has also discussed how greatly S itself can vary. Bikerman finally arrives at an equation $\sigma_{a}=\left(\frac{E F}{2 a}\right)^{1 / 2}$ which is similar in most respects to the Griffith relationship but in which $F$ is much larger than Griffith's $S^{\prime \prime}(76)$. 


\section{FRACTURE OF CEMENT PASTE}

The objective of this investigation is to examine the tensile fracture phenomena in hardened portland cement paste, including crack origin, growth, and inhibition. In the initial phase of the investigation the water-cement ratio and specimen size were variables. The results obtained are interpreted by means of the modified Griffith and strainenergy-release rate theories to test their applicability and to derive more acceptable models for the fracture of this material.

\section{Experimental Considerations}

An examination of the fractured surface of a brittle material can aid in the determination of the source of the fatal crack and the direction of crack propagation. Since hardened cement paste specimens tend to shatter when tested in compression, it is frequently impossible to examine the fractured surfaces adequately. Specimens tested in direct tension, such as the briquet test, are easily subjected to eccentric loadings, which make accurate determinations of the stress at failure difficult, even though they have relatively plane fracture surfaces. Specimens tested in flexure have a stress gradient across their cross section, varying from tension on one side to compression on the other. For these reasons, and others, it was deemed advisable to use a test that would not embody these objections, or at least reduce them.

The diametral-compression test(splitting tensile or Brazilian test)

(62) has recently been used to evaluate tensile strength of concrete 
cylinders. This test overcomes some of the objections to the other types of tensile tests in that a relatively uniform stress state is developed over a major portion of the cross section.

A specimen shape developed by Durelli, Morse, and Parks (25) is designed to fail in tension in the central bar (see Figure 1). The specimen is theta-shaped and is loaded in the plane perpendicular to the central web. A specimen of this shape, when loaded, experiences only tensile forces in the central web, with no stress gradient across that section. The theta specimen also has the advantage of allowing a small cross sectional area to be tested, which is of value in determining the effect of specimen size on the fracture phenomena.

Analysis of the stresses, in both the diametral-compression and the theta specimens, is based on elastic theory. Both tests were used in this investigation to evaluate the "tensile strength" of hardened portland cement paste.

Small specimen sizes were selected to minimize effects of shrinkage and thermal changes. Large cement paste specimens are also difficult to manufacture with uniform densities (Antrim (3) and Mullen (64)). Cylinders with a diameter of 1.1 inches or less, and lengths varying from 0.1 inch to over 2 inches were tested in diametral-compression. Theta specimens with a web thickness of 0.10 inches and depths varying from approximately one tenth inch to three tenths of an inch were tested. Preliminary results indicated that specimens of these sizes and shapes can be made and tested satisfactorily.

The small size of the paste specimens makes them sensitive to oils and greases used to prevent bonding of the cement paste to mold surfaces. 


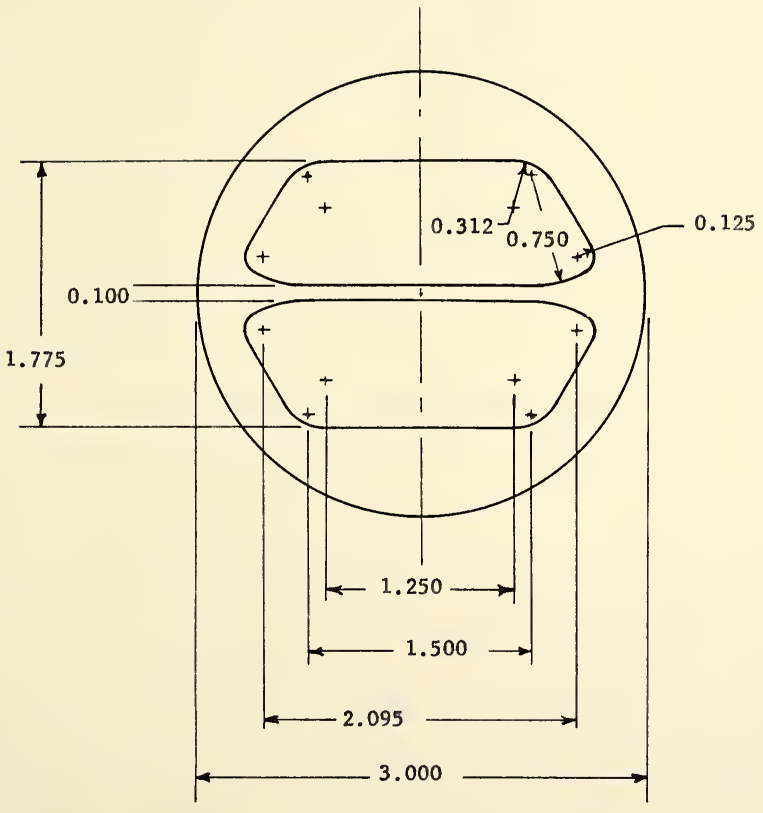

FIGURE 1. THETA SPECIMEN GEOMETRY 
Absorption of these materials into the paste affects the surface tension in the paste and hence perhaps the strength. With this in mind, materials that did not require a lubricant to break the bond were considered for the molds.

Teflon was selected as a mold material, since it is chemically inert, has a high coefficient of thermal expansion, and is easily machined. For the cylinder molds hollow teflon cylinders were used to provide cylindrical specimens that would not have mold joint marks on their surfaces, which could affect the failure of the specimen. The temperature susceptibility of these mold materials made it possible to remove the specimens from the molds by simply heating the mold surfaces slightIy, thereby causing them to expand away from the specimen.

One possible source of flaws that cause failure are the capillary pores in the hardened cement paste. To provide a range of capillarity, specimens were made with several different water-cement ratios. These ranged from a dense mix with a water-cement ratio of 0.3 to a lean mix with a water-cement ratio of 0.6 .

In his original work, Griffith noted that as glass was drawn toa very thin fibre the observed strength approached that of the strength calculated from intermolecular forces (34). The inference is that the smaller the cross section the lower the probability of a flaw existing and being critically oriented. With this in mind, specimen size was considered as a variable. Cylinders of various diameters and lengths were tested in diametral-compression. The thickness of the theta specimens also differed primarily owing to variation in the polishing operation used to eliminate flaws on the surfaces. 
The tensile strength of small specimens is greatly influenced by entrapped foreign substances. It has been shown by experimental stress analysis that stress concentrations of three or four (or more) times the average applied stress can occur when holes are present. Care was taken in handling the cement and water to prevent contamination. Any entrapped particle or void creates a stress concentration in the specimen when it is loaded. This was immediately obvious when theta specimens cast from paste mixed in a mechanical mixer were tested. Every specimen tested failed at entrapped air voids, or at obvious surface defects. To obtain a better understanding of the behavior of cement paste under tensile stress and to cause failure to occur at predetermined points (by insertion of artificial flaws of a known size and orientation) a method of mixing the paste was developed to prevent entrappment of air.

A method of mixing the cement paste under partial vacuum using deaired water and cement was developed and proved practical for mixes of the size required to cast three theta specimens and six cylinders. The entrapped air was practically eliminated by use of this mixing procedure. Extreme care was still required when placing the fresh paste in the molds to prevent entrappment of air.

The paste specimens were placed in lime water for curing upon removal from the molds. The specimens remained in the lime water until immediately prior to placement in the testing machine. Care was taken at all times to prevent the specimens from drying and thereby inducing shrinkage stresses.

A majority of the testing was performed with a constant rate of vertical head travel of 0.05 inches per minute. This rate was carefully 
checked each time a series of tests was performed since rate of strain (or rate of loading) has an influence on the magnitude of the load at failure. A hydraulic testing machine with two load cells (range 0 to 500 pounds and range 0 to 5000 pounds) was used to test the theta and diametral-compression specimens. A strip recorder and an $X-Y$ recorder made possible direct plots of the load versus vertical deflection while the test was in progress.

After a specimen was tested in tension, the fractured pieces were carefully stored in a container to keep them undamaged and available for examination. A binocular microscope with a range in power up to $120 \mathrm{X}$ was used to view the fractured surfaces. These surfaces were carefully checked and any obvious flaws (such as air voids) were noted as to size and position on the fractured face. The extent and location of any change in surface texture of the fractured face was also noted. Changes in surface texture provide information about the source and direction of propagation of the fatal crack.

To provide better insight into the source of critical cracks, specimens were manufactured with artificial flaws. Tests involved the use of thin teflon disks of various diameters placed in the central portion of the paste cylinders to be tested in diametral-compression. If an artificial flaw much larger than any inherent flaw is present and oriented in the failure plane of a specimen then the effect of size of the specimen would be diminished or eliminated. Artificial defects were also introduced just at the ends of the cylinders in a effort to originate a critical crack at that point. Preliminary tests indicated that the fatal crack did originate at points where artificial flaws were placed. 


\section{Materials}

The materials used were tap water, deionized water, and Type I port. land cement. The Type I portland cement was from a single clinker batch (laboratory designation 317). Table 1 shows the composition of the cement.

\section{Mixing of Cement Paste}

For mixes produced under atmospheric pressure a Hobart mixer (Model N-50) was used. The mixer, paddle, and mixing bowl conformed to the requirements of ASTM Designation: C305 Method for Mechanical Mixing of Hydraulic Cement Pastes and Mortars of Plastic Consistency (Figure 2).

The cement was weighed and placed in the mixing bowl. The water was measured with a graduated cylinder. The water was tap water that had been allowed to run for several minutes to stabilize the temperature. The water was added to the cement over a 10 second period with the mixer operating at the slow speed. Mixing continued at the slow speed for one minute. The speed was then increased to the medium speed for 30 seconds. The mixing bowl was removed at the end of that time and the paste mixed by hand for 30 seconds with a large spoon. Care was taken to scrape any material from the sides and blend it into the mass. The bowl was replaced and mixing continued at the medium speed for another 30 seconds. At the end of this time the mixing bowl was covered and allowed to stand undisturbed for one minute and 30 seconds. The mixing was then continued at the medium speed for an additionel minute. A total of five minutes elapsed between the addition of water and the completion of mixing.

For mixes produced under vacuum, a plexiglass cylinder containing balls and rods was used as the mixer (Figure 3). The evacuated cylinder 
Table 1

Physical and Chemical Properties of Cement 317

\section{Physical Properties}

Fineness, No 325 Sieve

Specific Surface, Blaine

Initial set

Final set

Air Entrained (ASTM Designation: C185-59)
95.9 percent

$3380 \mathrm{sq}$. cm. per gm.

$3 \mathrm{hr}$. $15 \mathrm{~min}$.

$5 \mathrm{hr} .05$ min.

8.5 percent

\section{Chemical Analysis}

Compound

Silicon Dioxide, $\mathrm{SiO}_{2}$

Aluminum Oxide, $\mathrm{AlO}_{3}$

Ferric Oxide, $\mathrm{Fe}_{2} \mathrm{O}_{3}$

Calcium Oxide, Ca. ${ }^{3}$

Magnesium Oxide, MgO

Sulphur Trioxide, $\mathrm{SO}_{3}$

Loss on ignition
Percentage Present

$$
\begin{array}{r}
21.76 \\
5.41 \\
1.97 \\
65.30 \\
1.11 \\
2.43 \\
1.78
\end{array}
$$

\section{Calculated Compound Composition}

\section{Compound}

Tricalcium Silicate, $\mathrm{C}_{3} \mathrm{~S}$

Dicalcium Silicate, $\mathrm{C}_{2}$

Tricalcium Aluminate, ${ }^{2} \mathrm{C}_{3} \mathrm{~A}$

Tetracalcium Aluminoferite, $\mathrm{C}_{4} \mathrm{AF}$

Calcium sulphate, $\mathrm{CaSO}_{4}$
Percentage Present

51.20

23.83

11.00

5.99

4.13 


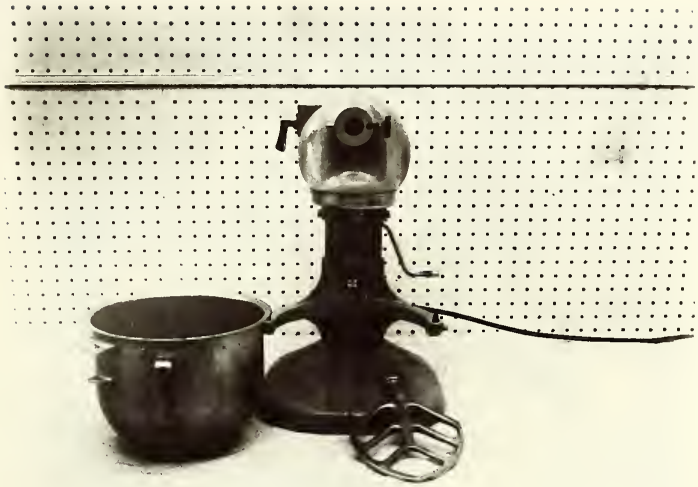

FIGURE 2. HOBART MIXER MODEL N-50 


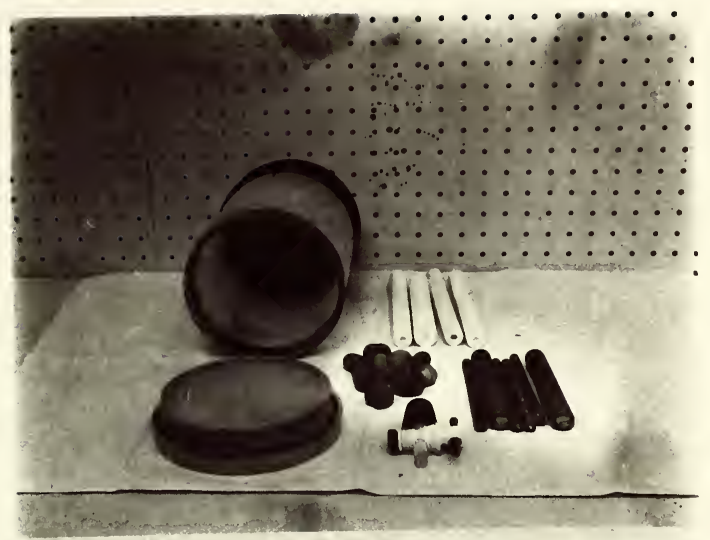

FIGURJ 3. PLWXIGLASS VACUUA MIXIIG CIIIIDIR 
containing the cement and water was rotated on a roller mill to provide for the mixing action as the balls and rods agitated the cement paste (Figure 4). The plexiglass cylinder was approximately 12 inches high with a 6 inch diameter. The cylinder was sealed on one end and fitted with a screw-on-cap, sealed with an 0-ring, at the opposite end.

The cement was carefully welghed and placed in the mixing cylinder along with 12 flint balls (approximately one inch in diameter) six metal rods and three teflon rods. The end cap was then placed on the cylinder. Vacuum grease was placed on the O-ring and the upper portions of the threads to insure an air-tight seal. A copper seat was provided in the permanently sealed end for the insertion of a stopcock which was held in place by a rubber stopper. The cylinder was then evacuated for fifteen minutes by means of a water-operated aspirator. The cylinder was kept in an upright position for the first half of the period and then rotated several times to fluff the cement and then placed on its side for the remainder of the fifteen minute period. At the end of this time the stopcock was closed, the aspirator hose was detached and the vessel containing the water was attached by means of a two inch section of vacuum tubing.

The water was deionized and had been deaired for fifteen minutes by bolling on an aspirator. The vessel containing the water was a calibrated separatory funnel with a ground glass stopcock and a ground glass stopper. Water was introduced into the tubing between the cylinder and the funnel, the funnel was attached, and the stopcock of the funnel was opened to allow any trapped air to escape. The stopcock on the cylinder was then opened until the proper amount of water had entered, at which 


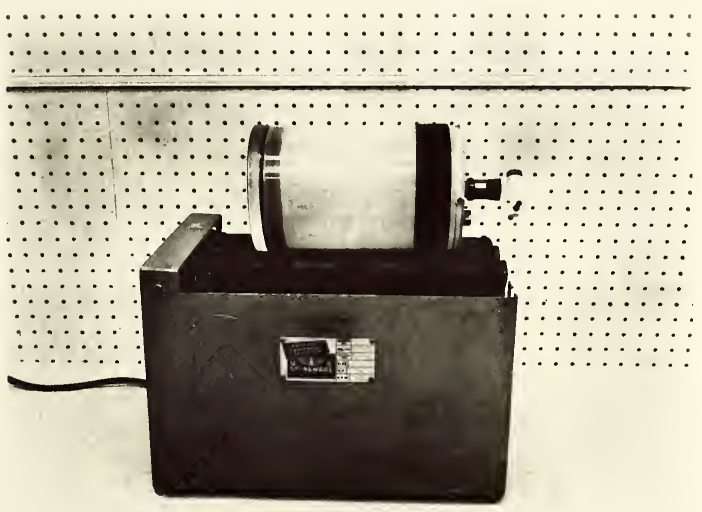

FIGURE 4. MIXING CYLINDER IN POSITION ON ROLIER MILI 
time the stopcock was closed and the connecting hose was detached.

The mixing cylinder was immediately placed on a Syntron-Jogger (Model PJ-15) to provide vibration and was then rotated by hand. This procedure provided the initial blending of the cement and water. After three minutes of combined vibration and hand turning, the cylinder was placed on a roller mill that rotated it at approximately $80 \mathrm{rpm}$. After five minutes of rotation, the cylinder was removed and re-vibrated for two minutes before it was returned to the roller mill for an additional five minutes. The cylinder was then allowed to stand for two minutes before a final three minutes of rotation. The cylinder was then removed, and the stopcock was opened to admit atmospheric pressure.

\section{Casting Specimens}

The amount of cement $(1000 \mathrm{~g})$ and the amount of water (dependent on the water-cement ratio) were selected so that sufficient cement paste would be available to cast three theta specimens and six cylinders. Immediately after mixing the container was placed next to the molds, and the paste was carefully blended with a large mixing spoon.

The theta molds were positioned on the vibrating table with the initial power setting at 50 on the scale. One large mixing spoonful of paste was sufficient to fill each of the three theta molds. All molds were overfilled and a round nosed spatula was used to "rod" the paste. Care was taken to rod the paste at the paste-mold interfaced to force to the surface any entrapped air. The vibration was then increased to a power setting of 90 for one minute and the overfilled molds then set aside while the cylinder molds were filled.

The six cylinder molds were placed on the vibrating table with the 
power setting at 50 . The cylinder molds were filled in three layers each of which was rodded 25 times. The vibrating table power setting was increased to 90 , and the six cylinders were vibrated for three minutes. Rubber stoppers were then placed in the tops of the molds, taking care not to trap air, and the molds were inverted to vibrate for three minutes with the power setting at 50 . The molds were allowed to stand for 20 minutes inverted.

During this 20 minute period the theta specimens were again placed on the vibrating table with the power setting at 50. The theta specimens were struck off with a straight edge to provide a plane top surface. A final brief vibration with the setting at 90 provided the final leveling. Each theta specimen was placed in the fog room immediately after the final leveling with an inverted plastic container placed over it to allow air circulation in an atmosphere of 100 percent relative humidity and to prevent free moisture from dropping onto the specimen face.

At the end of the 20 minute standing period the cylinder molds were reinverted and vibrated for two minutes with the setting at 50 . The molds were then allowed to stand for 8 minutes undisturbed after which they were again vibrated for two minutes in the inverted position. Another 8 minute standing period was provided before a final vibration at a setting of 50 for two minutes in the reinverted position. The cylindrical specimens in the stoppered plastic tubes were then placed in the fog room.

\section{Removal of Specimens from Molds}

All specimens remained in the fog room for approximately twenty hours after casting. At the end of this time the specimens were taken 
from the fog room and the molds were removed. Each cylinder mold was immersed in a hot water bath $\left(160\right.$ to $180^{\circ} \mathrm{F}$ ) for thirty seconds. The plastic test tube mold expanded slightly with the increase in temperature allowing the cylindrical paste specimen to slide out when the mold was tapped gently on a solid surface. The teflon cylinder molds required approximately three minutes in the water bath for a mold thickness of one quarter inch and one minute for a one-eighth inch wall thickness. It was hoped that the brief immersion of the molds in the water bath did not generate significant thermal stresses in the specimens.

As each specimen was removed from its mold it was placed immediately in a saturated calcium hydroxide solution for curing. Approximately one-half inch was cut from each end of the cylinders.

The theta molds required careful removal owing to the narrow web ( 0.10 inches) and the low strength of the paste after only twenty hours curing. The twelve screws that fastened the two halves of the mold were removed, and the mold was placed in the hot water bath so that the water level reached the midpoint of the mold. The high coefficient of thermal expansion of the teflon made it possible for the bottom half of the mold to expand in relation to the top half, and the mold separated easily. The top half containing the specimen was then held vertically and the perifery was immersed in the hot water. The teflon exponded and the specimen was extracted with only gentle pressure. The theta specimen, with the center inserts still in place, was then immersed in lime water for several minutes to make sure that the specimen did not start to dry. To remove the center insert portions of the teflon mold, the specimen was placed in a freezer with the teflon portions resting on steel 
blanks. The specimen remained in the freezer at $0^{\circ} \mathrm{F}$ for $1.5 \mathrm{~min}$. The inserts were then removed by gently tapping them out with a small wooden mallet. Extreme care was needed. Figure 5 shows a theta mold.

Once the theta specimens were removed from the molds they were placed in lime water for curing. Each specimen was carefully examined to check for surface defects. Any defects generally fell into two classes, one being entrapped air voids along the edges and the other being chipping that had occurred during the demolding procedures. Each specimen was then taken from the lime water and the bottom and top surfaces were polished on a glass plate using No. 1200 grit. This procedure eliminated any large surface defects and any laittance formed on the exposed surface during initial curing.

\section{Curing}

The specimens from each batch were kept together and allowed to cure in lime water until immediately prior to testing.

\section{Testing}

Three theta specimens and six cylindrical specimens were made from each $\mathrm{mix}$ in the initial portion of the investigation. Three of the cylinders were tested in compression and three were tested using the diametral-compression test. Compression tests were conducted using a Riehle screw-gear machine with a 50,000 pound capacity.

Other tests were performed using a hydraulic testing machine, which is a three-component unit manufactured by MS Division of Research, Inc. and consists of a 20 to $40 \mathrm{kip}$ load frame, a load control unit, and a power unit. A 500 pound load cell was used when theta specimens were 


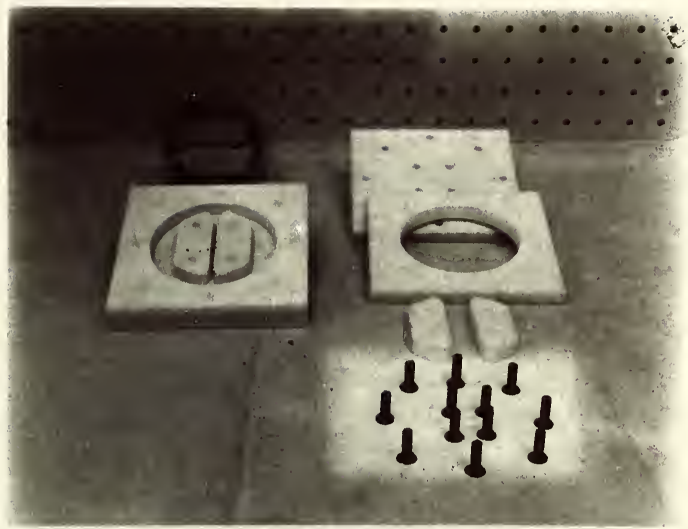

FIGURE 5. TERLON THETA SPECIMEN MOTD 
tested since the total load at failure was less than 200 pounds. A 5000 pound load cell was used for the diametral-compression tests. These load cells were checked with a proving ring prior to each series of tests.

Loads and vertical deformations were recorded with a brushpen recorder activated from the load cell and the hydraulic system. In addition an $X-Y$ recording unit was used to supplement the brush pen recorder. Direct plots of load versus vertical deflection were thus available. The specimens were loaded using a controlled rate of vertical head travel. which in the initial portion of the investigation was selected as 0.05 inch per minute, the standard testing rate given for concrete cylinders in ASTM Method: C 39.

\section{Compression Testing}

The cylindrical specimens to be tested in compression were removed from the curing water and the ends were polished with No. 1200 grit to provide a smooth plane surface and eliminate capping the specimen. The specimens were replaced in lime water until immediately prior to testing. The ends of the specimens were wiped to remove excess water, and the specimens were positioned in the testing machine with a wet cloth surrounding the specimen to prevent drying. A constant rate of vertical head travel of 0.05 inches per minute was used. Bearing platens with a spherical seat were used to ensure uniform load application. A typical testing arrangement is illustrated in Figure 6.

\section{Diametral-Compression Testing}

As in the compression test the ends of the cylinders were polished to provide smooth plane surfaces. For the performance of this "tensile 


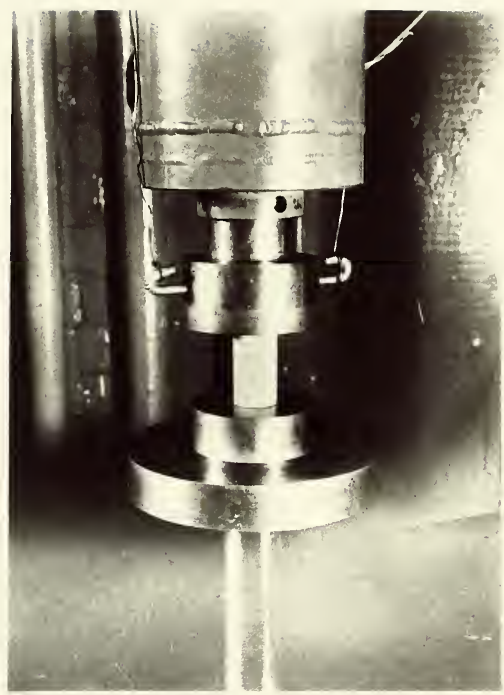

FIGURE 6. COMPRESSION TESTIING ARRANGEMENTT 
splitting" test it is necessary to apply the load to the sides of the cylinder through thin bearing strips of a comparatively resilient material. It is further necessary that these strips be exactly centered along the sides in a line parallel to the axis of the cylinder. In order to do this, these specimens were placed in a special jig (see Figure 7). The cardboard bearing strips were positioned between the bearing blocks and the specimen. The specimen and $\mathrm{jig}$ were then placed in the testing machine and a small seating load of approximately fifty pounds was applied. With the specimen seated, the holding jig was then removed, and the specimen alignment was checked (Figure 8). As in the compression test, the specimen was surrounded with a wet cloth to prevent drying. The cloth was also effective in preventing any part of the specimen from falling from the testing machine after failure.

Some testing was done at temperatures other than room temperature. For these tests at controlled temperatures a water bath was placed around the specimen and the bearing blocks.

Load was then applied using a constant rate of head travel of 0.05 inches per minute. The load was immediately released when fracture of the specimen occurred. This precaution was taken so that the specimen would not be shattered and so that the fracture faces could be examined.

\section{Theta Specimen Testing}

The theta specimens were removed from the lime water and immediately placed in the hydraulic testing machine. The loading ram was moved up so that the loading head just made contact with the specimen (see Figure 9). This type of test requires that the central web of the specimen be horizontal during loading. This was accomplished by observing the 


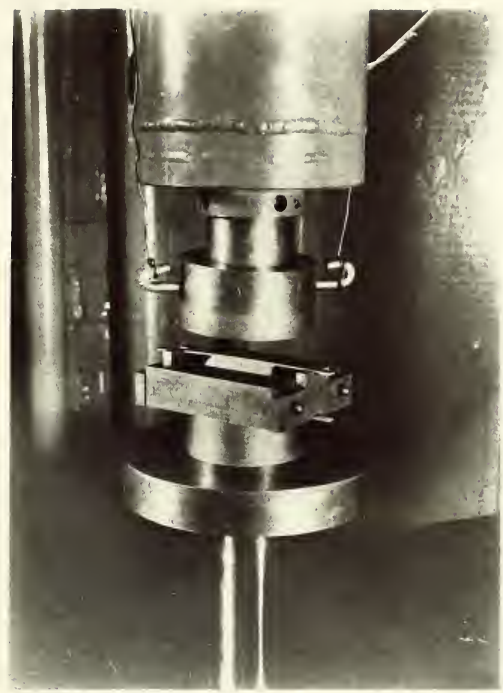

FIGURE 7. DIAMETRAI-COMPRESSION SPECIMEN HOLDER 


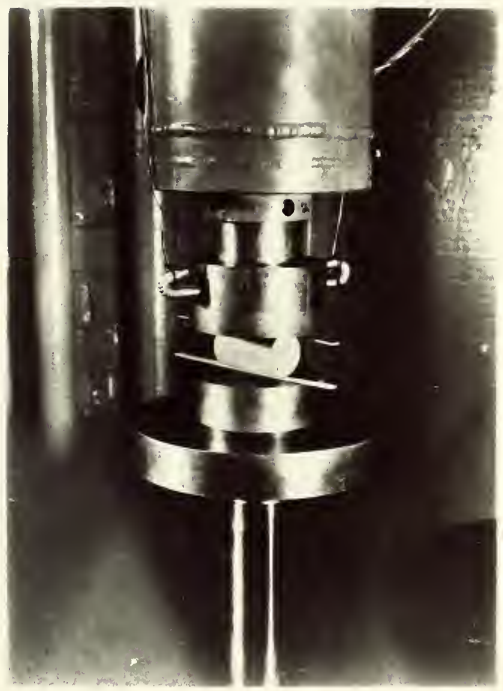

FIGURE 8. DIAMETRAL-COMPRESSION TESTING ARRANGEMEINT 


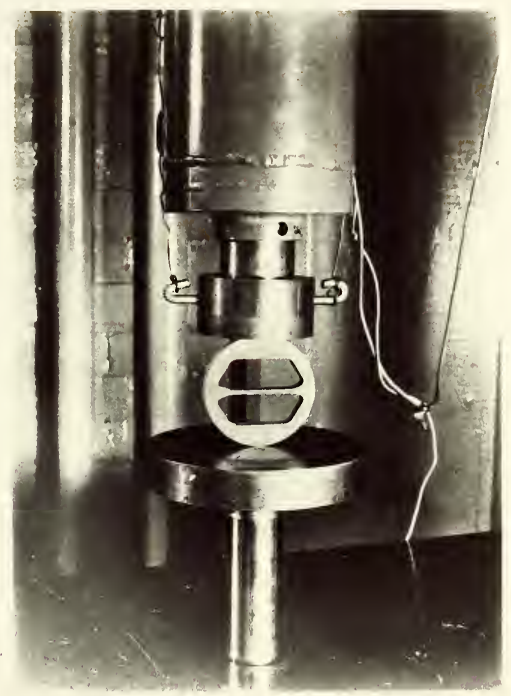

FIGURS 9. THENA SPLCTMIMN TESTING ARRANGEMENT 
free water on the web. Since the specimen was placed in the testing machine immediately after removing it from the curing water there was enough free water on the surface of the web to act as a level. Once the specimen was leveled and seated it was loaded with a constant rate of vertical head travel of 0.05 inches per minute.

The load was released immediately when failure of the web occurred. This was done to prevent fracture of the outer portion of the specimen and possible damage to the fracture surfaces. The outer ring of the theta was then cut with a diamond saw, which allowed the central web to be separated at the point of fracture. The thickness and depth of the web was then measured with a micrometer caliper. The web was broken on each side of the original break, and the pieces were marked to indicate the original fracture surface. These pieces were then placed in a small plastic vial for storage prior to microscopic examination of the fracture surfaces. 
RESULTS

During the course of this investigation over 150 theta specimens and 500 tensile splitting specimens were tested. A number of the specimens were made while mixing, molding, demolding, and testing procedures were being developed and perfected. As would be expected, test results from these specimens are variable. However, as procedures and techniques were perfected, the variability was reduced.

Theta specimens were tested with water-cement ratio and web thickness as the main variables. Diametral-compression specimens had watercement ratio, size, and testing temperature as the main variables. The results of these tests as well as the results of density determinations, compression tests, and modulus of elasticity determinations are presented in the following sections.

\section{Density Determinations}

Several placing techniques and procedures were investigated to determine the best techniques and procedures to produce specimens of uniform density. The water-cement ratios varied from 0.3 to 0.6 and a procedure was used that produced satisfactory results for the full range of vater-cement ratios. The procedure that produced the most uniform specimen was similar to that used by Mullen (64).

Density determinations were made on disks cut from the top, middle and bottom thirds of 2 inch long cylinders. A comparison was made between densities from cylinders placed in three layers and vibrated in 
the upright position (procedure A) and cylinders placed following the procedures detailed on page 36 (procedure B). These specimens, in contrast with those for the strength tests, were cast in plastic test tube molds and hence, there is a slight variance in the diameter of the disks from top to bottom. The results are given in Table 2 .

Density determinations were also made on the full size paste cylinders, and the results are given in Table 3. The specimens had various water-cement ratios. The density determinations were made 30 days after casting. The specimens were all from mixes from which other specimens were tested in diametral-compression, and the mixing procedures are the same.

\section{Results of Compression and Modulus of Elasticity Tests}

Compression tests were performed on cement paste cylinders with a height to diameter ratio of approximately two to one. There was a slight variation in height from cylinder to cylinder due to the sawing and lapping of the cylinder ends. Water-cement ratio was the only variable in this portion of the investigation. The compressive strength was determined to provide a basis of comparison between the diametral-compression tests and tests on theta specimens. A knowledge of the modulus of elasticity is required for use in the existing brittle fracture theories.

A summary of the results of compression tests is presented in Table 4. The results show a decrease in compressive strength with an increasing water-cement ratio, as would be expected.

The fractured compression specimens showed the same general form as that of typical concrete cylinders tested in compression. The typical conical portions were present at each end, but there was a great deal of 
Table 2

DENSITY DETERMINATION OF CYLINDRICAL SPECDMENS

$$
(w / c=0.3)
$$

\begin{tabular}{|c|c|c|c|c|c|c|}
\hline $\begin{array}{l}\text { Placing } \\
\text { Procedure }\end{array}$ & Specimen & Position & $\begin{array}{c}\text { Average } \\
\text { Dia. } \\
\text { (mm) }\end{array}$ & $\begin{array}{c}\text { Average } \\
\text { Thick. } \\
\text { (mm) }\end{array}$ & $\begin{array}{c}\text { Dry } \\
\text { Weight } \\
\text { (g) }\end{array}$ & $\begin{array}{r}\text { Density } \\
(\mathrm{g} / \mathrm{cc})\end{array}$ \\
\hline A & $\begin{array}{l}\mathrm{A} \\
\mathrm{A} \\
\mathrm{A}\end{array}$ & $\begin{array}{l}\text { Top } \\
\text { Middle } \\
\text { Bottom }\end{array}$ & $\begin{array}{l}25.92 \\
25.69 \\
25.39\end{array}$ & $\begin{array}{l}6.38 \\
5.925 \\
7.20\end{array}$ & $\begin{array}{l}6.0873 \\
5.6291 \\
6.7530\end{array}$ & $\begin{array}{l}1.824 \\
1.830 \\
1.852\end{array}$ \\
\hline A & $\begin{array}{l}B \\
B \\
B\end{array}$ & $\begin{array}{l}\text { Top } \\
\text { Middle } \\
\text { Bottom }\end{array}$ & $\begin{array}{l}25.88 \\
25.70 \\
25.37\end{array}$ & $\begin{array}{l}5.20 \\
6.04 \\
5.305\end{array}$ & $\begin{array}{l}5.0036 \\
5.7280 \\
4.9455\end{array}$ & $\begin{array}{l}1.829 \\
1.828 \\
1.844\end{array}$ \\
\hline B & $\begin{array}{l}\mathrm{C} \\
\mathrm{C} \\
\mathrm{C}\end{array}$ & $\begin{array}{l}\text { Top } \\
\text { Middle } \\
\text { Bottom }\end{array}$ & $\begin{array}{l}25.75 \\
25.68 \\
25.45\end{array}$ & $\begin{array}{l}4.04 \\
3.50 \\
3.69\end{array}$ & $\begin{array}{l}3.9200 \\
3.3423 \\
3.4629\end{array}$ & $\begin{array}{l}1.835 \\
1.843 \\
1.845\end{array}$ \\
\hline B & $\begin{array}{l}D \\
D \\
D\end{array}$ & $\begin{array}{l}\text { Top } \\
\text { Middle } \\
\text { Bottom }\end{array}$ & $\begin{array}{l}25.92 \\
25.66 \\
25.41\end{array}$ & $\begin{array}{l}3.86 \\
3.25 \\
3.78\end{array}$ & $\begin{array}{l}3.7187 \\
3.0950 \\
3.4916\end{array}$ & $\begin{array}{l}1.826 \\
1.842 \\
1.822\end{array}$ \\
\hline B & $\begin{array}{l}E \\
E \\
E\end{array}$ & $\begin{array}{l}\text { Top } \\
\text { Middle } \\
\text { Bottom }\end{array}$ & $\begin{array}{l}25.93 \\
25.67 \\
25.45\end{array}$ & $\begin{array}{l}3.42 \\
2.70 \\
3.33\end{array}$ & $\begin{array}{l}3.2970 \\
2.5300 \\
3.1106\end{array}$ & $\begin{array}{l}1.826 \\
1.811 \\
1.836\end{array}$ \\
\hline
\end{tabular}


Table 3

DENSITY OF ONE INCH BY TWO INCH CYLINDRICAL SPECIMENS

\begin{tabular}{lcccccc}
\hline w/c & $\begin{array}{c}\text { Specimen } \\
\text { Number }\end{array}$ & $\begin{array}{c}\text { Average } \\
\text { Diameter } \\
(\mathrm{mm})\end{array}$ & $\begin{array}{c}\text { Average } \\
\text { Thickness } \\
(\text { in })\end{array}$ & $\begin{array}{c}\text { Wet } \\
\text { Weight } \\
(\mathrm{g})\end{array}$ & $\begin{array}{c}\text { Dry } \\
\text { Weight } \\
(\mathrm{g})\end{array}$ & $\begin{array}{c}\text { Density } \\
(\mathrm{g} / \mathrm{cc})\end{array}$ \\
\hline 0.4 & $138-1$ & 25.63 & 1.977 & 52.7449 & 43.0470 & 1.662 \\
0.4 & $138-2$ & 25.71 & 1.948 & 51.8846 & 42.2579 & 1.645 \\
0.4 & $138-2$ & 25.83 & 1.971 & 52.2790 & 43.5254 & 1.660 \\
0.5 & $136-1$ & 25.78 & 1.899 & 48.4161 & 37.5998 & 1.494 \\
0.5 & $136-2$ & 25.60 & 1.867 & 46.9616 & 36.4886 & 1.495 \\
0.5 & $136-3$ & 25.65 & 1.898 & 47.8459 & 37.1177 & 1.491 \\
0.6 & $139-1$ & 25.67 & 1.928 & 46.4222 & 34.1072 & 1.346 \\
0.6 & $139-2$ & 25.75 & 2.018 & 48.8031 & 35.9080 & 1.347 \\
0.6 & $139-3$ & 25.78 & 1.877 & 45.1639 & 33.5689 & 1.351 \\
\hline
\end{tabular}

Table 4

COMPRESSION TEST RESULTS

\begin{tabular}{cccc}
\hline w/c & $\begin{array}{c}\text { Number of } \\
\text { Specimens }\end{array}$ & $\begin{array}{c}\text { Average } \\
\text { Compressive } \\
\text { Strength } \\
\text { (psi) }\end{array}$ & $\begin{array}{c}\text { Range } \\
\text { (psi) }\end{array}$ \\
\hline 0.4 & 19 & 14,500 & $12,040-15,750$ \\
0.5 & 15 & 9,200 & $7,640-10,100$ \\
0.6 & 9 & 6,600 & $6,000-7,090$ \\
\hline
\end{tabular}


shattering and columnar fracture in the central portion.

Cement paste cylinders of the same approximate dimensions as those tested to failure in compression were loaded in compression on the hydraulic testing machine to determine the modulus of elasticity. The specimens were loaded to 4300 pounds and load-deflection curves were plotted automatically on the $\mathrm{X}-\mathrm{Y}$ recorder. The load was applied at a constant rate of ram travel of 0.05 inches per minute.

The deflection monitored in the hydraulic testing system used in this investigation is that of the hydraulic ram and is the total deflection of the system, i.e., that of the specimen and the machine. The deflection of the machine was determined by applying the load with no specimen between the loading platens. The platens were positioned together and the same load was applied and the deflection of the system recorded automatically. The results showed a linear deflection of the testing system. Deflections of the paste specimens were then determined by subtracting the machine deflection from the total deflection.

Load deflection curves showed a linear relationship over the whole load range for the cement paste specimens. Table 5 is a summary of the results of the modulus of elasticity determinations.

Table 5

MODULI OF ELASTICITY OF HARDENED PASTES

\begin{tabular}{cccc}
\hline w/c & $\begin{array}{c}\text { Number of } \\
\text { Specimens }\end{array}$ & $\begin{array}{c}\text { Average } \\
\text { Modulus } \\
\left(\mathrm{psi} \times 10^{-6}\right)\end{array}$ & $\begin{array}{c}\text { Range } \\
\left(\mathrm{psi} \times 10^{-6}\right)\end{array}$ \\
\hline 0.4 & 6 & 2.56 & $2.40-2.70$ \\
0.5 & 6 & 1.97 & $1.87-2.08$ \\
0.6 & 6 & 1.54 & $1.40-1.64$ \\
\hline
\end{tabular}




\section{Results of Tests on Theta Specimens}

The theta specimen shape was originally developed in an attempt to overcome some of the difficulties present in other types of tensile specimens and tensile tests. This specimen shape has been evaluated by photoelastic studies (25). The equation for tensile stress in the central web was determined to be

$$
\sigma=13.8 \frac{\mathrm{P}}{\mathrm{Dt}}
$$

where:

$\sigma=$ tensile stress in the web in psi

$P=$ applied load in pounds

$D=$ specimen diameter in inches

$t=$ specimen thickness in inches

In this investigation, theta specimens with an outside diameter of 3.00 inches, a web width of 0.10 inches, and a thickness of approximately 0.3 inches were tested. The specimen thickness, $t$, varied from specimen to specimen because of the lapping of the faces to remove surface flaws. The water-cement ratio was a variable in this part of the investigation.

The results of early tests on specimens mixed with a mechanical mixer, and not in the vacuum equipment showed a high variability in the calculated stress at failure. These tests also showed that failure in the web occurred prior to failure in the outer ring of the specimen. Microscopic examination of the fractured veb surfaces showed either air voids or some type of flaw present in the fracture plane of 85 per cent of the specimens. The air voids ranged in size from 0.01 inches to 0.06 inches in diameter. Table 17 in Appendix A is a summary of the results 
of the microscopical examinations of the fracture planes of the theta specimens tested.

The use of a vacuum mixing technique proved satisfactory for producing specimens with a low incidence of air voids in the hardened specimens. Failures through air voids was reduced to fewer than 50 percent of the specimens when the vacuum mixing technique was used. A majority of the voids that were evident were at the specimen edges, indicating entrappment during placement of the mixture in the molds.

The results of tests on theta specimens which were mixed usind the vacuum mix procedures are given in Tables 6,7 , and 8 . The average tensile strengths for all theta specimens were: $\mathrm{w} / \mathrm{c}=0.4,1660 \mathrm{psi}$; $\mathrm{w} / \mathrm{c}=0.5,1400 \mathrm{psi} ; \mathrm{w} / \mathrm{c}=0.6,1180 \mathrm{psi}$. The statistical analysis of data in Tables 6, 7, and 8 is given in Appendix B.

Table 6

RESUTTS OF TESTS ON THETA SPECDMENS VACUUM MIXED WITH $W / C=0.4$

\begin{tabular}{rrc}
\hline $\begin{array}{c}\text { Specimen } \\
\text { Number }\end{array}$ & $\begin{array}{r}\text { Thickness } \\
(\mathrm{mm})\end{array}$ & $\begin{array}{c}\text { Failure Stress } \\
\text { (psi) }\end{array}$ \\
\hline $29-1$ & 9.29 & 920 \\
-2 & 10.00 & 1170 \\
-3 & 9.98 & 1630 \\
$30-1$ & 8.69 & 1560 \\
-2 & 6.05 & 1700 \\
-3 & 5.50 & 2040 \\
$31-1$ & 8.30 & 800 \\
-2 & 7.42 & 1465 \\
-3 & 3.82 & 1620 \\
$50-1$ & 6.26 & 2090 \\
-2 & 6.97 & 1810 \\
-3 & 7.71 &.- \\
$52-1$ & 6.73 & 2170 \\
-2 & 8.39 & 1255 \\
-3 & 8.36 & 1410 \\
\hline
\end{tabular}


Table 7

RESULTS OF TESTS ON THETA SPECIMENS VACUUM MIXED WITH $\mathrm{W} / \mathrm{C}=0.5$

\begin{tabular}{|c|c|c|}
\hline $\begin{array}{l}\text { Specimen } \\
\text { Number }\end{array}$ & $\begin{array}{l}\text { Thickness } \\
(\mathrm{mm})\end{array}$ & $\begin{array}{c}\text { Fallure Stress } \\
\text { (psi) }\end{array}$ \\
\hline $39-1$ & -- & -- \\
\hline-2 & 8.29 & 1200 \\
\hline-3 & 8.34 & 1080 \\
\hline $40-1$ & 9.11 & 705 \\
\hline-2 & 9.29 & 1070 \\
\hline-3 & 7.80 & 1230 \\
\hline $41-1$ & 7.44 & 1790 \\
\hline-2 & 8.31 & 1350 \\
\hline-3 & 7.63 & 1270 \\
\hline $42-1$ & 9.31 & 1040 \\
\hline-2 & - & -- \\
\hline-3 & 9.30 & 1090 \\
\hline $43-1$ & 8.32 & 1825 \\
\hline-2 & 8.16 & 1145 \\
\hline-3 & 8.84 & 1610 \\
\hline $44-1$ & 8.32 & 1195 \\
\hline-2 & 6.05 & 1755 \\
\hline-3 & 8.14 & 1535 \\
\hline $46-1$ & 8.01 & 1270 \\
\hline-2 & 7.88 & 1480 \\
\hline-3 & 7.50 & 1560 \\
\hline $49-1$ & 7.96 & 1220 \\
\hline-2 & 7.73 & 1360 \\
\hline-3 & 9.05 & 1020 \\
\hline $51-1$ & 6.26 & 1810 \\
\hline-2 & 6.97 & 1390 \\
\hline-3 & 7.71 & 1760 \\
\hline $54-1$ & 7.23 & 1695 \\
\hline-2 & - & - \\
\hline-3 & 8.05 & 1670 \\
\hline
\end{tabular}


Table 8

RESULTS OF TESTS ON THETA SPECIMENS VACUUM MIXED WITH $W / C=0.6$

\begin{tabular}{rcc}
$\begin{array}{c}\text { Specimen } \\
\text { Number }\end{array}$ & $\begin{array}{c}\text { Thickness } \\
(\mathrm{mm})\end{array}$ & $\begin{array}{c}\text { Failure Stress } \\
(\mathrm{psi})\end{array}$ \\
\hline $45-1$ & 8.34 & 925 \\
-2 & 7.57 & 1340 \\
-3 & 8.26 & 1400 \\
$47-1$ & 6.87 & 1275 \\
-2 & 7.41 & 1180 \\
-3 & 6.80 & 1255 \\
$48-1$ & 8.31 & 730 \\
-2 & 9.11 & 1065 \\
-3 & 7.28 & 1235 \\
$53-1$ & 6.21 & 940 \\
-2 & 6.03 & 1260 \\
-3 & 5.67 & 1135 \\
\hline
\end{tabular}

Careful microscopical examination of the fractured faces of the webs showed that the fracture started at right angles to the specimen faces and proceeded across the web in a generally flat plane. In instances where an air void was present in the fracture plane, the fracture always went through the center of the void. The sizes and positions of all visible voids were noted and a summary of the microscopical examination of the fracture planes is presented in Table 17 of Appendix A. During the examination of the fracture faces it was noted that a change in surface roughness occurred along the surface. Where fracture occurred through an entrapped air void, the fracture surface was relatively smooth in the vicinity of the void and increased in roughness as the distance from the vold increased. 
Figures 10, 11 , and 12 are photomicrographs taken of the fracture surfaces of three different theta specimens. In Figure 10 an air void is shown near one edge of the web with the surface roughness increasing from left to right, away from the air void. Figure 11 shows an air void near the outside surface about half way across the web thickness. Figure 12 shows an air void near a molded surface, with the smooth and rough areas easily visible.

\section{Results of Diametral-Compression Tests}

The diametral-compression (tensile splitting) test was used to evaluate the tensile strength of cylindrical cement paste specimens under the effects of both compositional and environmental variables. The two-dimensional stress analysis of the test method yields the following equations (62) for a specimen oriented so that the line load is in the $\mathrm{y}-\mathrm{direction}$ :

$$
\sigma_{x}=\frac{2 P}{\pi d t}
$$

and,

$$
\sigma_{y}=\frac{-6 P}{\pi d t}
$$

where:

$$
\begin{aligned}
& \sigma_{\mathrm{x}}=\text { stress in the } \mathrm{x} \text {-direction } \\
& \sigma_{\mathrm{y}}=\text { stress in the } \mathrm{y}-\text { direction } \\
& \mathrm{P}=\text { applied load } \\
& \mathrm{d}=\text { specimen diameter } \\
& \mathrm{t}=\text { specimen length }
\end{aligned}
$$

The maximum tensile stress occurs in the central portion of the specimen and is constant over approximately three-quarters of the 


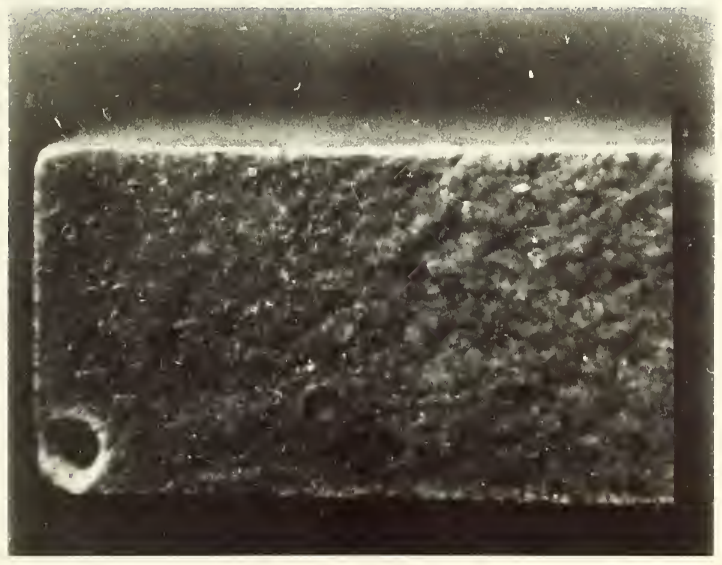

FIGURE 10. THELA SPECDUGI MO. $17-5$ (х22) 


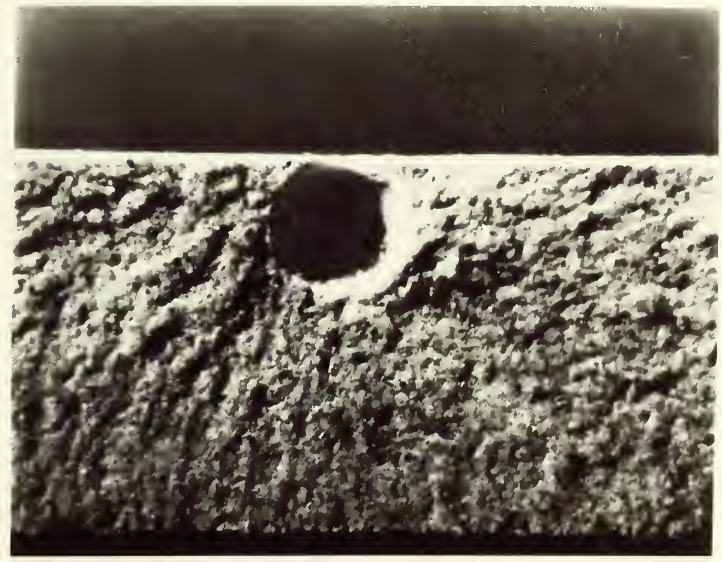

FIGURE 11. THEIA SPECIMEN NO. $29-2$ (х22) 


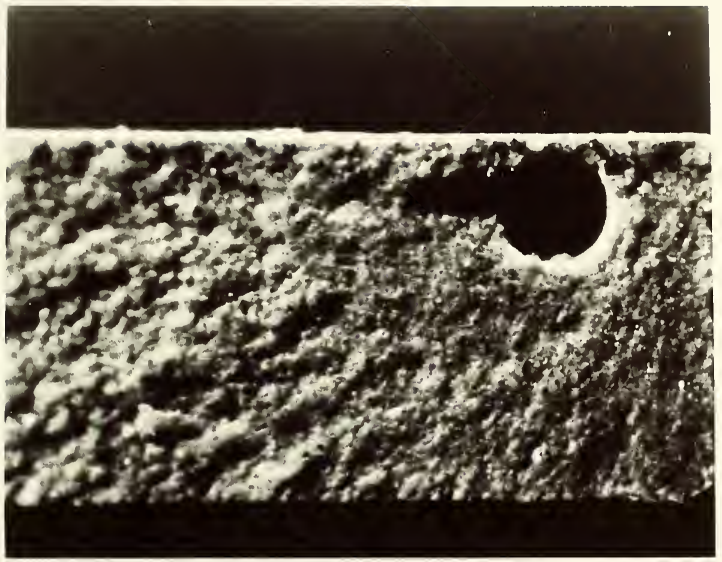

FIGURE 12. THIOIA SFECDULA NO. $31-2$ (x22) 
specimen diameter. Theoretical analyses of the test method (based on an elastic, homogeneous, isotropic solid) and photo-elastic studies (89) indicated that the length of the specimen should have no effect on the stress distribution within the specimen. The specimen diameter does not have an effect on the stress distribution within the specimen according to such analyses; however, bearing strips are necessary owing to the uneven surface of the specimens. A bearing strip width of approximately one-sixth of the diameter has been found satisfactory (89).

Water-cement ratio, specimen size, and testing temperature were considered as variables. Both the length and diameter of the cement paste cylinders were varied.

Initial diametral-compression tests were performed to check the results of tests made on theta specimens from the same mix. As in the early theta tests, the results were highly variable, owing in part to procedures and techniques of specimen fabrication that were still in the process of being perfected. Failure stresses calculated from the results of diametral-compression tests on one-inch by two-inch cylinders were as much as 40 percent lower than those of theta specimens from the same mix. Tests on a number of cylinders with various lengths indicated that size was a factor, and as the cross-sectional area of the test cylinders was reduced to about that of the theta specimens (by decreased diameter and/or shorter lengths) the failure stresses for the two types of tests became approximately equal. The results of some of the early tests with size as a variable are presented in Figure 13. Specimens 3-1 to 5-6D (see Appendix A) with a water-cement ratio of 0.4 are plotted. While these specimens ranged in age from 43 to 51 days, there was a definite 


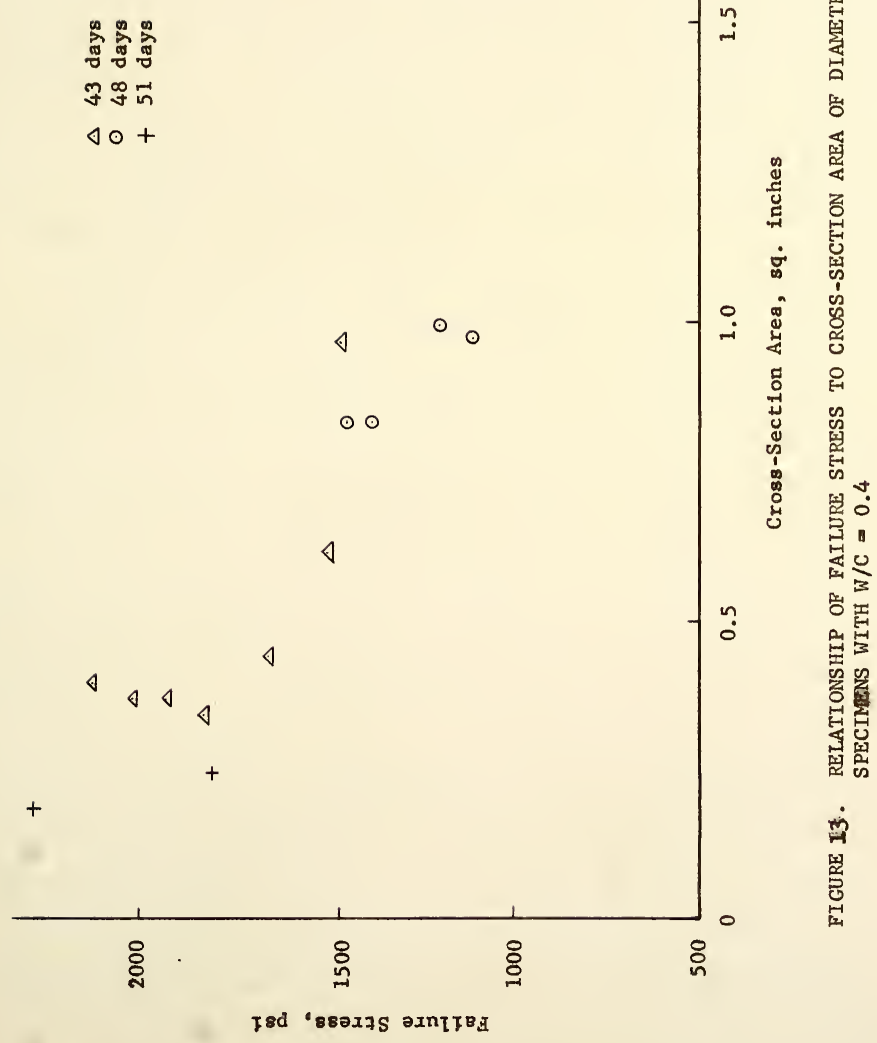


trend present to warrant a more detailed investigation, which is reported as part of the statistical study.

The rate of loading was varied on a limited number of specimens. The speed of vertical ram travel ranged from 0.005 inches per minute to 50 inches per minute, i.e., over four orders of magnitude, under automatic load application. Several specimens were loaded manually with the load applied in steps at a rate of 0.05 inches per minute and each load increment held for up to one half hour. This loading procedure was applied to one specimen over a period of four and one-half hours. These tests indicated that there was no difference in failure stresses over the range of loading rates checked.

A summary of results of diametral-compression tests is presented in Tables 9, 10, and 11, for water-cement ratios of $0.4,0.5$, and 0.6 respectively. These specimens are from the same mixes as the theta specimens summarized in Tables 6,7 , and 8 . Statistical analyses of the diametral-compression data are presented in Appendix B.

A statistically designed experiment was established to evaluate the effect of specimen size, testing temperature and water-cement ratio on the tensile stresses at failure as determined by the diametralcompression test. The design model selected was a three-factor factorial with three replications per cell. One inch diameter cement paste cylinders with lengths of approximately $0.3,1.0$ and 2.0 inches were tested at testing temperatures of $40^{\circ} \mathrm{F}, 72^{\circ} \mathrm{F}$ (room temperature) and $160^{\circ} \mathrm{F}$. Water-cement ratios of $0.4,0.5$, and 0.6 were used. To ensure a uniform temperature at testing, a water bath was used to keep the specimens at the appropriate temperature.and to prevent the specimens 
Table 9

RESULTS OF DIAMETRAL_COMPRESSION TESTS FOR $\mathrm{W} / \mathrm{C}=0.4$

\begin{tabular}{rrr}
\hline $\begin{array}{c}\text { Specimen } \\
\text { Number }\end{array}$ & $\begin{array}{r}\text { Length } \\
\text { (in.) }\end{array}$ & $\begin{array}{c}\text { Failure Stress } \\
\text { (psi) }\end{array}$ \\
\hline $30-1$ & 1.90 & 600 \\
-2 & 1.93 & 1250 \\
-4 & 1.86 & 855 \\
$31-1$ & 1.91 & 1240 \\
-2 & 1.88 & 1190 \\
$50-4$ & 2.14 & 1220 \\
-5 & 2.11 & 1115 \\
-6 & 1.58 & 690 \\
$52-1$ & 2.13 & 1105 \\
-2 & 2.14 & 1010 \\
-3 & 2.16 & 970 \\
-4 & 2.25 & 860 \\
-5 & 2.13 & 1285 \\
-6 & 2.08 & 1270 \\
\hline
\end{tabular}


Table 10

RESULTS OF DIAMETRAL-COMPRESSION TESTS FOR W/C $=0.5$

\begin{tabular}{|c|c|c|}
\hline $\begin{array}{l}\text { Specimen } \\
\text { Number }\end{array}$ & $\begin{array}{l}\text { Length } \\
\text { (in.) }\end{array}$ & $\begin{array}{l}\text { Failure Stress } \\
\text { (psi) }\end{array}$ \\
\hline $39-1$ & 2.02 & 930 \\
\hline-2 & 2.04 & 755 \\
\hline-3 & 2.08 & 795 \\
\hline $40-1$ & 2.14 & 885 \\
\hline-2 & 2.15 & 890 \\
\hline-3 & 2.14 & 945 \\
\hline $41-1$ & 1.98 & 830 \\
\hline-2 & 1.95 & 890 \\
\hline-3 & 2.14 & 895 \\
\hline $42-1$ & 2.13 & 810 \\
\hline-2 & 2.11 & 880 \\
\hline-3 & 2.09 & 840 \\
\hline $44-1$ & 2.10 & 810 \\
\hline-2 & 2.10 & 1030 \\
\hline-3 & 2.14 & 760 \\
\hline $46-1$ & 2.13 & 755 \\
\hline-2 & 1.96 & 650 \\
\hline-3 & 2.10 & 730 \\
\hline $49-1$ & 1.94 & 1000 \\
\hline-2 & 1.93 & 740 \\
\hline-3 & 1.61 & 910 \\
\hline $51-1$ & 1.84 & 810 \\
\hline-2 & 1.82 & 1120 \\
\hline-3 & 1.81 & 1110 \\
\hline $54-1$ & 2.06 & 800 \\
\hline-2 & 2.06 & 820 \\
\hline-3 & 1.96 & 665 \\
\hline-4 & 2.00 & 685 \\
\hline-5 & 1.98 & 1000 \\
\hline-6 & 2.01 & 980 \\
\hline
\end{tabular}


Table 11

RESULTS OF DIAMETRAL-COMPRESSION TESTS FOR $\mathrm{W} / \mathrm{C}=0.6$

\begin{tabular}{rcc}
\hline $\begin{array}{c}\text { Specimen } \\
\text { Number }\end{array}$ & $\begin{array}{c}\text { Length } \\
\text { (in.) }\end{array}$ & $\begin{array}{c}\text { Failure Stress } \\
\text { (psi) }\end{array}$ \\
\hline $45-1$ & 2.03 & 520 \\
-2 & 1.89 & 785 \\
-3 & 1.98 & 805 \\
$47-1$ & 1.86 & 525 \\
-2 & 1.85 & 635 \\
-3 & 1.90 & 820 \\
$48-1$ & 1.93 & 650 \\
-2 & 1.88 & 395 \\
-3 & 1.86 & 795 \\
$53-1$ & 1.45 & 625 \\
-2 & 1.57 & 585 \\
-3 & 1.75 & 730 \\
\hline
\end{tabular}

from drying on the surface. A summary of the calculated tensile failure stresses is given in Table 12. The results of the statistical analysis of these data is in Appendix $B$.

The analysis of variance and the hypothesis tests show that Specimen Size, Testing Temperature, and Water-Cement Ratio are significant at a 5 per cent probability of a Type I error. Tests of the two-way and three-way interactions shows that both the Water-Cement Ratio - Size and Water-Cement Ratio - Temperature interactions are significant at the 5 per cent level. The other interactions are not significant. Examination of the test results indicates a general decrease in the average failure stress with increasing temperature.

An $x$-ray diffraction analysis was made of samples from specimens tested at $40^{\circ} \mathrm{F}$ and $160^{\circ} \mathrm{F}$. The analysis showed no difference between the 
Table 12

SUMMARY OF FAILURE STRESSES FROM DIAIETRAL-COMPRESSION TESTS

\begin{tabular}{|c|c|c|c|c|}
\hline \multirow{2}{*}{$\begin{array}{l}\text { Specimen } \\
\text { Length } \\
\text { (in.) }\end{array}$} & \multirow{2}{*}{$\begin{array}{l}\text { Testing } \\
\text { Temperature } \\
\left({ }^{O} F\right)\end{array}$} & \multicolumn{3}{|c|}{ Water-Cement hatio } \\
\hline & & 0.4 & 0.5 & 0.6 \\
\hline 0.3 & 40 & $\begin{array}{l}2050 \\
1585 \\
1810\end{array}$ & $\begin{array}{r}1160 \\
1155 \\
980\end{array}$ & $\begin{array}{l}950 \\
710 \\
660\end{array}$ \\
\hline 0.3 & 72 & $\begin{array}{l}1550 \\
1660 \\
1665\end{array}$ & $\begin{array}{r}980 \\
1055 \\
1090\end{array}$ & $\begin{array}{l}700 \\
720 \\
760\end{array}$ \\
\hline 0.3 & 160 & $\begin{array}{l}1325 \\
1190 \\
1305\end{array}$ & $\begin{array}{r}835 \\
935 \\
1010\end{array}$ & $\begin{array}{l}680 \\
695 \\
630\end{array}$ \\
\hline 1.0 & 40 & $\begin{array}{l}1285 \\
1570 \\
1235\end{array}$ & $\begin{array}{r}595 \\
1020 \\
640\end{array}$ & $\begin{array}{l}620 \\
675 \\
545\end{array}$ \\
\hline 1.0 & 72 & $\begin{array}{r}830 \\
1340 \\
1250\end{array}$ & $\begin{array}{r}1060 \\
905 \\
875\end{array}$ & $\begin{array}{l}490 \\
680 \\
690\end{array}$ \\
\hline 1.0 & 160 & $\begin{array}{l}880 \\
565 \\
530\end{array}$ & $\begin{array}{l}720 \\
755 \\
320\end{array}$ & $\begin{array}{l}485 \\
670 \\
525\end{array}$ \\
\hline 2.0 & 40 & $\begin{array}{r}1135 \\
890 \\
1360\end{array}$ & $\begin{array}{l}780 \\
910 \\
985\end{array}$ & $\begin{array}{l}710 \\
635 \\
530\end{array}$ \\
\hline 2.0 & 72 & $\begin{array}{r}1110 \\
1080 \\
880\end{array}$ & $\begin{array}{l}840 \\
795 \\
840\end{array}$ & $\begin{array}{l}625 \\
660 \\
680\end{array}$ \\
\hline 2.0 & 160 & $\begin{array}{r}1055 \\
595 \\
425\end{array}$ & $\begin{array}{l}600 \\
465 \\
290\end{array}$ & $\begin{array}{l}595 \\
380 \\
490\end{array}$ \\
\hline
\end{tabular}


specimens.

As in the initial tests on theta specimens, it was noted that the presence of entrapped air voids contributed to the variability of the test results. It was also noted that a fracture pattern was present on the fracture surfaces of the diametral-compression specimens similar to those noted on the fracture web surfaces of the theta specimens. Figure 14 shows a diametral-compression specimen tested to failure where the surface pattern is present showing a transformation from a relatively smooth area to a very rough surface along the length of the cylinder. Figure 15 shows another specimen on which the rough area is not so pronounced.

Three general types of failures were noted on cylinders tested in diametral-compression. In the normal tensile failure mode fracture was initiated at some point in the central plane and the specimen split into two nearly identical halves, as illustrated by the specimens shown in Figures 14 and 15. If the load was not removed immediately from the fractured specimen the two halves took up the load, and secondary failure occurred in each half. This type of failure is referred to as a "triple-cleft" failure and is illustrated in Figure 16. The third mode of failure was a shear-type failure in the region immediately adjacent to the bearing strips, and is illustrated in Figure 17. In testing this sample, one-inch bearing strips were so placed to produce a shear failure that is easily distinguished. 


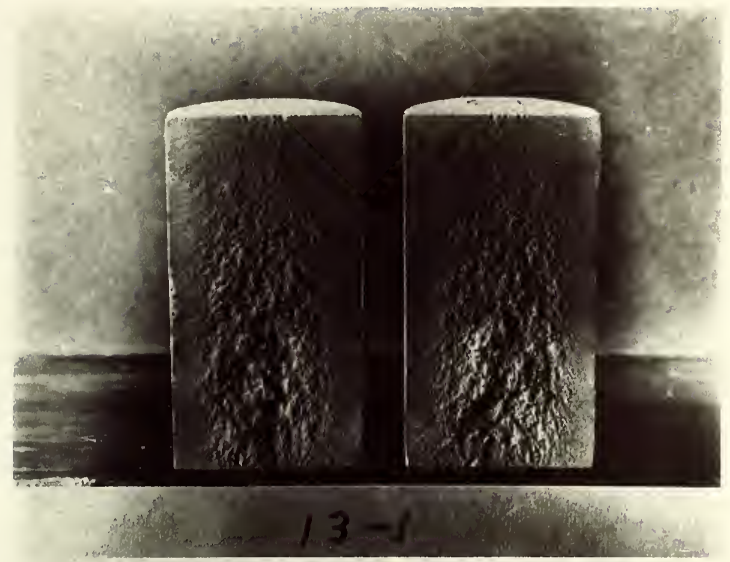

FIGURE 14. DIANTHRAL-COUPRESSIOA SPECTIRN NO. 13-1 


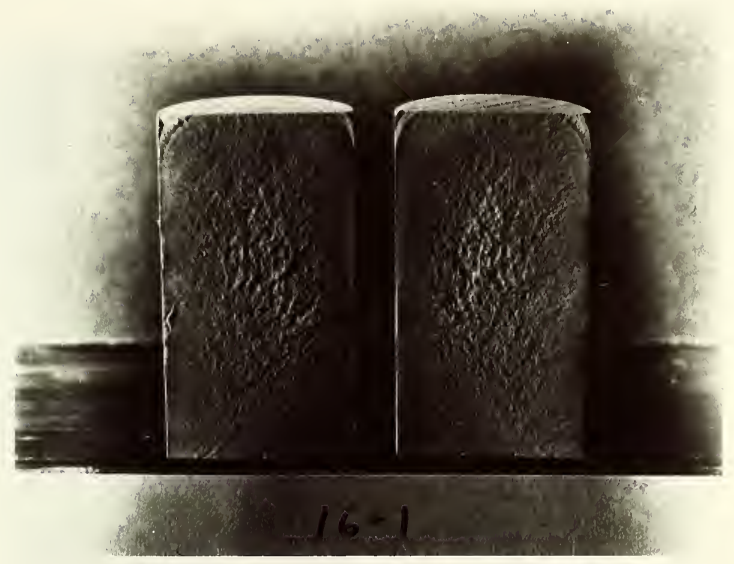

FIGURE 15. DIAVETRAL-COMPRESSION SPECIMEN NO. 16-I 


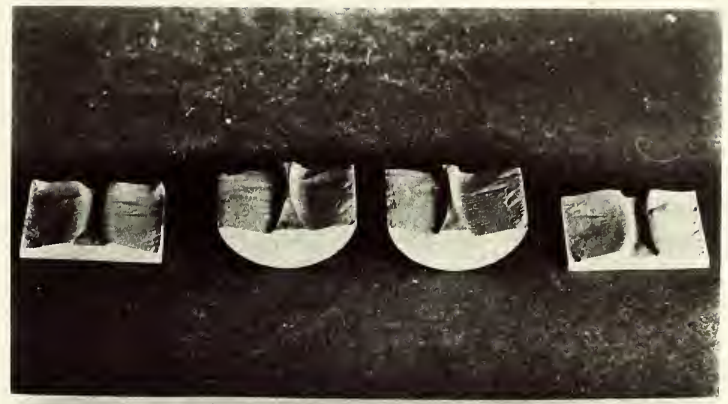

$$
119-5 \mathrm{~T}
$$

FIGURE 16. TRIPLE-CLRFT FAIIURE 


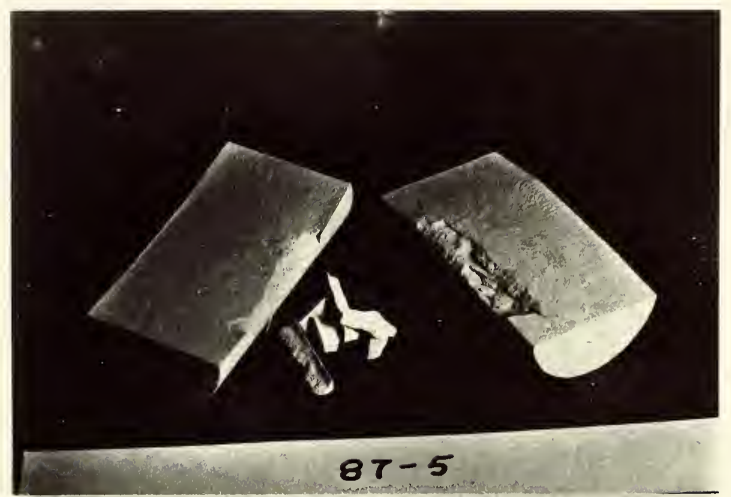

FIGURE 17. SHIAR-TYPE FAIIURE 
Results of Tests on Cylinders with Artificial Flaws

Attempts were made to induce artificial flaws into cement paste cylinders to be tested in diametral-compression. The early attempts were of limited value. Teflon disks were placed in the fresh paste but their influence could not be accurately determined since the disks tended to move about in the fresh paste owing to its handling, and their location in the hardened specimen could not be determined. Holes drilled at the ends of several cylinders produced fracture patterns similar to those produced by natural air voids. Figure 18 shows a fractured cylinder with a natural air void in the fracture plane. Figure 19 shows a fractured cylinder with a shallow hole drilled at one end to initiate failure.

A series of tests was conducted on diametral-compression specimens with teflon disks exposed at the end of the specimen by cutting the specimen with a diamond saw until the teflon disk was just observed. The specimen was placed in the testing machine with the teflon disk oriented vertically. Figure 20 shows one of the specimens tested to failure. A summary of the test results is given in Table 13 . 


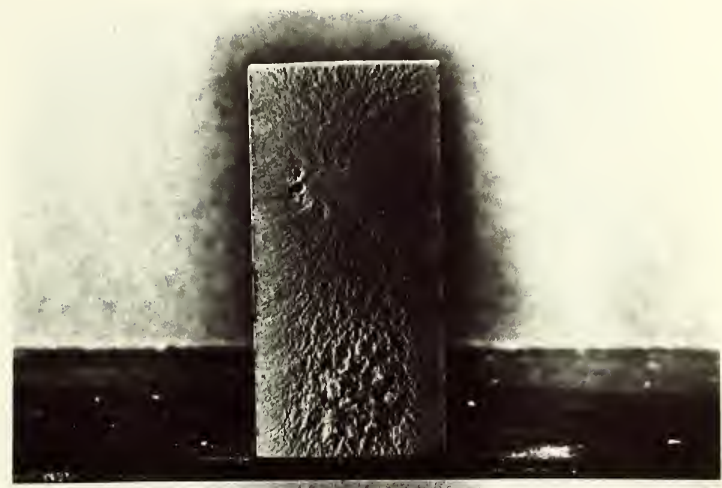

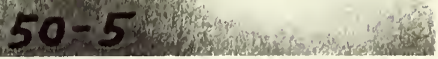

FIGURT 18. DIAMEYRAL-COMPRESSION SPECIMEN WITH AIR VOID 


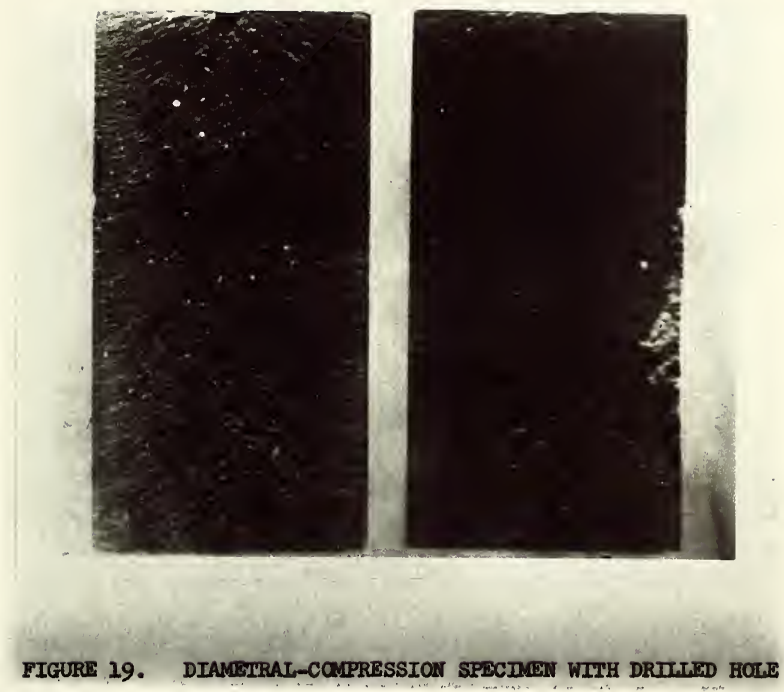




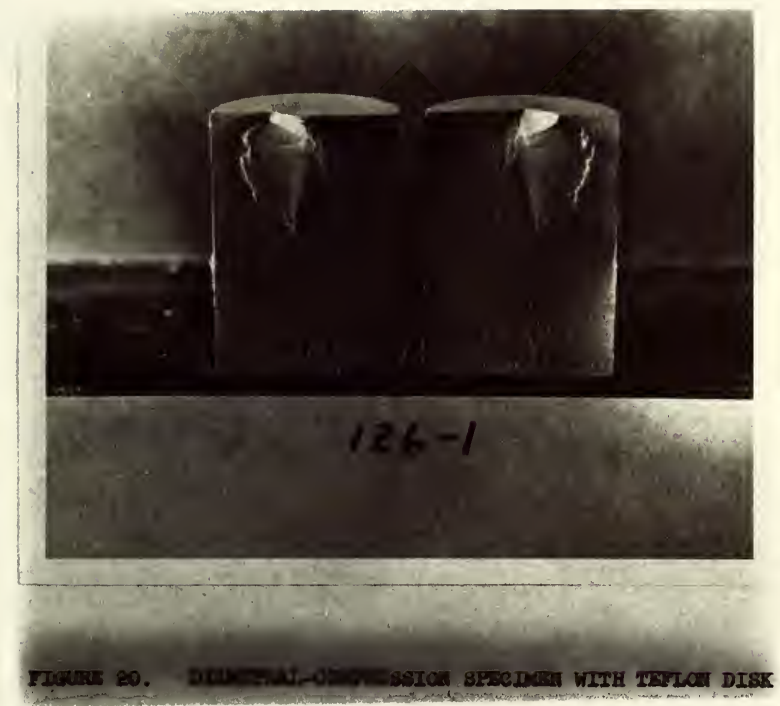


Table 13

SUMMARY OF DIAMETRAL COMPRESSION TESTS FOR SPECIMENS WITH TEFLON INSERTS

\begin{tabular}{rlcc}
\hline $\begin{array}{c}\text { Specimen } \\
\text { Number }\end{array}$ & $\begin{array}{c}\text { Age } \\
\text { (days) }\end{array}$ & $\begin{array}{c}\text { Depth of } \\
\text { Flaw } \\
\text { (inches) }\end{array}$ & $\begin{array}{c}\text { Failure Stress } \\
\text { (psi) }\end{array}$ \\
\hline $126-1$ & 46 & 0.12 & 870 \\
-2 & 46 & 0.18 & 440 \\
-3 & 46 & 0.09 & 940 \\
-4 & 46 & 0.08 & 630 \\
-5 & 46 & 0.093 & 640 \\
-6 & 46 & 0.095 & 905 \\
$128-1$ & 39 & 0.11 & 840 \\
-2 & 39 & & 1050 \\
-3 & 39 & & 790 \\
$129-1$ & 39 & 0.065 & 900 \\
-2 & 39 & & 970 \\
-3 & 39 & 0.035 & 995 \\
$130-1$ & 38 & 0.14 & 480 \\
-2 & 38 & 0.03 & 775 \\
-3 & 38 & 0.035 & 1000 \\
$131-1$ & 38 & 0.18 & 655 \\
-2 & 38 & 0.18 & 575 \\
-3 & 38 & 0.14 & 480 \\
$132-1$ & 37 & 0.075 & 565 \\
-2 & 37 & 0.072 & 775 \\
$141-1$ & 29 & 0.072 & 605 \\
-2 & 29 & & 605 \\
-3 & 29 & & \\
\hline
\end{tabular}




\section{DISCUSSION OF RESULTS}

The early part of the investigation was concerned with the establishment of procedures and techniques for testing hardened portland cement paste specimens with various water-cement ratios under tensile stresses. Small specimens were used to reduce the problems of thermal and shrinkage stresses developing within the specimens. The small specimen sizes also reduced the possibility of non-homogeneity caused by settling and bleeding of the fresh paste, especially at the higher watercement ratios. Testing of small specimens was complicated by their size, but one-inch diameter cylinders and 0.3 -inch thick theta specimens proved satisfactory.

The mixing and placing procedures used did produce specimens of relatively uniform density. Density determinations made on disks cut from the top, middle and bottom thirds of paste cylinders showed that the mixing and molding procedures detailed previously do produce specimens that are more uniform than those vibrated only in an upright position. The determinations made on companion specimens showed good agreement.

The tefion and plastic molds proved to be ideal. These materials were impervious to chemical reaction with the cement paste, and it was possible to produce specimens with no joint marks on their surfaces. The relatively high temperature susceptibility of the mold materials enabled the removal of specimens quickly and easily by applying a small 
amount of heat to the exterior mold surfaces.

The results of the compression tests on one inch diameter cylinders showed a decrease in compressive strength and elastic modulus with an increase in water-cement ratio. These changes would be expected, since the increase in water-cement ratio increases the void content of the hardened paste. The modulus of elasticity values, as reported in Table 5, are in good agreement with values determined in other investigations (40).

The test results for density, compressive strength and modulus of elasticity were more variable for the lower water-cement ratios. One possible explanation is that the number of capillary pores and other larger voids (or weak areas) will be greater in the higher water-cement ratio pastes than in the lower. The presence of only one flaw of critical size and orientation will trigger a fatal crack. The lower watercement ratio pastes have fewer of these flaws, and the probability of finding one so oriented to trigger a failure is relatively lower than in a higher water-cement ratio paste. Tests on theta specimens indicated the same general trend.

Tests of theta specimens and subsequent microscopical examination of the frostured surfaces showed that definite patterns existed on these surfaces. However, the cross-sectional area of approximately 0.03 square inches was too small to allow a detailed examination of the patterns. A careful examination of diametral-compression specimens showed the same patterns present. Lines appeared on the fracture surface of the diametral-compression specimens curving away from one end of the specimen or from defects such as air voids (see Figures 15 and 18). These 
hackle marks have been observed in studies of the fracture of metals and ceramics (2l). The marks radiate away from the source of the fracture and are caused by elastic waves rebounding from the exterior boundaries of the specimen as the crack propagates. In specimens where no defect was apparent, the hackle originated from the end of the cylinder, indicating that failure was initiated at that point. The surfaces showed a relatively smooth area grading into a rougher area. In diametralcompression specimens where entrapped air voids occurred in the central plane the hackle marks radiated in all directions from the void, as previously noted in Figure 18.

The hackle lines do indicate the place of fatal crack initiation. The study of specimens with artificial flaws show the same distinct patterns raijating from the artificial flaw.

It will be observed that the fracture surface became very rough, as distinct from the "pattern roughness" of the hackle, at larger distances from the crack origin. This increased roughness is probably caused by multiple branching of the crack front owing to the increasingIy large releases of strain energy that must be absorbed in some way. The phenomenon was present to a lesser degree in those lower strength (and modulus) specimens that have a smaller strain energy release on fracture.

There appear to be three reasons why a majority of the cylinders tested in diametral-compression showed patterns of failure initiating at an end of the specimen. One reason is that stress concentrations may occur at the ends of the cylinders. Photoelastic studies of this test (89) seemed to show no pronounced end effect. Even so, the change in 
size of the "central rib" of the triple-cleft failure specimens (Figure 16) may be an indication of stress differences along the length of the specimen.

Another cause for failure starting at the end may be in the difference in boundary conditions from the center of the cylinder to the end. Plane strain conditions would be more nearly satisfied in the central length of the cylinder while plane stress conditions would be more nearly satisfied at the ends of the cylinders. If the material has a Poisson's ratio of approximately 0.3 there would be an increase in stress of five per cent at the ends. A third possible reason may be found by considerjig the nature of the cement paste itself. Griffith's theory shows that a crack of length $2 c$ on the interior of a specimen behaves the same as a crack of lencth (or depth) $c$ on the surface of a specimen. In cement paste, cracks (or defects such as capillary pores) up to lenfth 2c may occur at or very near the surface as well as in the interior of a specimen. The obvious conclusion in this case would be that failure wourd start at the exterior surface first owing to the critical crack length. All three possibilities probably occur to some degree in the cement paste specimens. In any event, the crack always started at the ends unless a large flaw was present in the interior.

The initial diametral-compression tests were performed to check the results of tests made on theta specimens from the same mix. As in the early theta tests, the results were highly variable, owing in part to procedures and techniques that were still in the process of being established and perfected. Failure stresses calculated from the results of diametral-compression tests on one-inch by two-inch cylinders were as 
much as 40 percent lower than those of theta specimens from the same mix. There are two possible explanations for the differences: one is that the two types of tests do not measure the same material property. However, both types of tests have been subjected to photoelastic studies which indicate that the stress equations are valid if the assurmptions of homogeneity, isotropy, and elasticity are met. The second possibility is a size effect. The area on which tension exists in the theta web is approximately 0.03 square inches, while it is approximately two square inches for the larger cylinders tested. Tests on a number of cylinders with different central plane areas, produced by a change in length or diameter, did show that the smaller the cross-sectional area the higher the calculated stresses at failure, for the diametral-compression specimens, and providing no very large flaw was present.

One hypothesis advanced to explain the effect of size on failure stress is based on statistical considerations. The basic assumption is that there exists in specimens a number of inherent flaws and as the size of the specimen is reduced the probability of a critical flaw being present and critically oriented is reduced. The result is that the smallex the specimen, the less the probability of failure at a given stress.

If a large flaw did exist, however, the failure seems to have been so exclusively governed by the size of this flaw that the size effect is substantially eliminated. The results in Table 18 for specimens with drilled holes and teflon inserts, but of various specimen lengths, show roughly equivalent failure stresses;" and no pronounced "size effect". It should be pointed out that the maximum tensile stress in the 
diametral-compression specimen occurs in the portion of the specimen directly in line with the direction of load application. While fracture may originate at any point in the central plane the tensile stress decreases away from the central plane, and therefore failure is generally limited to the central plane area where the stresses are a maximum. In the theta specimen, on the other hand, the central web has a uniform cross-section for approximately 1.5 inches of its length. The tensile stress is uniform along this length, and hence, the specimen can fail at any plane along the web. The results of statistical analyses of test results from both theta specimens and diametral-compression specimens indicate a higher coefficient of variation associated with the theta test than with the diametral-compression test. The statistical analyses are given in Appendix B. One would expect a higher variability in the theta specimen strengths because a chance large flaw, such as an air bubble, would be influential at any point in the web, whereas the same flaw would cause failure in the cylinder only if it happened to become located in the central plane on which the maximum tension develops during the test.

For a porous material saturated with a liquid, further considerations involve the load-carrying ability of the liquid. These cement paste specimens have a porosity due to the nature of the material, and in a saturated condition the pores are filled with water. The permeability of cement paste is such that if a specimen is loaded, part of the load is transferred to the vater and a pore water pressure is created. If the cross section is small enough, even at low permeabilities, the pressure may dissipate or be decreased during loading. In the 
larger specimens, the pressure cannot dissipate fast enough, and relatively large pore water pressures may exist. These conditions may be analogous to a "drained" and "undrained" test, respectively, of a soil sample. The solid structure in the smaller specimens would carry most of the load, while in the larger specimens the solid structure might carry only a part, and the pore water might carry the rest of the loa . The total stress is equal to the sum of the effective stress (see reference 112, page 79) and the pore water pressure. If failure is the result of ruptured solid bonds, then the effective stress is of prinary concern. While total stresses calculated for the large specimen may be less than that for a smaller specimen, the effective stresses may be equal, which would tend to explain the observed "size effect".

Evidence that pore water pressures of considerable magnitude were present in the larger diametral-compression specimens was foun. The fractured faces in these specimens vere foun to have a relatively large amount of free water on their fractured faces immeiately after testing. Since the permeability of the cement paste is very low, there must exist pore water pressures of a relatively large magnitude to cause the observed water movement.

To investigate the possibility of pore water pressures affectins the magnitude of the failure stresses as determined by the diametralcompression test, a limited number of specimens were tested at varying rates of loading. The speed of vertical ram travel ranged from 0.005 inches per minute to 50 inches per mimute under automatic load application. Several specimens were loaded nanually with the load applied in steps. This loading procedure was used to apply the load in one case 
over a period of four and one-half hours. These limited tests indicated that there was no difference in failure stresses over the range of loading rate used. If pore water pressure, and the subsequent dissipation of these pressures with time, was a factor, the variation in loading rates should have indicated a difference in failure stresses, but no such difference was apparent. It should be noted that the appearance of free water on the fracture faces at completion of the test was much less for the samples with higher $\mathrm{W} / \mathrm{C}$, and therefore of higher permeability. This observation is in accordance with the general idea of the existence of pore water pressures and the attendant movement of water.

The various equations that have been derived to explain brittle fracture have been discussed in the review of previous work. Of these, the one most applicable to the present work is that of Sack, equation (2) here repeated

$$
\sigma^{2} c=\frac{\pi E \gamma}{2\left(1-\mu^{2}\right)}
$$

where

$$
\begin{aligned}
& \sigma=\begin{array}{l}
\text { tensile failure stress at onset of unstable crack } \\
\text { propagation }
\end{array} \\
& c=\text { radius of the disc-shaped crack } \\
& \vec{E}=\text { Young's modulus } \\
& \gamma=\text { surface free energy of material } \\
& \mu=\text { Poisson's ratio of material }
\end{aligned}
$$

In Appendix $C$ is derived an alternate expression along with the assumptions leading thereto. The final result is equation (17), for plane strain

$$
c^{2}=\frac{2 E \gamma}{\left(1-\mu^{2}\right)}
$$


where the symbols are the same as before.

These equations are appropriate to the conditions just as the crack begins to propagate spontaneously and, therefore, to the onset of final failure. The portion of the physical substance is therefore a small region just at the periphery of the crack. It cannot be a truly differential region because any physical substance is a non-continuum, but it must be a region small compared with the crack size yet large compared with the physical units that are undergoing change, i.e., atoms, crystalline defects, etc.

Accordingly, we are not here concerned with any processes that occur after the onset of spontaneous crack propagation. It is recognized that as the crack grows larger an increasingly larger amount of strain energy must be absorbed somehow. Since the strain energy release rate is proportional to the first power of the crack size, while the surface energy accomodation rate is constant, other energy absorption mechanisms must increasingly come into play as the crack propagates and becomes larger. Some possible mechanisms are increased area formed due to roughness and crack branching (both observed in the fracture patterns in this work), generation of heat and sound, and kinetic energy of the fracture fragments. All no doubt play a part. But the point to be emphasized is that these factors are of no concern with respect to the applicability of the foregoing equations, which refer only to the instant of beginning of spontaneous propagation of the crack.

It was previously mentioned that in most of the theta specimens, the fracture passed through the center of an air bubble. In both the theta specimens and the cylinders containing a teflon disc, the patterns 
on the fracture faces indicated that the fracture started at the air bubble or at the small teflon insert. It is therefore reasonable to assume that these were the fatal defects and that their size can be considered the initial crack size.

By assuming observed air voids in the theta specimens to be the critical failure cracks, a plot of the failure stress versus flaw size was made (see Figure 21). During microscopical examination of the fractured surfaces the flaws were classified as either edge or interior flaws and the flaw size, c, was determined accordingly. The critical crack size is the radius of an interior flaw or the depth of a surface flaw in the Griffith equation and in Sack's modification.

The figure also shows the data obtained with the cylinders containing the teflon inserts, which is also listed in Table 13.

An examination of the data in Table 13 shows a great deal of scatter. The positioning and alignment of the teflon disk under the load accounts for some (if not a major portion) of the scatter. The teflon disks could not be accurately placed in the fresh paste and as a result the orientation of the disks varied not only in angle to the central plane but also in actual position across the cylinder diameter.

Calculations based on Sack's extension of Griffith's theory to three dimensions (Equation 2) give a theoretical curve that compares favorably in shape with the experimental data, as shown in Figure 21. Also plotted is the curve of equation (39). The value of elastic modulus used was $2.56 \times 10^{6} \mathrm{psi}$, the average of the determined values. The value of Poisson's ratio used was 0.25 . The surface free energy term used was $420 \mathrm{ergs} / \mathrm{cm}^{2}$. The reasons for the adoption of this value are given in 


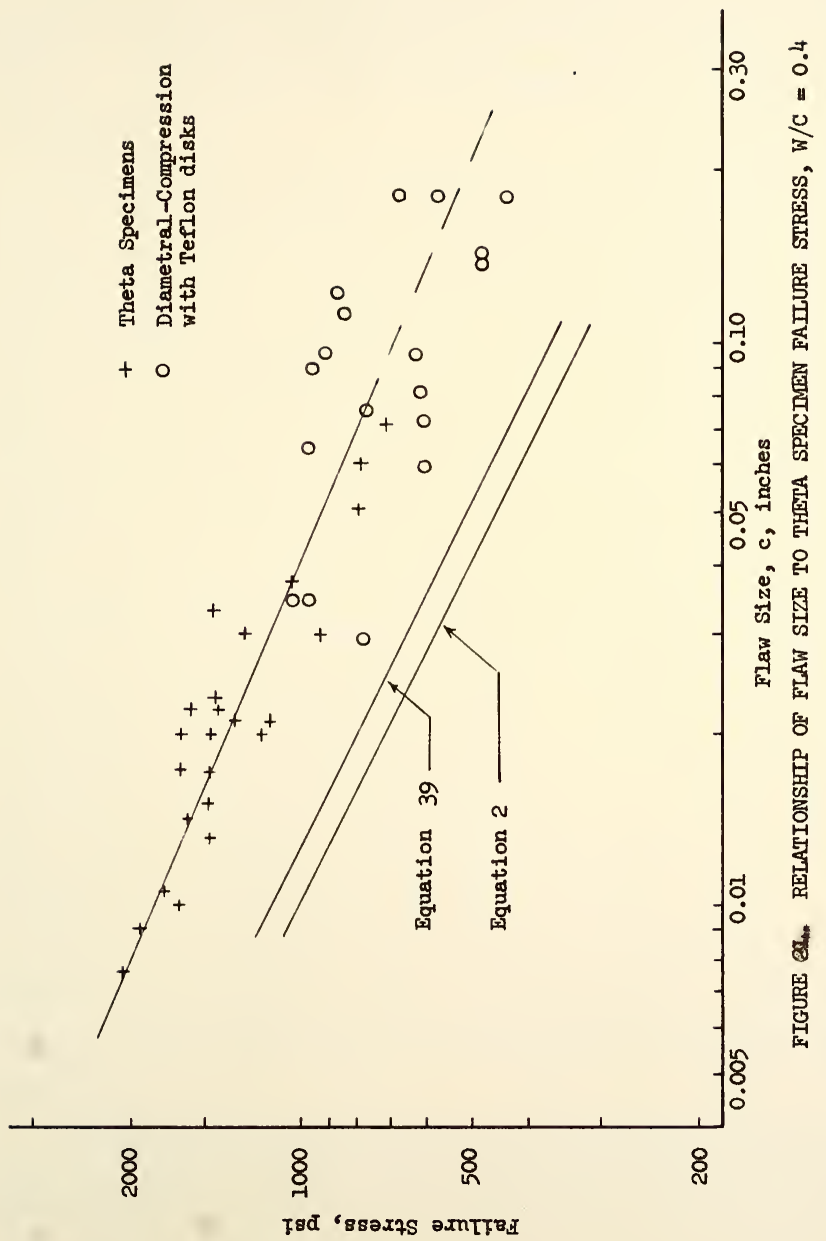


detail in Appendix D.

The slope of the derived equations in Figure 21 is -0.5 . The statistical evaluation of the experimental data, given in Appendix B, results in a slope value of -0.44 , so the agreement from this point of view is reasonable.

It is obvious from Figure 21 that the data do not conform to either of the theoretical lines shown. What this means is that other energyconsuming processes must be operative, within the small physical space that is pertinent to the applicability of the theory. The necessity for the consideration of other energy-consuming processes has been recognized for a long time. The original Griffith formulation was modified by Orowan (71) to account for the consumption of energy by plastic deformation. With relatively ductile materials the work of plastic deformation may be many times that consumed by the creation of new surface; even with those materials ordinarily considered very brittle, the ratio of the two consumed energies may be as high as 10 (102). Even glass is now considered to be not perfectly brittle but to have a plastic component of the consumption of fracture energy. The words "plastic component" need not be taken too literally because they refer to any energyconsuming process other than the formation of surface.

The plastic deformations in the vicinity of the crack tip in metals are fairly well understood in terms of dislocation theory. Little has been done on other materials or the details of other energy-consuming processes.

A parameter that has been widely used as a materials constant in fracture mechanics is the so-called strain-energy-release rate, G. When 
applied to the critical state of incipient spontaneous crack propagation the symbol $G_{C}$ is used. Some confusion seems to exist concerning this parameter. Tetelman and McEvily (102) and Kaplan (51), among others, define $G_{c}$ as

$$
G_{c}=\frac{\pi c \sigma^{2}}{E}
$$

for the Griffith case, but Glucklich (27) used twice this value. Analysis shows that $G_{c}$ is the change in strain energy per unit of "plan" crack area formed during a small extension of the crack. The "plan" area, $A_{p}$, is the apparent or "visual" area and is half the true or real area, for a plane crack surface. For the case of the disc-shaped or spherical flaw (Appendix C) this value becomes

$$
G_{c}=\frac{d E}{\epsilon A_{p}}=\frac{c \sigma^{2}}{E}
$$

If the material is "purely brittle", that is, if production of new surface is the only energy-consuming process taking place, then the thermodynamic criterion of crack instability is

$$
\mathrm{dE}_{\epsilon}=d \mathrm{E}_{\mathrm{S}}
$$

where the energies in question are free energies, rather than internal energies or enthalpies. This is the basis of the Griffith Theory. If equation (20) is divided by the change in "plan" crack area,

$$
\frac{d E}{d A_{p}}=G_{c}=\frac{d E_{s}}{d A_{p}}=2 \gamma
$$

If, on the other hand, energy is consumed by other processes, then additional terms must be inserted in equation (20), 


$$
d E_{\epsilon}=d E_{s}+d E_{p}
$$

where $d E_{p}$ is the change in energy consumed by those other processes. This is usually referred to as the work of plastic deformation, because that is the process occurring in metals and other crystalline substances with some ductility. The term is, however, not restrictive and can refer to other processes as well, so that

$$
d E_{p}=d E+d E_{2}+\cdots
$$

By analogy with equation (21), the strain energy release rate equation can include these other processes,

$$
G_{c}=2 \gamma+G_{p}
$$

where

$$
G_{p}=\frac{d E_{p}}{d A_{p}}
$$

With specific reference to the data in Figure 21 , for the $\mathrm{W} / \mathrm{C}=0.4$ pastes, $G_{c}$ can be calculated from any point on the data line, by means of equation (19), if the slope is -0.5 , which it is approximately. If this is done $G_{c}$ turns out to be $0.0156 \mathrm{lb} / \mathrm{in}$, in the traditional units for $G_{c}$. This value can be compared with those obtained by others for similar systems. Moavenzadeh et al (6i) reported, in the only data found on pastes, values of $0.013-0.017 \mathrm{lb} / \mathrm{in}$. for 28 day old pastes of $\mathrm{W} / \mathrm{C}=0.5$. Others $(51,56)$ have reported values of about $0.05-0.15$ lb/in. for concretes.

The close correspondence between the values obtained here for pastes with those obtained by Moavenzadeh et al (61), who used a notched-beam technique that is completely different from the one used here, is a mutual confirmation of the validity of both techniques. 
If the surface were purely brittle and surface creation were the only energy-consuming process, $G_{c}$ would be equal to $2 \gamma$. The conversion factor between the units commonly used for each is $1 \mathrm{lb} / \mathrm{in} .=1.75 \times 10^{5}$ ergs $/ \mathrm{cm}^{2}$. So for the $W / C=0.4$ pastes, a surface free energy of 1370 ergs $/ \mathrm{cm}^{2}$ would be required for the paste. This is a value far higher than any measured or even suggested for such a system.

The analysis of the probable surface free energy of a $\mathrm{W} / \mathrm{C}=0.4$ paste given in Appendix D results in a value of $420 \mathrm{ergs} / \mathrm{cm}^{2}$. If this value is assumed correct, a possible explanation of the discrepancy between it and the calculated $G_{C}$ is that a larger area of new surface is produced than $2 \mathrm{~A}_{\mathrm{p}}$, i.e., that a "roughness" of the newly-formed surface must be taken into account. The magnitude of this "roughness" can be estimated as the ratio between the two surface energies just mentioned. This ratio is $1370 / 420=3.26$. So, if the "reaI" area produced is 3.26 times the apparent area produced, the results can be reconciled without involving other energy-absorbing mechanisms than creation of surface. The question of the physical region to which the theory and resultant equations is applicable has been previously discussed. If this region is really small compared with the size of the formative units of the system, there should be no difference between the true and apparent areas; if not there may be. In view of the other studies showing plastic behavior in a variety of substances normally considered brittle (102), it is probably safe to assume that the notion of roughness at the crack tip is insufficient to explain the observed differences.

The alternative is to assume a plane fracture at the onset of unstable crack propagation and a reasonable value for the surface free 
energy, and to assign the remainder of the strain energy release rate to some other form of energy consumption, such as "plastic" deformation. If the surface free energy is taken as $420 \mathrm{ergs} / \mathrm{cm}^{2}$, then twice this value, or $0.00480 \mathrm{Ib} / \mathrm{in}$., will be the "rate" of consumption of energy by surface formation, and the difference between this value and $G_{c}$ will be 0.0108 Ib/in. for the "plastic" component. This calculation shows the surface component to be 30.8 percent and the "plastic" component to be 69.2 per cent of the total strain energy release rate. The ratio of "plastic" to "surface" energy consumption is 2.25. Tetelman and McEvily (102) refer to a material as "intrinsically brittle" when this ratio is less than 5 .

A limited amount of data on the pastes of $W / C=0.5$ show a flatter relationship between $\sigma$ and $c$ than is shown on the $0.4 \mathrm{~W} / \mathrm{C}$ pastes; the empirical equation is, very roughly,

$$
\sigma^{5} c=\text { constant }
$$

but the data are too few to draw any such conclusion firmly.

As has been previously mentioned, in well crystallized materials, such as metals, the "plastic" energy absorption mechanism is thought to be accountable to plastic deformations caused by dislocation movement. For hardened, saturated, cement paste, the possible energy absorption mechanisms are more conjectural. The solid portion of the paste consists primarily of relatively well-crystallized calcium hydroxide and a very finely divided (specific surface of about $200 \mathrm{~m}^{2} / \mathrm{g}$ ) and poorly crystallized calcium silicate hydrate called cement gel or tobermorite gel (82). Studies of the creep or long-term deformation of hardened cement paste (113) have indicated that the oven-dry material does not deform 
plastically, or creep, at all and that the principal process for the deformation of wet pastes is by the so-called "seepage" mechanism, or the movement of water through the porous body. It is true that the stresses imposed in the study mentioned (113) were much smaller than those existing in the region of the tip of the crack in a specimen undergoing fracture. So it would be dogmatic to assert that plastic deformation of the solid skeleton of a saturated paste could not occur under such high stress concentrations. But there seems no doubt that movement of water can be an energy-absorbing mechanism and it may be the principal or even the only one operating. That movement of the water does take place seems to be shown by the wetness of the fracture faces, which has been previously discussed.

In an effort to gain insight into the processes occurring during fracture, the tests at various temperatures were made. The data are given in Table 12, and are plotted in Figures 22-4. Because of the large scatter, no curves have been drawn through the points in these figures. A trend is, however, obvious. The temperature dependency of the strengths of the $W / C=0.4$ pastes is relatively large, while that of the $\mathrm{W} / \mathrm{C}=0.6$ pastes is practically nil, with the $\mathrm{W} / \mathrm{C}=0.5$ pastes being about halfway between.

These samples had no large flaws and exhibited a size effect, which is large for the $W / C=0.4$ pastes and small for the $W / C=0.6$, with the $\mathrm{W} / \mathrm{C}=0.5$ again intermediate .

If very rough lines are drawn through the data, their slopes are about equal for the several sizes. The slope values are approximately $-4 \mathrm{psi} / \mathrm{deg} . \mathrm{F}$ for the $\mathrm{W} / \mathrm{C}=0.4$ pastes, $-2 \mathrm{psi} / \mathrm{deg} . \mathrm{F}$ for the $\mathrm{W} / \mathrm{C}=0.5$ 


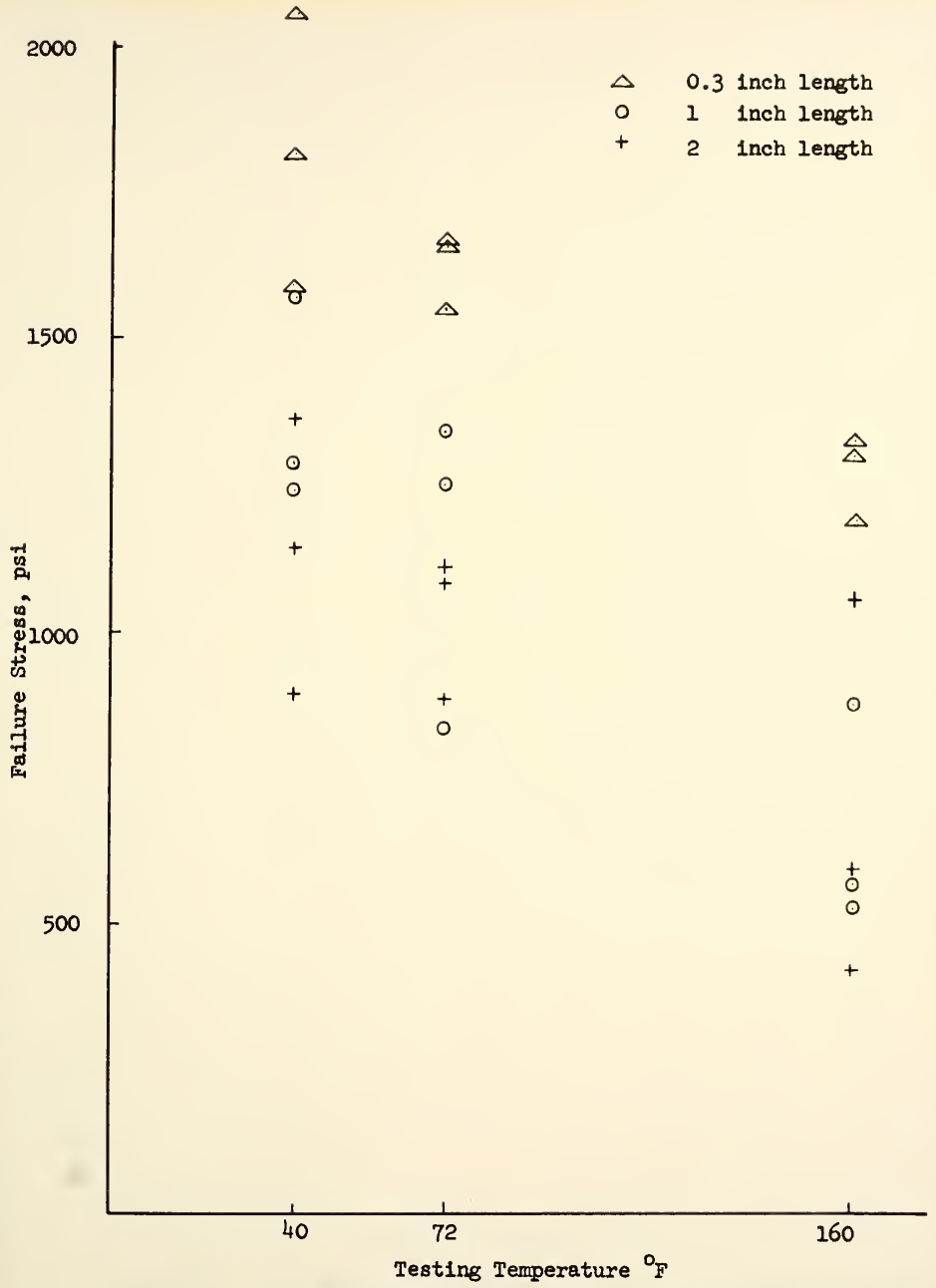

FIGURE 22. TEMPERATURE DEPENDENCE OF TENSTIE FAILURE STRESS FOR $0.4 \mathrm{~W} / \mathrm{C}$ DIAMETRAL-COMPRESSION SPECIMENS 


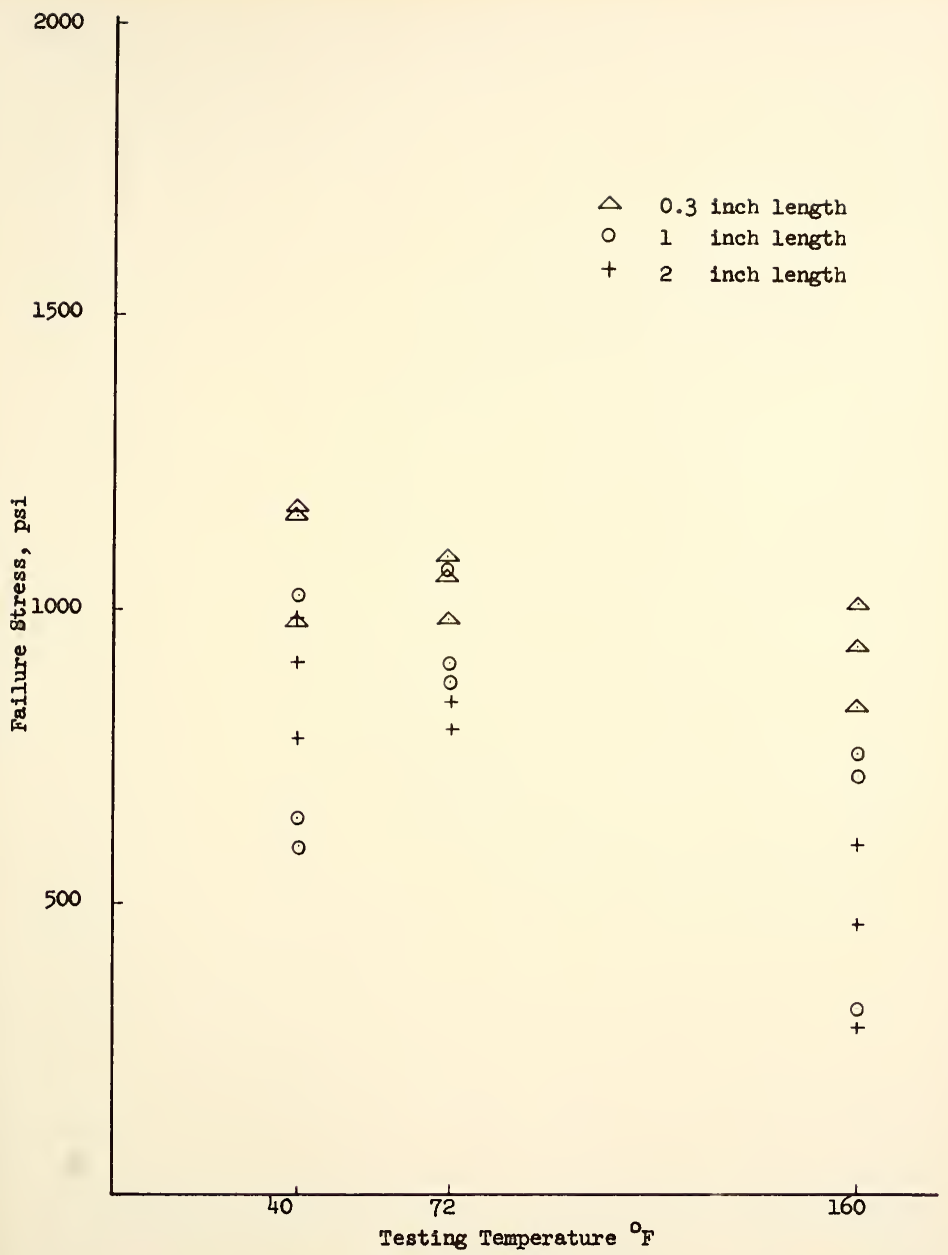

FIGURE 23. TEMPERATURE DEPENDENCE OF TENSTIE FAILURE STRESS FOR $0.5 \mathrm{~W} / \mathrm{C}$ DIAMETRAL-COMPRESSION SPECIMENS 


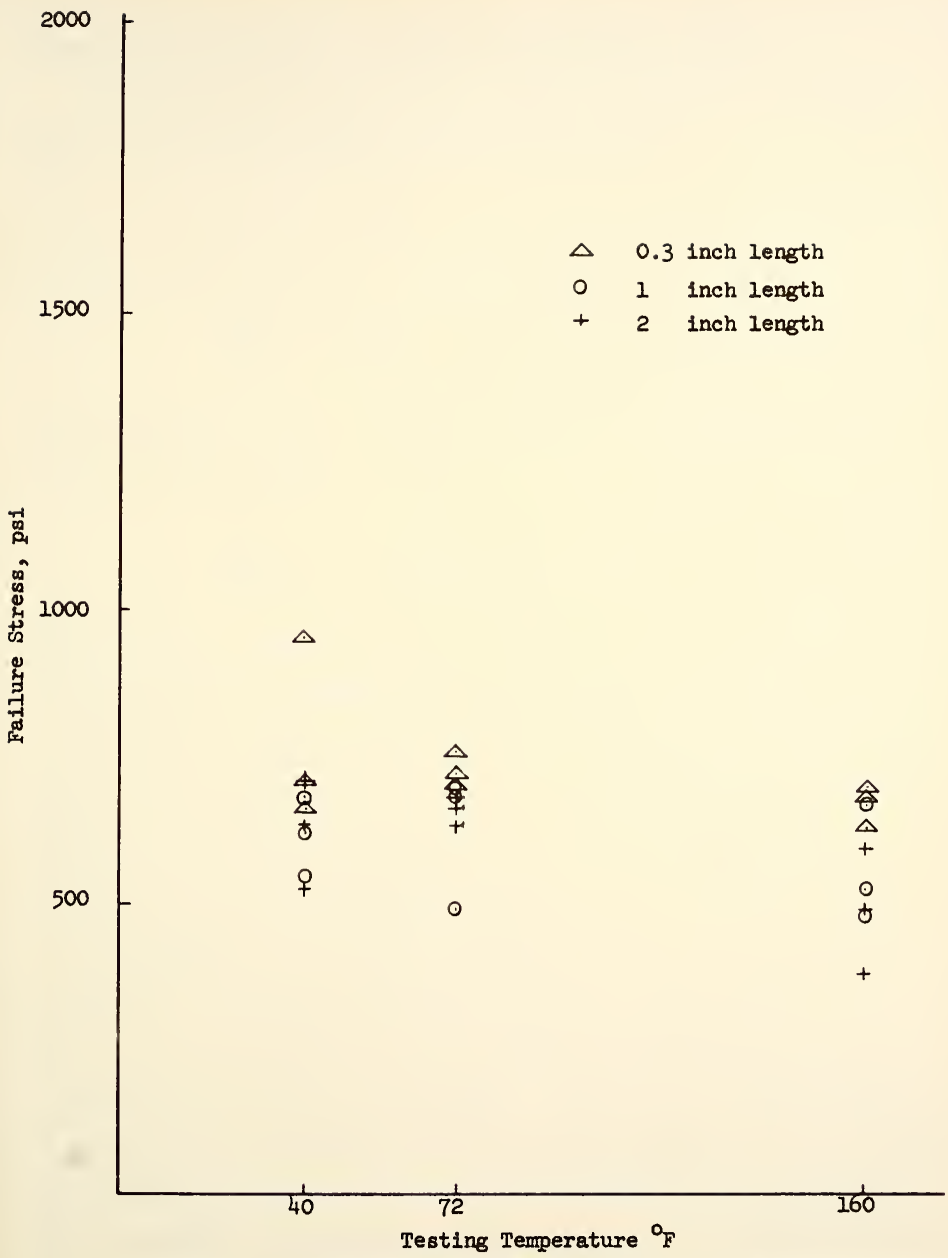

FIGURE 24. TEMPERATURE DEPENDENCE OF TENSIIE FAIIURE STRESS FOR $0.6 \mathrm{w} / \mathrm{C}$ DIAMETRAL-COMPRESSION SPECIMENS 
pastes, and less than $-1 / 2 \mathrm{psi} / \mathrm{deg} \mathrm{F}$ for the $\mathrm{W} / \mathrm{C}=0.6$ pastes.

If equation (36) is modified to include a term $\gamma_{p}$ for the "plastic work" (in surface free energy units) the result is

$$
\sigma^{2} c=2 E\left(\gamma+\gamma_{p}\right)
$$

If this is differentiated with respect to temperature, then

$$
\sigma^{2}\left(\frac{\partial c}{\partial T}\right)+2 \sigma q\left(\frac{\partial \sigma}{\partial T}\right)=2\left(\gamma+\gamma_{p}\right)\left(\frac{\partial E}{\partial T}\right)+2 \xi\left(\frac{\partial \gamma}{\partial T}\right)+2 E\left(\frac{\partial \gamma p}{\partial T}\right)
$$

If it is assumed that the crack size does not change with temperature, $\partial c / \partial T=0$, and equation $(28)$ becomes

$$
\sigma q\left(\frac{\partial \sigma}{\partial T}\right)=\left(\gamma+\gamma_{p}\right) \frac{\partial E}{\partial T}+E\left(\frac{\partial \gamma}{\partial T}\right)+E\left(\frac{\partial \gamma_{p}}{\partial T}\right)
$$

All terms in this equation can be estimated, at least reasonably, except $\partial \gamma_{p} / \partial T$, for which the equation can then be solved.

The data in Figure 21 were used for a oc combination of $1000 \mathrm{psi}$ and 0.04 in., respectively. The slope of the strength curve, $\partial \sigma / \partial T$ was taken as - 4 psi/deg. F from Figure 22. The total "effective surface energy", $\gamma+\gamma_{p}$, has been previously evaluated from the data in Figure 21 as $1370 \mathrm{erg} / \mathrm{cm}^{2}$. The modulus dependency, $\partial \mathrm{E} / \partial \mathrm{T}$, has been little investigated. Richards and Radjy (114) reported data for pastes of $\mathrm{W} / \mathrm{C}=0.35$ and steam-cured at $97^{\circ} \mathrm{C}$. Their value was approximately - $2250 \mathrm{psi} / \mathrm{deg}$. F, which was used here, in spite of the differences in $\mathrm{W} / \mathrm{C}$ and curing. The modulus value was the measured one of $2.56 \times 10^{6} \mathrm{psi}$. The temperature coefficient of surface free energy of the system is not known accurately. The handbook value for water is $-0.08 \mathrm{erg} / \mathrm{cm}^{2} \mathrm{deg}$. F. The value for solids is probably about the same, so this is the one used here. 
If these values are inserted in equation (29) the solution for $\partial \gamma_{p} / \partial T$ is $9.6 \mathrm{erg} / \mathrm{cm}^{2} \mathrm{deg} . \mathrm{F}$. It can be seen from the relative magnitudes of the terms in equation (29) that the strength-temperature dependency is almost totally controlled by $\partial \gamma_{p} / \partial T . \quad \gamma_{p}$ is the difference between the total "effective" value of $1370 \mathrm{erg} / \mathrm{cm}^{2}$ and the calculated value of $420 \mathrm{erg} / \mathrm{cm}^{2}$ for the surface component alone, or $950 \mathrm{erg} / \mathrm{cm}^{2}$. So in percentage terms, $\partial \gamma_{\mathrm{p}} / \partial \mathrm{T}$ is about - 1 percent per degree $\mathrm{F}$.

Further speculation can now perhaps be made concerning the role of water in the fracture process and its movement as an energy absorbing mechanism. The definition of permeability is

$$
\frac{V}{a t}=\frac{K \Delta P}{\eta \Delta V}
$$

where

$$
\begin{aligned}
V / t & =\text { volume flow rate of permeant } \\
a & =\text { approach area } \\
K & =\text { permeability } \\
\eta & =\text { viscosity of permeant } \\
\Delta P & =\text { pressure difference causing flow } \\
\Delta & =\text { flow path length }
\end{aligned}
$$

It can be seen that the energy absorbed in the flow process is proportional to the viscosity, so if the flow rate remains constant a decrease in viscosity, caused by a temperature increase, should bring about a decrease in "plastic" energy absorption, $\gamma_{p}$, and be in the direction called for by the strength-temperature data. The handbooks show a decrease of the viscosity of water from 1.60 centipoise at $40 \mathrm{~F}$ to 0.40 centipoise at $160 \mathrm{~F}$ or a dependence of -0.01 centipoise/deg. F. If this is put in terms of percent of the average, 1.0 centipoise, the result is -1 
percent per degree F, or just the same value as the previously calculated $\partial \gamma_{p} / \partial T$. The comparison is tempting, albeit most speculative. 


\section{SUMMARY OF RESULTS}

The major findings of this study can be summarized as follows:

1. Techniques have been developed for the fabrication of substantially air-free specimens of hardened cement paste in theta and cylinder forms, using teflon molds. These forms have proved satisfactory for the determination of the tensile strength of the pastes using compression loading techniques.

2. A size effect was found for those specimens that did not have a large flaw in the tension field. Smaller specimens of the same water-cement ratio failed at a higher load. If the specimen did have a relatively large flaw, either in the form of an air bubble, a drilled hole, or a small teflon disc, the size effect was substantially absent. In addition the usual dependency of strength on water-cement ratio was found.

3. Studies of the fractured surfaces show patterns that are similar to those noted in other studies of the fracture of metals and ceramics. These patterns indicated the probable source of the fracture to be the aforementioned flaws, if such were present. No evidence was seen for any significant amount of slow crack growth.

4. Immediately after fracture of the saturated specimens the broken faces were frequently found to be excessively wet, indicating a movement of water during the test. Strength determinations 
in which the loading rate was varied over four orders of magnitude failed to show any significant difference in fracture stress.

5. An equation was derived for the relationship between tensile fracture stress and the size of a disc-shaped or spherical flaw. Simple assumptions were used in this derivation. The equation is the same as those developed elsewhere except for a small multiplying factor.

6. An empirical equation was developed for the relationship between failure tensile stress and flaw size in $W / C=0.4$ pastes, on the assumption that the size of the fatal flaw was that of the air bubble or inserted teflon disc from which the fracture seemed to emanate. The exponential dependence of these parameters was almost the same as that of the various derived equations, but the coefficient was different. The value of strain energy release rate calculated from these data was about the same as those determined by others using different techniques.

7. The data referred to in (6), above require as an explanation either: a) the assumption of an unrealistically high surface energy of the material, about 3 times that calculated for the system using reasonable assumptions, or b) the inclusion of an area factor of the same magnitude relating true area of fracture at the crack periphery just prior to fracture to the apparent area, or c) the consumption of about 70 percent of the released strain energy by some process other than new surface formation, or d) some combination of all these. It is considered that (c) 
is most likely; possible energy consumption processes are plastic deformation of the solid phase of the paste or flow of water in the pores of the the paste.

8. Increase of temperature of the test specimen brought about a comparatively large decrease in tensile fracture stress for the pastes with $\mathrm{W} / \mathrm{C}=0.4$, a smaller one for those with $\mathrm{W} / \mathrm{C}=0.5$, and very little change for those with $\mathrm{W} / \mathrm{C}=0.6$.

9. An analysis of the temperature dependence of the tensile strength of the $\mathrm{W} / \mathrm{C}=0.4$ pastes showed that the influence of temperature on the presumed "plastic" or "non-surface" energy consuning processes controls the strength-temperature relationship of the paste. A calculated relative value of this "plastic work"-temperature coefficient was the same as that for the influence of temperature on the viscosity of water. 


\section{CONCLUSIONS}

The following conclusions seem reasonable and are based on the results of this study of the fracture of saturated, hardened portland cement pastes.

1. Patterns exist on the fracture surfaces of hardened cement pastes broken in tension that are similar to those of other brittle materials and by means of which the probable source of the fracture can be determined.

2. Air voids and other large defects, if present, serve as the source of fracture cracks of hardened cement paste.

3. For pastes of relatively low water-cement ratio, the form of the dependence of the tensile failure stress on the flail size is almost the same as that of the Griffith theory and its modifications.

4. An increase of testing temperature brings about a decrease in the tensile strengths of pastes of relatively low water-cement ratio, but has little effect on the strengths of pastes of relatively high water-cement ratio.

5. It is indicated that, for pastes of relatively low water-cement ratio, a significant proportion of the strain energy released at the onset of fracture is consumed by some process other than the formation of new surface. This proportion falls, however, well within the range of intrinsically brittle materials. 
6. The temperature-strength relationships suggest that the strain energy not consumed by the formation of new surface is consumed by the flow of water in the pores of the paste. 
BIBLIOGRAPHY 


\section{BIBLIOGRAPHY}

1. Alexander, K. M., Discussion of Hsu and Slate's article, J. ACI., Proc., Vol. 60, No. 12, December 1963, pp. 1787-1796.

2. Alexander, Kenneth M., Warslaw, John and Gilbert, D. J., "AggregateCement Bond, Cement Paste Strength and the Strength of Concrete," Paper presented at the International Conference on the Structure of Concrete and its Behavior Under Load, September 28-30, 1965.

3. Antrim, J. D., "A Study of the Mechanism of Fatigue in Cement Paste and Plain Concrete," Ph. D. Thesis, Purdue University, January 1964.

4. Barenblatt, G. I., "Mathematical Theory of Equilibrium Cracks," Advances in Applied Mechanics, Vol. 7, pp. 55-129, 1962.

5. Bhowmich, S. K., "On the Effect of a Spherically Isotropic and Nonhomogeneous Spherical Inclusion with a Rigid Core on the Axis of a Large Isotropic Cylinder Under Torsion," Atti della Accademia della Scienze di Torino, Fis. Mat. Nat., Vol. 95, No. 5, pp. 612-617, 1961.

6. Blackman, James S., Smith, Gerald M. and Young, Lyle E., "Stress Distribution Affects Ultimate Tensile Strength," Journal of the ACI, Vol. 30, No. 6, pp. 679-684, December 1958.

7. Blakey, F. A. and Beresford, F. D., Discussion of Crack Propagation and the Fracture of Concrete by M. F. Kaplan, Journal ACI, Proc., Vol. 59, No. 6, Part 2, pp. 919-923, 1962.

8. Bloem, Delmar L. and Gaynor, Richard D., "Effects of Aggregate Properties on Strength of Concrete," Journal of the ACI, Proceedings, Vol. 60, No. 10, pp. 1429-1455, October 1963.

9. Bombolakis, E. G., "Photoelastic Investigation of Brittle Crack Growth within a Field of Uniaxial Compression," Techonophysics, I (No. 4): 343-351, 1964.

10. Brace, W. F., "An Extension of the Griffith Theory of Fracture to Rocks," Journal of Geophysical Research, Vol. 65, No. 10, October 1960 , pp. $3477-3480$.

11. Brace, W. F. and Bombolakis, E. G., "A Note on Brittle Crack Growth in Compression," J. Geophys. Res., Vol. 68(No. 12): pp. 3709-3713, 1963. 
12. Bresler, B. and Pister, K. S., "Strength of Concrete Under Combined Stress," Journal of the ACI, Vol. 30, No. 3, pp. 321-345, September 1958.

13. Brown, Colin B., "Models for Concrete Stiffness with Full and Zero Contiguity," Paper presented at the International Conference on the Structure of Concrete and its Behavior Under Load, September 28-30, 1965.

14. Brunauer, Stephen, "Tobermorite Gel - The Heart of Concrete," PCA Bulletin 138, 1962.

15. Carlson, R. W., "The Chemistry and Physics of Concrete Shrinkage," Proceedings, ASTM, Vol. 35, pp. 370-379, 1935.

16. Charles, R. J., "A Review of Glass Strength," in Progress in Ceramic Science, edited by J. E. Burke, Pergamon Press, 1961.

17. Chen, I. S., "On the Problem of Stress Concentration in the Presence of Many Holes," Problems of Continuum Mechanics, Philosopherical Society of Industrial and Applied Mathematics, pp. 69-73, 1961.

18. Clausin, D. P., "Comparison of Griffith's Theory with Mohr's Failure Criteria," Quart. Colo. School Mines, Vol. 54(No. 3), pp. 285-297, 1959.

19. Copelan , L. E. and Schulz, Edith G., "Electron Optical Investigation of the Iydration Products of Calcium Silicates and Portland Cement," Journal of the PCA Research and Development Laboratories, Vol. 4, No. 1, pp. 2-12, 1062.

20. Cordon, William A. and Gillespie, H. Aldridge, "Variables in Concrete Aggregates and Portland Cement Paste Which Influence the Strength of Concrete," Journal of the ACI, Proceedings, Vol. 60, No. 8, pp. 1020-1052, August 1963.

21. Corten, II. T. and Park, F. R., "Fracture," International Science and Technology, 15: 24-36, 1963.

22. Cottrell, A. H., "Theoretical Aspects of Fracture," Proceedings of an International Conference on the Atomic Mechanism of Fracture Feld in Swampscott, Hassachusetts, April 12-16, 1959, Fracture, The Technological Press of MIT and John Wiley and Sons, Inc. TNew York, 1959.

23. Cruz, Carlos R., "An Optical Method for Determining the Elastic Constants of Concrete," Journal of the Portland Cement Association Research and Development Laboratories, Vol. 4, No. 2, pp. 24-32, May 1962. 
24. Davis, R. E., "A Summary of the Results of Investigation Having to do with Volumetric Changes in Cements, Mortars and Concrete Due to Causes Other Than Stress," Journal of ACI, February 1930, Proceedings, Vol. 26, pp. 407-443, 1930.

25. Durelli, A. J., Morse, S., and Parks, V., "The Theta Specimen for Determining Tensile Strength of Brittle Materials, "Materials Research and Standards, ASTM, Vol. 2, No. 2, pp. 114-117, Bebruary 1962.

26. Ernsberger, F. M., "Current Status of the Griffith Crack Theory of Glass Strength," Progress in Ceramic Science, Vol. 3, The Macllillan Company, 1963, New York, pp. 57-76.

27. Glucklich, Joseph, "On the Compression Failure of Plain Concrete." T. and A. M. Report No. 215, Department of Theoretical and Applied Mechanics, University of Illinois, March 1962.

28. Glucklich, Joseph, Discussion of "Crack Propagation and the Fracture of Concrete," by M. F. Kaplan, Journal ACI, Proc., Vol. 59, No. 6, Part 2, pp. 923, 1962.

29. Glucklich, J. "The Effect of Microcracking on Time-Dependent Deformations and the Long-Term Strength of Concrete," International Conference on the Structure of Concrete, Imperial College, London, September 1965.

30. Glucklich, J., "Fracture of Plain Concrete," Journal of Engineering Mechanics Division, Proc. Am. Soc. Civil Engineers, Vol. 89, No. Ea6, pp. 127-138, 1963.

31. Glucklich, J., "Static and Fatigue Fractures of Portland Cement Mortar in Flexure," private communication.

32. Glucklich, J. and Ishai, O., "Rheological Behavior of Hardened Cement Paste Under Low Stress," Journal of the ACI, Vol. 32, No. 8, pp. 947-964, February 1961.

33. Goyal, S. C., "The Mechanism of Fracture in Concrete," Indian Concrete Journal, 1964, 38(5), 185-91.

34. Griffith, A. A., "The Phenomena of Rupture and Flow in Solids," Phil. Trans. Royal Society of London, Vol. 22l, 1920, pp. 163-198.

35. Griffith, A. A., "The Theory of Rupture," Proceedings of the First International Congress for Applied Mechanics," Delft, 1924, pp. $55-63$.

36. Hansen, Torben C., "Cracking and Fracture of Concrete and Cement Paste," Unpublished Paper, 1967. 
37. Hansen, Torben C., "Theories of Multi-Phase Materials Applied to Concrete, Cement Mortar and Cement Paste," Paper presented at the International Conference on the Structure of Concrete and its Behavior Under Load, September 28-30, 1965.

38. Hansen, Torben C. and Nielsen, Knud E. C., "Influence of Aggregate Properties on Concrete Shrinking," Journal of the ACI, Proceedings, Vol. 62, No. 7, pp. 783-794, July 1965.

39. Hasselman, D. P. H. and Fulrath, R. M., "Proposed Fracture Theory of a Dispersion-Strengthened Glass Matrix," Journal of the American Ceramic Society, Vol. 49, No. 2, pp. 68-72, February 1966.

40. Helmuth, Richard A. and Turk, Danica H., "Elastic Moduli of Hardened Portland Cement and Tricalcium Silicate Pastes: Effect of Porosity", Symposium on Structure of Portland Cement Paste and Concrete, IRB Special Report 90, pp. 135-153, 1966.

41. Hirsch, Teddy J., "Modulus of Elasticity of Concrete Affected by Elastic Moduli of Cement Paste Matrix and Aggregate," Journal of the ACI, Proceedings, Vol. 59, No. 3, pp. 427-451, March 1962.

42. Hsu, Thomas T. C., "Nathematical Analysis of Shrinkage Stresses in a Model of Hardened Concrete," Journal of the ACI, Proceedings, vol. 60, No. 3, pp. 371-390, March 1963.

43. Hsu, Thomas T. C., "Microcracks Between Coarse Aggregate and PasteMortar in Concrete," Ph. D. Thesis, Cornell University, January 1964.

44. Hsu, Thomas T. C., Slate, Floyd O., Sturman, Gerald M. and Winter, Georee, "licrocracking of Plain Concrete and the Shape of the Stress-Strain Curve," Journal ACI, Proc., Vol. 60, No. 2, February 1963, pp. 209-224.

45. Inglis, C. I., "Stresses in a Plate due to the Presence of Cracks and Sharp Corners," Trans. Inst. Naval Architects, London, Vol. LV, pp. 215-230, 1913.

46. Irwin, G. R., "Effects of Size and Shape on Fracture of Solids," properties of Crystalline Solids, ASTM Special Technical Publication No. 283, pp. 118-128, 1960.

47. Irwin, George R., "Fracturing and Fracture Mechanics," T. and A. M. Report No. 202, Department of Theoretical and Applied Mechanics, University of Illinois, October 1961.

48. Jones, R. and Kaplan, M. F., "The Effect of Coarse Aggregate on the Mode of Failure of Concrete in Compression and Flexure," Magazine of Concrete Research, Vol. 9, No. 26, p. 89, August 1957. 
49. Jura, George and Garland, Carl W., "The Experimental Deternination of the Surface Tension of Magnesium Oxide," Journal of the American Chemical Society, Vol. 74, pp. 6033, December 1962.

50. Kaplan, Maurice F., "The Application of Fracture Mechanics to Concrete," Paper presented at the International Conference on the Structure of Concrete and its Behavior Under Load, September 28-30, 1965.

51. Kaplan, M. F., "Crack Propagation and the Fracture of Concrete," Journal of the ACI, Vol. 58, No. 5, pp. 591-610, November 1961.

52. Kingery, W. D., Introduction to Ceramics, John Wiley and Sons, N. Y., 1960.

53. Kirmser, P. G. and Dailey, George, "Stress Analysis of a Universal Concrete Test Specimen," Paper presented at the RILEM International Symposium on the Experimental Research of Field Testing of Concrete, October 5-7, 1964.

54. Knaap, W. van der, "Nonlinear Behavior of Elastic Porous Media," Trans, ADME, 216: 179-187, 1959.

55. Krahl, Nat W., Victory, Sidney P., Jr. Erkmen, Erkin and Sims, James R., "The Behavior of Plain Mortar and Concrete Under Triaxial Stress," Paper presented at the Sixty-Eighth Annual Meeting of the ASTM, June 13-18, 1965.

56. Lott, James and Kesler, Clyde E., "Crack Propagation in Plain Concrete," T.A.M. Report No. 648, University of IIlinois, 1964.

57. Malhotra, H. L., "The Effect of Tenperature on the Compressive Strength," Magazine of Concrete Research, pp. 85-94, August 1956.

58. Malhotra, V. M., Zoldners, N. G. and Woodrooffe, H. M., "Ring Test for Determining the Tensile Strength of Concrete," Paper presented at the Sixty-Eighth Annual Meeting of the ASTM, June 13-18, 1965.

59. McClintock, F. A. and Walsh, J. B., "Friction on Griffith Cracks in Rocks Under Pressure," Proc. Fourth Natl. Congr. Appl. Mech., pp. 1015-1021, 1962.

60. McHenry, Douglas and Karni, Joseph, "Strength of Concrete Under Combined Tensile and Compressive Stress," Journal of the ACI, Vol. 29, No. 10, pp. 829-839, April 1958.

61. Moavenzadeh, F., Kuguel, R. and Keat, L. B., "Fracture of Concrete", Dept. Report No. R68-5, Dept. of Civil Engineering, Massachusetts Institute of Technology, March 15, 1968. 
62. Mitchell, Neal B., Jr., "The Indirect Tension Test for Concrete," Materials Research and Standards, Vol. 1, No. 10, pp. 780-788, October 1961.

63. Moavenzadeh, F., Williamson, R. B. and Wissa, A. E. Z., Rock Fracture Research, MIT Dept. of Civil Engineering, Research Report R 66-56, November 1966.

64. Mullen, W. G., "Creep of Portland Cement Paste," Ph. D. Thesis, Purdue University, June 1963.

65. NaKayama, Junn, "Direct Measurement at Fracture Energies of Brittle Heterogeneous Naterials," Journal of the American Ceramic Society, Vol. 48, No. 11, pp. 583-587, November 1965.

66. Neville, A. M., "Properties of Concrete," John Wiley and Sons, Inc., New York, 1963.

67. Newman, Kenneth, "Criteria for the Behavior of Plain Concrete Under Complex States of Stress," Paper presented at the International Conference on the Structure of Concrete and its Behavior Under Load, September 28-30, 1965.

68. Newman, K. and Lachance, L., "The Testing of Brittle Materials Under Uniform Uniayial Compressive Stress," Proceedings, ASIII, Vol. 64, pp. 1044-1067, 1964.

69. Nurse, K. W., "Adhesion and Cohesion in Solids," Paper presented at the International Conference on the Structure of Concrete and its Behavior Under Load, September 28-30, 1965.

70. Orc.ard, D. F., Concrete Technology, Volume I, John Wiley and Sons, 1962.

71. Orowan, E., "Energy Criteria of Fracture," Welding Research Supplement, March 1955, pp. 157-5-160-3.

72. Orowan, E., "Fracture and Strength of Solids," Phys. Soc. (Iondon), Reports on Procress in Physics, Vol. 12, pp. 185-232, 1949.

73. Orowan, E., Nature, London, Vol. 153, p. 341.

74. Passmore, E. M., Spriggs, R. M. and Vasilos, "Strength-Grain SizePorosity Relations in Alumina," Journal of the American Ceramic Society, Vol. 48, No. 1, pp. 1-7, January 21, 1965.

75. Paulding, B. W., Jr., "Techniques Used in Studying the Fracture Mechanics of Rock," Paper presented at the Fifth Pacific Area National Meeting of the ASTIS, Seattle, Vashington, October 31 to November 5, 1965. 
76. Phillips, C. J., "The Strength and Weakness of Brittle Materials," Am. Scientist, Vol. 53, No. I, pp. 20-51, 1965.

77. Pickett, Gerald, "Effect of Aggregate on Shrinkage of Concrete and Hypothesis Concerning Shrinkage," PCA Bulletin 66, February 1956. Proc. ACI, Vol. 52, pp. 581-590, 1956.

78. Pincus, George and Gesund, Hans, "Bvaluating the Tensile Strength of Concrete," Materials Research and Standards, ASTM, Vol. 5, No. 9, pp. 454-458, September 1965.

79. Powers, T. C., "Causes and Control of Volume Change," Journal of the Research and Development Laboratories, PCA, Vol. 1, No. 1, pp. 29-39, January 1959.

80. Powers, T. C., "Physical Properties of Cement Paste," PCA Bulletin 154,1960 .

81. Powers, T. C., "Some Physical Aspects of the Hydration of Portland Cement," PCA, Bulletin 125, 1961.

82. Powers, T. C., "The Physical Structure and Engineering Properties of Concrete," PCA Bulletin 90, 1958.

83. "Progress in Measuring Fracture Toughness and Using Fracture Mechanics," Fifth Report of a Special ASTM Comittee, Materials Research and Standards, March 1964, pp. 107-119.

84. Robinson, George S., "Methods of Detecting the Formation and Propagation of Microcracks in Concrete," Paper presented at the Inter national Conference and The Structure of Concrete and its Behavior Under Load, September 28-30, 1965.

85. Robinson, L. H., Jr., "The Effect of Pore and Confining Pressure on the Failure Process in Sedimentary Rocks," Third Symposium on Rock Mechanics, Quarterly of the Colorado School of Mines, Vol. 54, No. 3, July 1959, pp. 177-199.

86. Romualdi, James P., "The Static Cracking Stress and Fatigue Strength of Concrete Reinforced with Short Pieces of Thin Steel Wire," Paper presented at the International Conference on the Structure of Concrete and its Behavior Under Load, September 28-30, 1965.

87. Roper, Harold, "Volume Changes of Concrete Affected by Aggregate Types," Journal of the Research and Development Laboratories, PCA, Vol. 2, No. 3, pp. 13-19, September 1960.

88. Roper, Harold, Cox, Joseph E. and Erlin, Bernard, "Petrographic Studies on Concrete Containing Shrinking Aggregate, "Journal of the PCA, Vol. 6, No. 3, pp. 2-18, September, 1964. 
89. Rudnick, A., Hunter, A. R. and Holden, F. C., "An Analysis of the Diametral-Compression Test," Materials Research and Standards, ASTM, Vol. 3, No. 4, pp. 283-289, April 1963.

90. Sack, R. A. "Extension of Griffith's Theory to Three Dimension," Proc. Phys. Soc. (London), 58: 729-736, 1946.

91. Saemann, J. C. and Washa, G. W., "Variation of Mortar and ConcreteProperties with Temperature," ACI Journal, Proceedings, Vol. 54, No. 5, November 1957, pp. 385-395.

92. Savin, G. N., Stress Concentration Around Holes, Translated from Russian, W. Johnson editor, Pergamon Press, 1961.

93. Schiller, K. K., "Porosity and Strength of Brittle Solids (with Particular Reference to Gypsum)", Mechanical Properties of NonMetallic Brittle Materials, W. H. Walton ed., Intersciencem 1958.

94. Scholer, C. F., "An Investigation of the Bond Between Portland Cement Mortar and Coarse Aggregate," $\mathrm{Ph}$. D. Thesis, Purdue University, November 1964.

95. Singh, B. G., "Specific Surface of Aggregates Related to Compressive and Flexural Strength of Concrete," Journal of the ACI, Proc. Vol. 54, No. 10, pp. 897-907, April 1958.

96. Skempton, A. W., "Effective Stress in Soils, Concrete and Rocks," Pore Pressure and Suction in Soils, Butterworth Scientific Publications, London, 1961.

97. Slate, Floyd D. and Olsefski, Stanley, "X-Rays for Study of Internal Structures and Microcracking of Concrete," Journal of the ACI, Proceedings, Vol. 60, No. 5, pp. 575-588, May 1963.

98. "The Slow Growth and Rapid Propagation of Cracks," Second Report of a Special ASTM Committee, Materials Research and Standards, May 1961, pp. 389-393.

99. Steinour, Harold H., "Ther Setting of Portland Cement," PCA Bulletin 98, November 1958.

100. Sturman, Gerald M., Shah, Surendra P. and Winter, George, "Effect of Flexural Strain Gradients on Microcracking and Stress-Strain Behavior of Concrete," Journal of the ACI, Proceedings, Vol. 62, No. 7, pp. 805-822, July 1965.

101. Taylor, H. F. W., "The Chemistry of Cement Hydration," in Progress in Ceramic Science, edited by J. E. Burke, Pergamon Press, 1961.

102. Tetelman, A. S. and McEvily, A. J., Jr., Fracture of Structural Materials, John Wiley and Sons, N. Y., 1967. 
103. Timoshenko, S. and Goodier, J. N., Theory of Elasticity, Second Edition, McGraw-lilll Book Co., Inc., New York, N. Y. (1951).

104. Walsh, J. B., "The Effect of Cracks on the Compressibility of Rocks," J. Geophys. Res., Vol. 70, pp. 381-389, 1965.

105. Walsh, J. B., "The Effect of Cracks on the Uniaxial Elastic Compression of Rocks," J.Geophys. Res., Vol. 69, pp. 3449-3456, 1964.

106. Walsh, J. B. and Brace, W. F., "A Fracture Criterion for Brittle Anisotropic Rock," J. Geophys. Res., Vol. 69, pp. 3449-3456, 1964.

107. Washburn, Jack, "Mechanism of Fracture," Mechanical Behavior of Materials at Elevated Temperatures, edited by John E. Dorn, McGraw-Hill Book Company, Inc., 1961, New York.

108. Wells, A. A. and Post, D., "The Dynamic Stress Distribution Surrounding a Running Crack - a Photoelastic Analysis," Proc. of the Soc. for Experimental Stress Analysis, Vol. XVI, No. 1, 1958, pp. 69-92.

109. Welsh, G. B., "Tensile Splitting Test on Concrete Cubes and Beams", Civil Engineering and Public Works Review (8 Buckingham St., London, W. C. 2), Vol. 60, No. 709, pp. 1161-1167, August, 1965.

110. Weymouth, C. A. G., "Effect of Particle Interference in Mortars and Concrete," Rock Products, Vol. 36, No. 2, pp. 26-30, 1933.

111. Wright, R. N., Hall, W. J., Terry, S. W., Nordell, W. J., and Erhard, G. R., "Studies of Some Brittle Fracture Concepts," SSC-170, Final Report of Project SR-163 Fracture Concepts, The Ship Structure Committee, U. S. Coast Guard, September 1965.

112. Wu, T. H., "Soil Mechanics," Allyn and Bacon, Inc. 1966.

113. Mullen, W. G. and Dolch, W. L., "Creep of Portland Cement Paste," Proceedings, ASTM, Vol. 64, pp. 1146-1170, 1964.

114. Richards, C. W. and Radjy, F., "A New Application of Internal Friction to Concrete Research," Materials Research and Standards, ASTM, Vol. 6, No. 8, pp. 386-392, August 1966. 
APPENDIX A 
APPENDIX A

Table 14

CONPRESSION TEST RESULTS

\begin{tabular}{|c|c|c|c|c|c|}
\hline $\begin{array}{l}\text { Specimen } \\
\text { Number }\end{array}$ & $\mathrm{W} / \mathrm{C}$ & $\begin{array}{l}\text { Age, } \\
\text { days }\end{array}$ & $\begin{array}{l}\text { Failure } \\
\text { Stress, }\end{array}$ & psi & Remarks \\
\hline $2-4$ & 0.4 & 28 & 15,000 & & \\
\hline $2-5$ & 0.4 & 28 & & & Test no good - specimen off center \\
\hline $2-6$ & 0.4 & 28 & 6,710 & & " " " " " \\
\hline $3-2$ & 0.4 & 51 & 16,700 & & \\
\hline $6-4$ & 0.4 & 42 & 8,450 & & Ends generally not plane \\
\hline $6-5$ & 0.4 & 42 & 12,580 & & " " " " " \\
\hline $6-6$ & 0.4 & 42 & 9,770 & & $"$ \\
\hline $8-4$ & 0.5 & 37 & 12,400 & & \\
\hline $8-5$ & 0.5 & 37 & 10,800 & & \\
\hline $8-6$ & 0.5 & 37 & 10,650 & & \\
\hline $16-4$ & 0.4 & 32 & 15,600 & & \\
\hline $16-5$ & 0.4 & 32 & 14,400 & & \\
\hline $16-6$ & 0.4 & 32 & 15,400 & & \\
\hline $17-4$ & 0.4 & 32 & 15,200 & & \\
\hline-5 & 0.4 & 32 & 15,050 & & \\
\hline-6 & 0.4 & 32 & 15,750 & & \\
\hline $18-4$ & 0.4 & 31 & 15,050 & & \\
\hline-5 & 0.4 & 31 & 15,350 & & \\
\hline-6 & 0.4 & 31 & 15,000 & & \\
\hline $30-6$ & 0.4 & 28 & 13,700 & & Vacuum Mix \\
\hline $31-5$ & 0.4 & 28 & 14,740 & & \\
\hline-6 & 0.4 & 28 & 12,040 & & \\
\hline $32-4$ & 0.4 & 37 & 12,940 & & Vacuum Mix \\
\hline-5 & 0.4 & 37 & 13,660 & & \\
\hline-6 & 0.4 & 37 & 10,870 & & $"$ \\
\hline $33-4$ & 0.4 & 37 & 10,950 & & \\
\hline-5 & 0.4 & 37 & 13,620 & & \\
\hline-6 & 0.4 & 37 & 15,850 & & \\
\hline $34-4$ & 0.4 & 36 & 13,110 & & Vacuum Mix \\
\hline-5 & 0.4 & 36 & 13,880 & & $"$ \\
\hline-6 & 0.4 & 36 & 13,750 & & $"$ \\
\hline $35-4$ & 0.4 & 36 & 16,260 & & \\
\hline-5 & 0.4 & 36 & 14,990 & & \\
\hline-6 & 0.4 & 36 & 15,500 & & \\
\hline $40-4$ & 0.5 & 28 & 9,320 & & Vacuum Mix on all following specimens \\
\hline-5 & 0.5 & 28 & 9,740 & & \\
\hline-6 & 0.5 & 28 & 9,520 & & \\
\hline
\end{tabular}


Table 14, continued

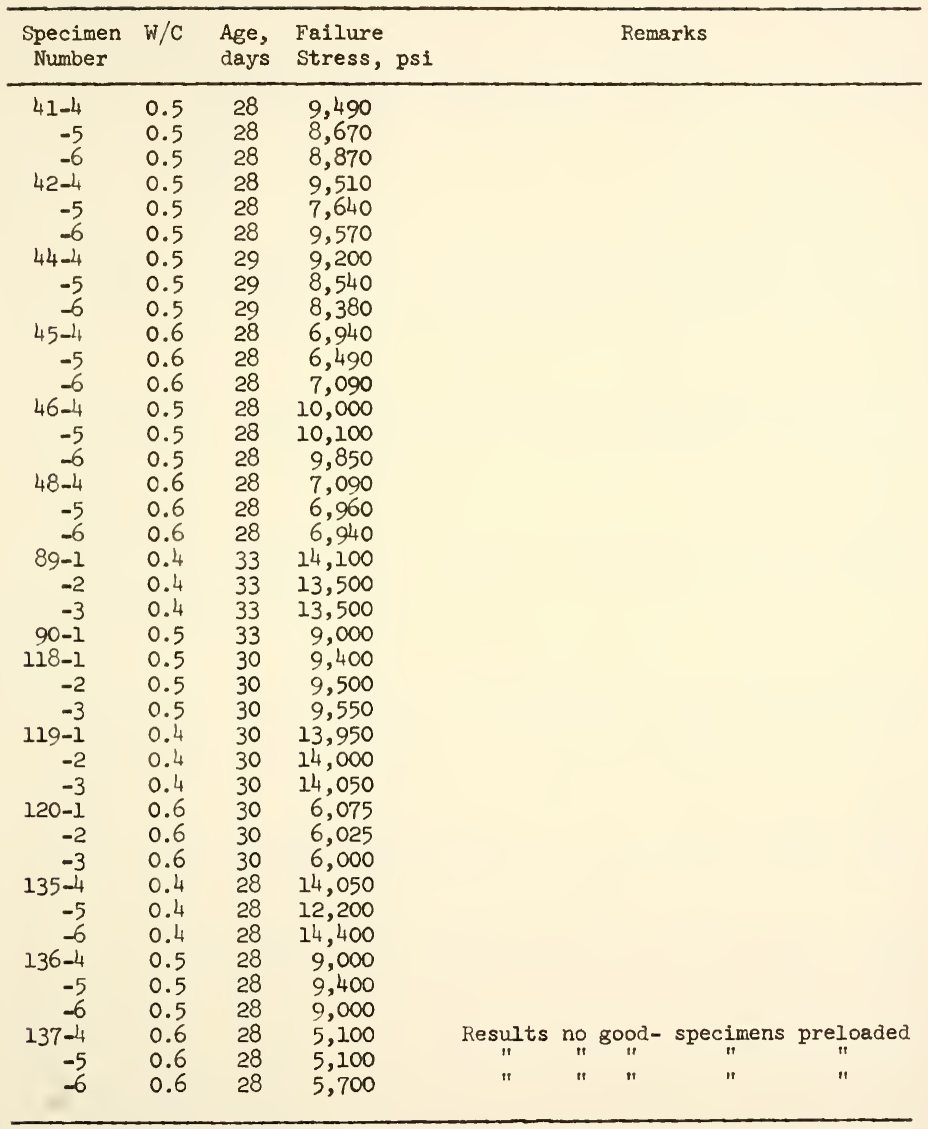




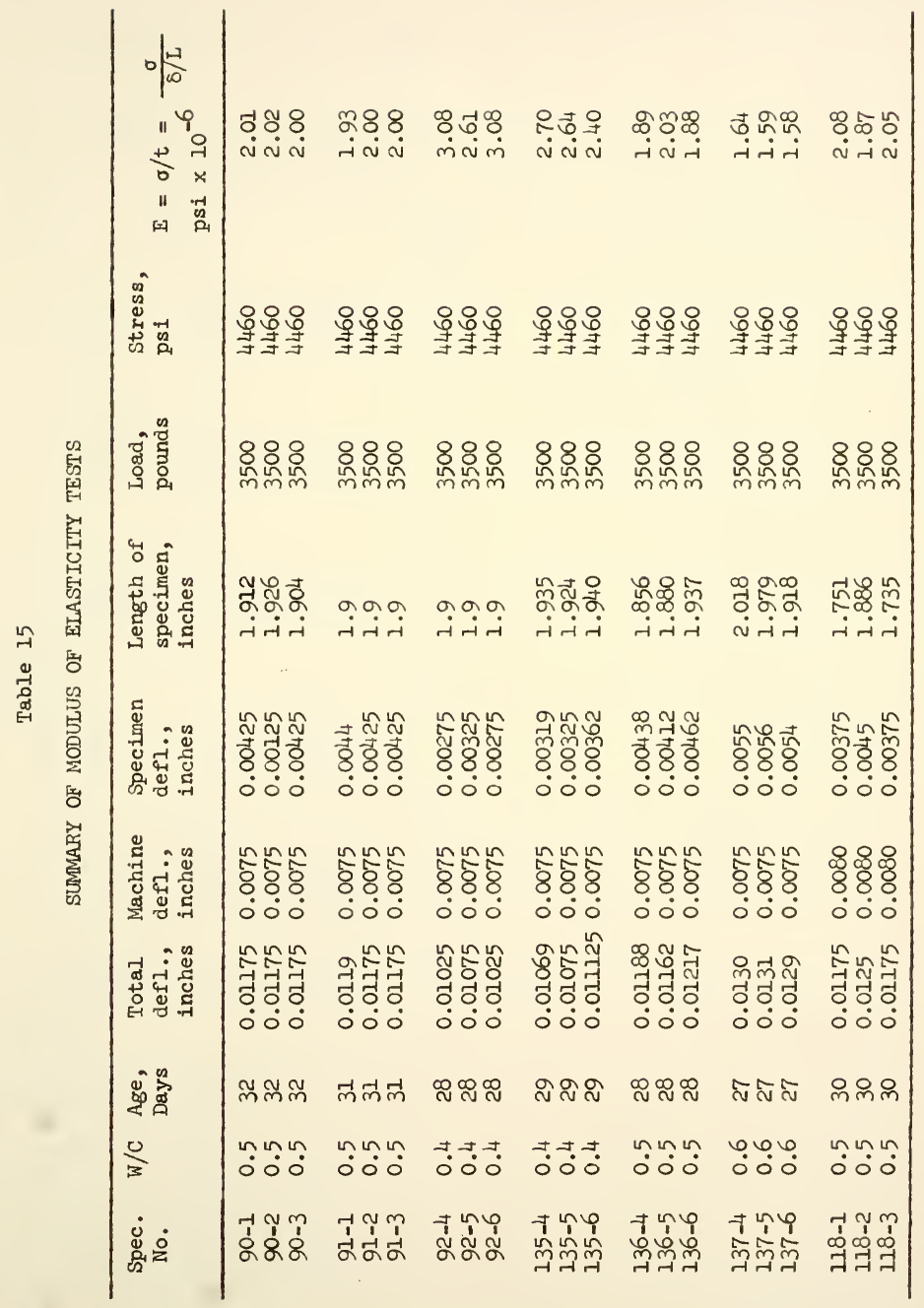




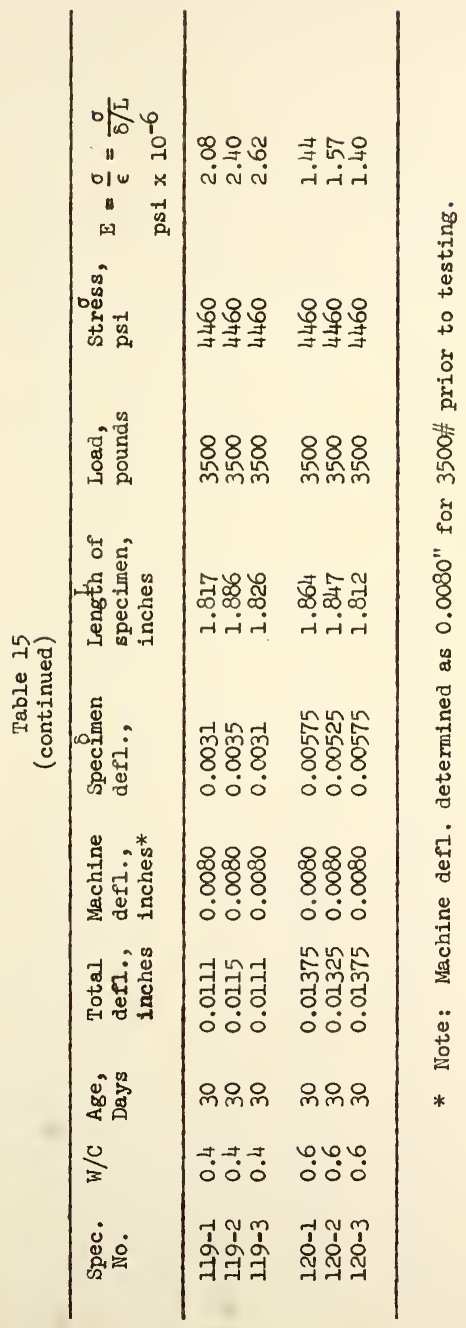


Table 16

SUMMARY OF TESTS ON THETA SPECIMENS

\begin{tabular}{|c|c|c|c|c|c|}
\hline $\begin{array}{l}\text { Speci- } \\
\text { men } \\
\text { Number }\end{array}$ & $w / C$ & $\begin{array}{l}\text { Age, } \\
\text { days }\end{array}$ & $\begin{array}{l}\text { Thick- } \\
\text { ness, } \\
\text { mm }\end{array}$ & $\begin{array}{l}\text { Failure } \\
\text { Stress, } \\
\text { psi }\end{array}$ & Remarks \\
\hline $1-1$ & 0.4 & -- & --- & ---- & Broke on removal \\
\hline $2-1$ & 0.4 & 30 & 9.48 & 1450 & \\
\hline $3-1$ & 0.4 & 29 & 8.26 & 1630 & \\
\hline $4-1$ & 0.4 & 28 & 8.00 & 2260 & \\
\hline $5-1$ & 0.4 & 23 & 9.30 & 605 & \\
\hline $6-1$ & 0.4 & 63 & 9.31 & 1880 & \\
\hline $7-1$ & 0.5 & 44 & 8.28 & 1700 & \\
\hline $8-1$ & 0.5 & 36 & 8.60 & 1450 & \\
\hline $9-1$ & 0.25 & -- & --- & --- & Impossible to $\mathrm{mix}$ \\
\hline $10-1$ & 0.3 & 35 & 9.21 & 1610 & \\
\hline-2 & 0.3 & 35 & 9.98 & 1620 & \\
\hline-3 & 0.3 & 35 & 9.99 & 1690 & \\
\hline $11-1$ & 0.3 & 34 & 10.02 & 935 & \\
\hline-2 & 0.3 & 34 & 10.00 & 1640 & \\
\hline-3 & 0.3 & 34 & 10.00 & 1580 & \\
\hline $12-1$ & 0.3 & 32 & 9.27 & 1920 & \\
\hline-2 & 0.3 & 32 & 9.96 & 1310 & \\
\hline-3 & 0.3 & 32 & 9.96 & 1880 & \\
\hline $13-1$ & 0.4 & 31 & 9.85 & 1630 & \\
\hline-2 & 0.4 & 31 & 9.88 & 1450 & \\
\hline-3 & 0.4 & 31 & 9.86 & 1400 & \\
\hline $14-1$ & 0.4 & 30 & 9.13 & 1650 & \\
\hline-2 & 0.4 & 30 & 9.89 & 1030 & \\
\hline-3 & 0.4 & 30 & 9.87 & 1450 & \\
\hline $15-1$ & 0.4 & 30 & 9.86 & 1370 & \\
\hline-2 & 0.4 & 30 & 9.92 & 1120 & \\
\hline-3 & 0.4 & 30 & 9.93 & 790 & \\
\hline $16-1$ & 0.4 & 30 & 9.15 & 1570 & \\
\hline-2 & 0.4 & 30 & 9.89 & 710 & \\
\hline-3 & 0.4 & 30 & 9.86 & 1410 & \\
\hline $17-1$ & 0.4 & 30 & 9.90 & 1390 & \\
\hline-2 & 0.4 & 30 & 9.96 & 1340 & \\
\hline-3 & 0.4 & 30 & 6.88 & 1910 & \\
\hline $18-1$ & 0.4 & 29 & 9.19 & 1990 & \\
\hline-2 & 0.4 & 29 & 9.88 & 1470 & \\
\hline-3 & 0.4 & 29 & 9.91 & 1270 & \\
\hline $19-1$ & 0.4 & 28 & 8.79 & 1200 & Figh early cement \\
\hline-2 & 0.4 & 28 & 9.45 & 1340 & 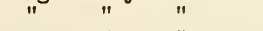 \\
\hline-3 & 0.4 & 28 & 8.36 & 1330 & $"$ \\
\hline
\end{tabular}


Table 16, continued

\begin{tabular}{|c|c|c|c|c|c|}
\hline $\begin{array}{l}\text { Speci- } \\
\text { men } \\
\text { Number }\end{array}$ & $\mathrm{W} / \mathrm{C}$ & $\begin{array}{l}\text { Age, } \\
\text { days }\end{array}$ & $\begin{array}{l}\text { Thick- } \\
\text { ness, } \\
\text { mm }\end{array}$ & $\begin{array}{l}\text { Failure } \\
\text { Stress, } \\
\text { psi }\end{array}$ & Remarks \\
\hline $20-1$ & 0.5 & 28 & 9.92 & 620 & High early cement \\
\hline-2 & 0.5 & 28 & 9.96 & 785 & " $"$ " \\
\hline-3 & 0.5 & 28 & 9.90 & 650 & " $\quad$ " \\
\hline $22 A-1$ & 0.5 & 14 & 9.95 & 940 & Vac. mix - High early cement \\
\hline-2 & 0.5 & 14 & 10.02 & 1320 & " " " " " \\
\hline-3 & 0.5 & 14 & 9.89 & 1005 & $" \quad "$ \\
\hline $22-1$ & 0.5 & 14 & 9.89 & 745 & $" \quad " \quad " n$ \\
\hline-2 & 0.5 & 14 & 9.94 & 495 & " " " " \\
\hline-3 & 0.5 & 14 & 9.93 & 585 & $" \quad " \quad " \quad$ \\
\hline $23-1$ & 0.5 & 29 & $-\infty$ & $--\infty$ & bad test - twisted under load \\
\hline-2 & 0.5 & 29 & 9.90 & 875 & Vac. mix - High early cement \\
\hline-3 & 0.5 & 29 & 9.81 & & " " " " \\
\hline $24-1$ & 0.5 & 28 & --- & --- & Outer ring broken first \\
\hline-2 & 0.5 & 28 & 10.04 & 580 & Vac. Mix - High early cement \\
\hline-3 & 0.5 & 28 & --- & -- & Broken demolding \\
\hline $25-1$ & 0.5 & 28 & 9.31 & 850 & Vac. mix - High early cement \\
\hline-2 & 0.5 & 28 & 10.00 & 445 & " " " " " \\
\hline-3 & 0.5 & 28 & 10.02 & 920 & " $" n$ \\
\hline $26-$ & 0.4 & - & --- & -- & Vac. mix with HE did not work \\
\hline $27-1$ & 0.6 & 42 & 7.35 & 1050 & " " " " " \\
\hline-2 & 0.6 & 42 & --- & -- & Bad test outer ring broke \\
\hline-3 & 0.6 & 42 & 6.83 & 990 & Vac. mix - High early cement \\
\hline $28-1$ & 0.6 & 41 & 7.80 & 1050 & " " " " " \\
\hline-2 & 0.6 & 41 & 7.46 & 1020 & $" \quad "$ \\
\hline-3 & 0.6 & 41 & 7.24 & 840 & $" \quad "$ \\
\hline $29-1$ & 0.4 & 29 & 9.29 & 920 & Vac. Mix - Notched \\
\hline-2 & 0.4 & 29 & 10.00 & 1170 & " \\
\hline-3 & 0.4 & 29 & 9.98 & 1630 & $" \quad "$ \\
\hline $30-1$ & 0.4 & 28 & 8.69 & 1560 & $"$ \\
\hline-2 & 0.4 & 28 & 6.05 & 1700 & $"$ \\
\hline-3 & 0.4 & 28 & 5.50 & 2040 & $"$ \\
\hline $31-1$ & 0.4 & 28 & 8.30 & 800 & No. Vac. \\
\hline-2 & 0.4 & 28 & 7.42 & 1465 & $" \quad "$ \\
\hline-3 & 0.4 & 28 & 3.82 & 1620 & $"$ \\
\hline $32-1$ & 0.4 & 36 & 7.54 & 1970 & Vac. Mix \\
\hline-2 & 0.4 & 36 & 7.19 & 1660 & " \\
\hline-3 & 0.4 & 36 & 7.82 & 2045 & 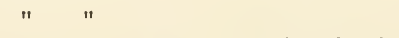 \\
\hline $33-1$ & 0.4 & 36 & 8.55 & 1860 & No. Vac. - broke outside of web \\
\hline-2 & 0.4 & 36 & 9.04 & 1385 & " " \\
\hline-3 & 0.4 & 36 & 8.86 & 1700 & $" \quad "$ \\
\hline $34-1$ & 0.4 & 35 & 7.53 & 2000 & Vac. Mix \\
\hline-2 & 0.4 & 35 & 8.08 & 1865 & \\
\hline-3 & 0.4 & 35 & 9.01 & 1960 & $"$ \\
\hline $35-1$ & 0.4 & 35 & $7 \cdot 35$ & 1925 & No. Vac. \\
\hline-2 & 0.4 & 35 & 8.06 & 1855 & $"$ " \\
\hline-3 & 0.4 & 35 & 8.41 & 1655 & $"$ \\
\hline
\end{tabular}


Table 16, continued

\begin{tabular}{|c|c|c|c|c|c|}
\hline $\begin{array}{l}\text { Speci- } \\
\text { men } \\
\text { Number }\end{array}$ & $\mathrm{W} / \mathrm{C}$ & $\begin{array}{l}\text { Age, } \\
\text { days }\end{array}$ & $\begin{array}{l}\text { Thick- } \\
\text { ness, } \\
\text { mm }\end{array}$ & $\begin{array}{l}\text { Failure } \\
\text { Stress, } \\
\text { psi }\end{array}$ & Remarks \\
\hline $36-1$ & 0.5 & 63 & -- & $-\cdots$ & Broken demolding \\
\hline-2 & 0.5 & 63 & 8.04 & 1410 & Vac. mix on all following \\
\hline-3 & 0.5 & 63 & 7.40 & 1250 & \\
\hline $37-1$ & 0.5 & 62 & 6.22 & 1450 & \\
\hline-2 & 0.5 & 62 & 6.87 & 1530 & \\
\hline-3 & 0.5 & 62 & 4.78 & 1220 & \\
\hline $38-1$ & 0.5 & 62 & 7.46 & 1565 & \\
\hline-2 & 0.5 & 62 & 7.63 & 1380 & \\
\hline-3 & 0.5 & 62 & 7.50 & 1495 & \\
\hline $39-1$ & 0.5 & 28 & -- & - & Broken demolding \\
\hline-2 & 0.5 & 28 & 8.29 & 1200 & \\
\hline-3 & 0.5 & 28 & 8.34 & 1080 & \\
\hline $40-1$ & 0.5 & 28 & 9.11 & 705 & \\
\hline-2 & 0.5 & 28 & 9.29 & 1070 & \\
\hline-3 & 0.5 & 28 & 7.80 & 1230 & \\
\hline $41-1$ & 0.5 & 28 & 7.44 & 1790 & \\
\hline-2 & 0.5 & 28 & 8.31 & 1350 & Fell and chipped \\
\hline-3 & 0.5 & 28 & 7.63 & 1270 & \\
\hline $42-1$ & 0.5 & 28 & 9.31 & 1040 & \\
\hline-2 & 0.5 & 28 & $-\ldots$ & $\ldots$ & Broken demolding \\
\hline-3 & 0.5 & 28 & $9 \cdot 30$ & 1090 & \\
\hline $43-1$ & -0.5 & 29 & 8.32 & 1825 & Bearing card used \\
\hline-2 & 0.5 & 29 & 8.16 & 1145 & " " " \\
\hline-3 & 0.5 & 29 & 8.84 & 1610 & \\
\hline $44-1$ & 0.5 & 29 & 8.32 & 1195 & \\
\hline-2 & 0.5 & 29 & 6.05 & 1755 & \\
\hline-3 & 0.5 & 29 & 8.14 & 1535 & \\
\hline $45-1$ & 0.6 & 28 & 8.34 & 925 & \\
\hline-2 & 0.6 & 28 & 7.57 & 1340 & \\
\hline-3 & 0.6 & 28 & 8.26 & 1400 & \\
\hline $46-1$ & 0.5 & 28 & 8.01 & 1270 & \\
\hline-2 & 0.5 & 28 & 7.88 & 1480 & \\
\hline-3 & 0.5 & 28 & $7 \cdot 50$ & 1560 & \\
\hline $47-1$ & 0.6 & 28 & 6.87 & 1275 & \\
\hline-2 & 0.6 & 28 & 7.41 & 1180 & \\
\hline-3 & 0.6 & 28 & 6.80 & 1255 & \\
\hline $48-1$ & 0.6 & 28 & 8.31 & 730 & \\
\hline-2 & 0.6 & 28 & 9.11 & 1065 & \\
\hline-3 & 0.6 & 28 & 7.28 & 1235 & \\
\hline $49-1$ & 0.5 & 29 & 7.96 & 1220 & \\
\hline-2 & 0.5 & 29 & 7.73 & 1360 & \\
\hline-3 & 0.5 & 29 & 9.05 & 1020 & \\
\hline $50-1$ & 0.4 & 28 & 6.99 & 2090 & \\
\hline-2 & 0.4 & 28 & 7.55 & 1810 & \\
\hline-3 & 0.4 & 28 & 9.08 & $\ldots$ & Outer ring broke during test \\
\hline
\end{tabular}


Table 16, continued

\begin{tabular}{|c|c|c|c|c|c|}
\hline $\begin{array}{l}\text { Speci- } \\
\text { men } \\
\text { Number }\end{array}$ & $\mathrm{w} / \mathrm{C}$ & $\begin{array}{l}\text { Age, } \\
\text { days }\end{array}$ & $\begin{array}{l}\text { Thick- } \\
\text { ness, } \\
\text { mm }\end{array}$ & $\begin{array}{l}\text { Failure } \\
\text { Stress, } \\
\text { psi }\end{array}$ & Remarks \\
\hline $51-1$ & 0.5 & 28 & 6.26 & 1810 & \\
\hline-2 & 0.5 & 28 & 6.97 & 1390 & \\
\hline-3 & 0.5 & 28 & 7.71 & 1760 & \\
\hline $52-1$ & 0.4 & 34 & 6.73 & 2170 & \\
\hline-2 & 0.4 & 34 & 8.39 & 1255 & \\
\hline-3 & 0.4 & 34 & 8.63 & 1410 & \\
\hline $53-1$ & 0.6 & 28 & 6.21 & 940 & \\
\hline-2 & 0.6 & 28 & 6.03 & 1260 & \\
\hline-3 & 0.6 & 28 & 5.67 & 1135 & \\
\hline $54-1$ & 0.5 & 28 & 7.23 & 1695 & \\
\hline-2 & 0.5 & -- & -- & -- & Broken when polishing \\
\hline-3 & 0.5 & 28 & 8.05 & 1670 & \\
\hline
\end{tabular}


Table 17

SUMMARY OF MICROSCOPIC STUDY OF THETA SPECIMENS

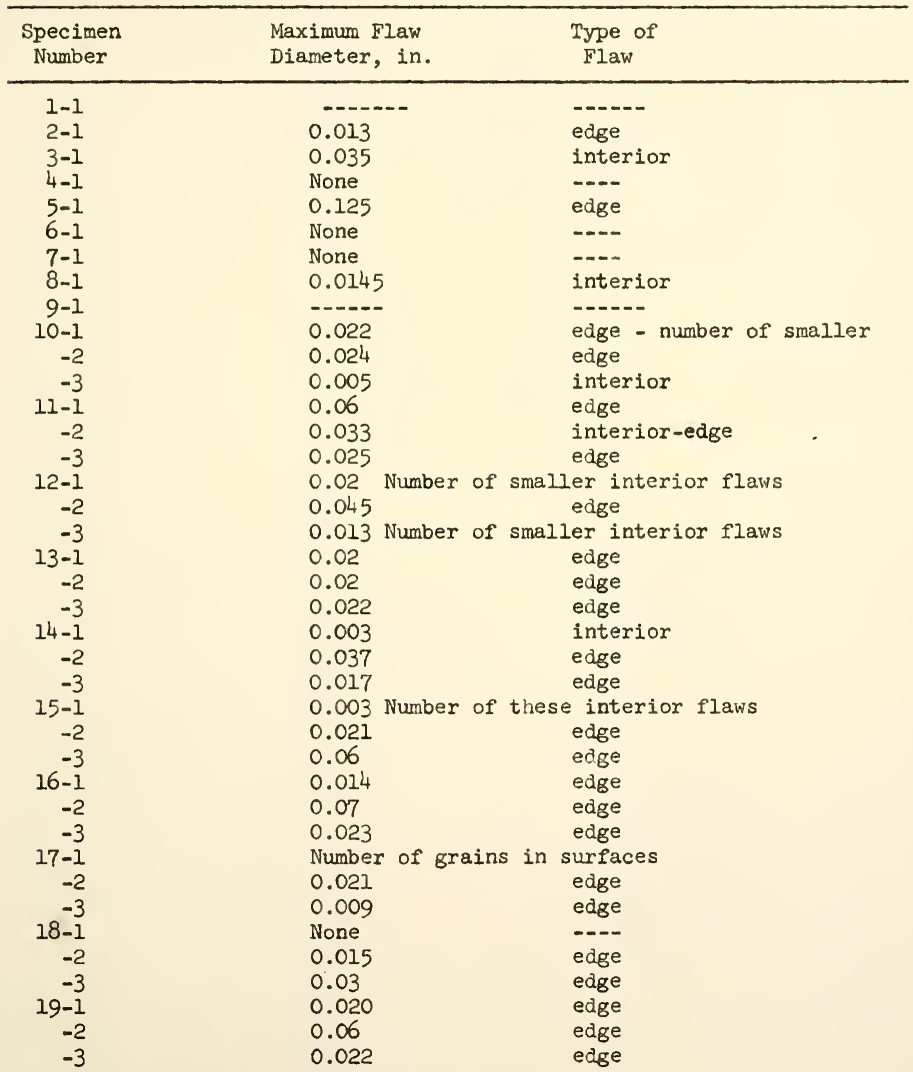


Table 17, continued

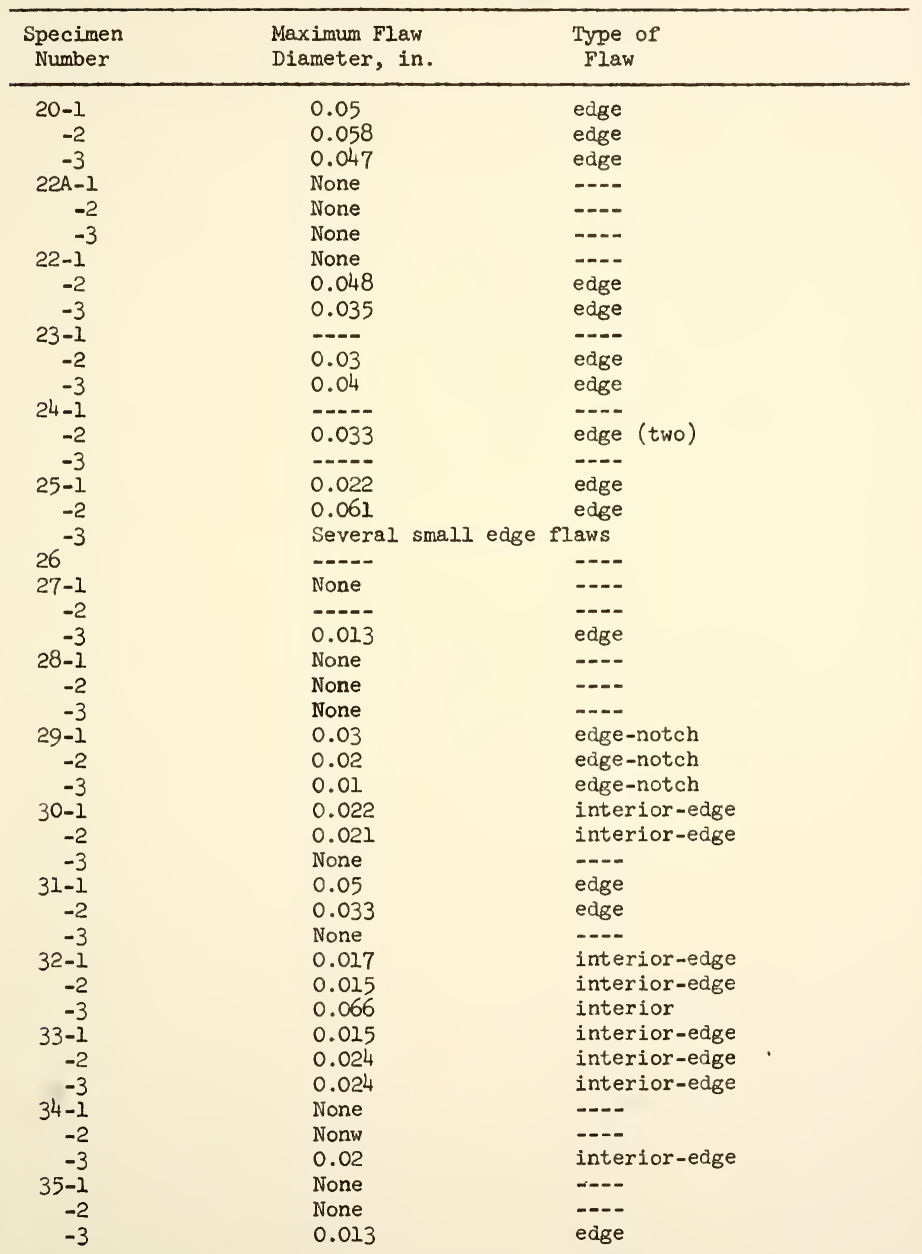


Table 17, continued

\begin{tabular}{|c|c|c|}
\hline $\begin{array}{l}\text { Specimen } \\
\text { Number }\end{array}$ & $\begin{array}{l}\text { Maximum Flaw } \\
\text { Diameter, in. }\end{array}$ & $\begin{array}{l}\text { Type of } \\
\text { Flaw }\end{array}$ \\
\hline $36-1$ & - - & --- \\
\hline-2 & 0.01 & edge \\
\hline-3 & 0.03 & edge \\
\hline $37-1$ & None & $\ldots$ \\
\hline-2 & None & $\cdots$ \\
\hline-3 & 0.015 & interior-edge \\
\hline $38-1$ & None & $--2-$ \\
\hline-2 & None & --- \\
\hline-3 & None & $\ldots$ \\
\hline $39-1$ & ---- & $-\cdots$ \\
\hline-2 & None & --- \\
\hline-3 & None & \\
\hline $40-1$ & None & Break not typical \\
\hline-2 & None & Break not typical \\
\hline-3 & None & --- \\
\hline $41-1$ & None & --- \\
\hline-2 & 0.01 & edge \\
\hline-3 & 0.01 & edge \\
\hline $42-1$ & None & $\ldots-$ \\
\hline-2 & -... & $\ldots$ \\
\hline-3 & 0.02 & edge \\
\hline $43-1$ & None & --- \\
\hline-2 & 0.025 & interior-edge \\
\hline-3 & None & Break not typical \\
\hline $44-1$ & 0.02 & edge \\
\hline-2 & None & $\ldots$ \\
\hline-3 & None & $\ldots$ \\
\hline $45-1$ & 0.01 & edge \\
\hline-2 & None & --- \\
\hline-3 & None & $-\ldots$ \\
\hline $46-1$ & 0.035 & edge \\
\hline-2 & 0.015 & interior \\
\hline-3 & None & $-\ldots$ \\
\hline $47-1$ & None & $\ldots$ \\
\hline-2 & None & --- \\
\hline-3 & None & --- \\
\hline $48-1$ & None & Break not typical \\
\hline-2 & 0.01 & edge \\
\hline-3 & None & $-\infty$ \\
\hline $49-1$ & None & $\ldots-$ \\
\hline-2 & 0.015 & edge-interior \\
\hline-3 & 0.025 & edge \\
\hline $50-1$ & 0.015 & interior \\
\hline-2 & None & $-\cdots$ \\
\hline-3 & - & --- \\
\hline $51-1$ & None & --- \\
\hline-2 & 0.02 & interior \\
\hline
\end{tabular}


Table 17, continued

\begin{tabular}{rll}
\hline $\begin{array}{c}\text { Specimen } \\
\text { Number }\end{array}$ & $\begin{array}{c}\text { Maximum Flaw } \\
\text { Diameter, in. }\end{array}$ & $\begin{array}{c}\text { Type of } \\
\text { Flaw }\end{array}$ \\
\hline $51-3$ & None & $\cdots$ \\
$52-1$ & None &..- \\
-2 & 0.015 & edge (two) \\
-3 & 0.018 & interior-edge \\
$53-1$ & 0.025 & edge \\
-2 & None & $-\cdots$ \\
-3 & None & $-\cdots$ \\
$54-1$ & None & --- \\
-2 & ---- & edge \\
-3 & 0.03 & \\
\hline
\end{tabular}


Table 18

SUMMARY OF DIAMETRAL-COMPRESSION TESTS

\begin{tabular}{|c|c|c|c|c|c|c|}
\hline $\begin{array}{l}\text { Speci- } \\
\text { men } \\
\text { Number }\end{array}$ & W/c & $\begin{array}{l}\text { Age, } \\
\text { days }\end{array}$ & $\begin{array}{l}\text { Diam., } \\
\text { in. }\end{array}$ & $\begin{array}{l}\text { Length, } \\
\text { in. }\end{array}$ & $\begin{array}{c}\text { Failure } \\
\text { Stress, } \\
\text { psi }\end{array}$ & Remarks \\
\hline $1-1$ & 0.4 & 92 & 1.0 & 2.06 & 650 & \\
\hline-2 & 0.4 & 92 & 1.0 & 2.07 & 890 & \\
\hline-3 & 0.4 & 92 & 1.0 & 2.12 & 740 & \\
\hline $2-1$ & 0.4 & 28 & 1.0 & 1.985 & 1190 & \\
\hline-2 & 0.4 & 28 & 1.0 & 1.955 & 990 & \\
\hline-3 & 0.4 & 28 & 1.0 & 1.955 & 990 & \\
\hline $3-1$ & 0.4 & 51 & 1.0 & 1.89 & 1275 & \\
\hline$-3 \mathrm{~A}$ & 0.4 & 51 & 1.0 & 0.24 & 1800 & \\
\hline$-3 B$ & 0.4 & 51 & 1.0 & 0.185 & 2280 & Chipped and removed \\
\hline$-3 \mathrm{C}$ & 0.4 & 51 & 1.0 & 0.31 & 1330 & Tilted under load \\
\hline-4 & 0.4 & 51 & 1.0 & 1.91 & 1100 & Load held for $3 \mathrm{~min}$. \\
\hline-5 & 0.4 & 51 & 1.0 & 1.91 & 1210 & \\
\hline-6 & 0.4 & 51 & 1.0 & 1.95 & 965 & \\
\hline $4-2$ & 0.4 & 48 & 1.0 & 1.89 & 1060 & \\
\hline-3 & 0.4 & 48 & 1.0 & 1.90 & 1340 & \\
\hline$-4 A$ & 0.4 & 48 & 1.0 & 0.832 & 1440 & \\
\hline$-4 B$ & 0.4 & 48 & 1.0 & 0.972 & 1100 & \\
\hline$-5 \mathrm{~A}$ & 0.4 & 48 & 1.0 & 0.832 & 1370 & \\
\hline$-5 B$ & 0.4 & 48 & 1.0 & 0.995 & 1190 & \\
\hline-6 & 0.4 & 48 & 1.0 & 1.92 & 1090 & \\
\hline $5-1 \mathrm{~A}$ & 0.4 & 43 & 1.0 & 0.431 & 1650 & \\
\hline$-1 B$ & 0.4 & 43 & 1.0 & 0.394 & 2120 & \\
\hline$-1 C$ & 0.4 & 43 & 1.0 & 0.965 & 1450 & \\
\hline-2 & 0.4 & 43 & 2.0 & 1.95 & 1210 & \\
\hline-3 & 0.4 & 43 & 1.0 & 1.88 & 860 & \\
\hline-4 & 0.4 & 43 & 1.0 & 1.87 & 1220 & \\
\hline-5 & 0.4 & 43 & 1.0 & 1.85 & 1220 & \\
\hline$-6 A$ & 0.4 & 43 & 1.0 & 0.338 & 1820 & \\
\hline$-6 B$ & 0.4 & 43 & 1.0 & 0.362 & 2010 & \\
\hline$-6 c$ & 0.4 & 43 & 1.0 & 0.362 & 1920 & \\
\hline$-6 D$ & 0.4 & 43 & 2.0 & 0.610 & 1490 & \\
\hline $6-1$ & 0.4 & 42 & 1.0 & 1.92 & 1250 & \\
\hline-2 & 0.4 & 42 & 1.0 & 1.85 & 1240 & \\
\hline-3 & 0.4 & 42 & 1.0 & 1.85 & 970 & \\
\hline $7-1$ & 0.5 & 44 & 1.0 & 1.883 & 560 & \\
\hline $7-2$ & 0.5 & 44 & 1.0 & 1.870 & 770 & \\
\hline $8-1$ & 0.5 & 37 & 1.0 & 1.807 & 565 & \\
\hline-2 & 0.5 & 37 & 1.0 & 1.813 & 580 & \\
\hline-3 & 0.5 & 37 & 1.0 & 1.972 & 610 & \\
\hline
\end{tabular}


Table 18, continued

\begin{tabular}{|c|c|c|c|c|c|c|c|c|c|c|}
\hline $\begin{array}{l}\text { Speci- } \\
\text { men } \\
\text { Number }\end{array}$ & $\mathrm{W} / \mathrm{C}$ & $\begin{array}{l}\text { Age, } \\
\text { days }\end{array}$ & $\begin{array}{c}\text { Diam., } \\
\text { in. }\end{array}$ & $\begin{array}{l}\text { Length, } \\
\text { in. }\end{array}$ & $\begin{array}{c}\text { Failure } \\
\text { Stress, } \\
\text { psi }\end{array}$ & & Rems & arks & & \\
\hline $10-1$ & 0.3 & 37 & 1.0 & 1.930 & 1100 & & & & & \\
\hline-2 & 0.3 & 37 & 1.0 & 1.949 & 1140 & & & & & \\
\hline-3 & 0.3 & 37 & 1.0 & 1.974 & 1030 & & & & & \\
\hline $11-1$ & 0.3 & 36 & 1.0 & 1.933 & 610 & & & & & \\
\hline-2 & 0.3 & 36 & 1.0 & 1.968 & 840 & & & & & \\
\hline-3 & 0.3 & 36 & 1.0 & 1.945 & 1110 & & & & & \\
\hline $12-1$ & 0.3 & 33 & 1.0 & 1.906 & 970 & & & & & \\
\hline-2 & 0.3 & 33 & 1.0 & 1.879 & 1050 & & & & & \\
\hline-3 & 0.3 & 33 & 1.0 & 1.912 & 680 & & & & & \\
\hline $13-1$ & 0.4 & 33 & 1.00 & 1.899 & 1070 & & & & & \\
\hline-2 & 0.4 & 33 & 1.00 & 1.922 & 800 & & & & & \\
\hline$-\overline{3}$ & 0.4 & 33 & 1.00 & 1.897 & 770 & & & & & \\
\hline $14-1$ & 0.4 & 32 & 1.00 & 1.869 & 870 & & & & & \\
\hline-2 & 0.4 & 32 & 1.00 & 1.877 & 680 & & & & & \\
\hline-3 & 0.4 & 32 & 1.00 & 1.853 & 1140 & & & & & \\
\hline $15-1$ & 0.4 & 31 & 1.00 & 1.896 & 960 & & & & & \\
\hline-2 & 0.4 & 31 & 1.00 & 1.912 & 830 & & & & & \\
\hline-3 & 0.4 & 31 & 1.00 & 1.923 & 830 & & & & & \\
\hline $16-1$ & 0.4 & 32 & 1.00 & 1.855 & 790 & & & & & \\
\hline-2 & 0.4 & 32 & 1.00 & 1.902 & 690 & & & & & \\
\hline-3 & 0.4 & 32 & 1.00 & 1.935 & 720 & & & & & \\
\hline $17-1$ & 0.4 & 32 & 1.00 & 2.033 & 1040 & & & & & \\
\hline-2 & 0.4 & 32 & 1.00 & 1.974 & 860 & & & & & \\
\hline-3 & 0.4 & 32 & 1.00 & 1.883 & 830 & & & & & \\
\hline $18-1$ & 0.4 & 31 & 1.00 & 1.877 & 970 & & & & & \\
\hline-2 & 0.4 & 31 & 1.00 & 1.869 & 870 & & & & & \\
\hline-3 & 0.4 & 31 & 1.00 & 1.950 & 830 & & & & & \\
\hline $19-1$ & 0.4 & 30 & 1.00 & 1.875 & 660 & High & Early & Cement & & \\
\hline-2 & 0.4 & 30 & 1.00 & 1.843 & 690 & $"$ & $"$ & $"$ & & \\
\hline-3 & 0.4 & 30 & 1.00 & 1.789 & 800 & $"$ & $"$ & $"$ & & \\
\hline $20-1$ & 0.5 & 28 & 1.00 & 1.888 & 790 & $"$ & $"$ & $"$ & & \\
\hline-2 & 0.5 & 28 & 1.00 & 1.857 & 600 & $"$ & $"$ & $"$ & & \\
\hline-3 & 0.5 & 28 & 1.00 & 1.872 & 770 & $"$ & $"$ & $"$ & & \\
\hline $22 A-1$ & 0.5 & 14 & 1.00 & 1.900 & 550 & $"$ & $"$ & $"$ & Vac. & $\operatorname{mix}$ \\
\hline-2 & 0.5 & 14 & 1.00 & 1.853 & 550 & $"$ & $"$ & $"$ & $"$ & $"$ \\
\hline-3 & 0.5 & 14 & 1.00 & 1.800 & 620 & $"$ & $"$ & " & $"$ & $"$ \\
\hline $22-1$ & 0.5 & 14 & 1.00 & 1.900 & 790 & $"$ & $"$ & $"$ & $"$ & $"$ \\
\hline-2 & 0.5 & 14 & 1.00 & 1.880 & 800 & $"$ & $"$ & $"$ & $"$ & $"$ \\
\hline-3 & 0.5 & 14 & 1.00 & 1.937 & 480 & $"$ & $"$ & $"$ & $"$ & $"$ \\
\hline $23-1 \mathrm{~T}$ & 0.5 & 57 & 1.10 & 1.325 & -- & $"$ & $"$ & $"$ & $"$ & $"$ \\
\hline$-1 B$ & 0.5 & 57 & 1.10 & 1.937 & 480 & $"$ & $"$ & $n$ & $"$ & $"$ \\
\hline$-2 T$ & 0.5 & 57 & 1.10 & 2.008 & 630 & $"$ & $"$ & $"$ & $"$ & $n$ \\
\hline$-2 M$ & 0.5 & 57 & 1.10 & 1.438 & 845 & $"$ & $"$ & $"$ & $"$ & $"$ \\
\hline$-2 B$ & 0.5 & 57 & 1.10 & 1.971 & 630 & $"$ & $"$ & $"$ & $"$ & $"$ \\
\hline$-3 T$ & 0.5 & 57 & 1.10 & 1.202 & 580 & $"$ & $"$ & $"$ & $"$ & $"$ \\
\hline$-3 B$ & 0.5 & 57 & 1.10 & 1.953 & 710 & $"$ & $"$ & $"$ & $"$ & $"$ \\
\hline
\end{tabular}


Table 18, continued

\begin{tabular}{|c|c|c|c|c|c|c|}
\hline $\begin{array}{l}\text { Speci- } \\
\text { men } \\
\text { Number }\end{array}$ & $\mathrm{W} / \mathrm{C}$ & $\begin{array}{l}\text { Age, } \\
\text { days }\end{array}$ & $\begin{array}{l}\text { Diam., } \\
\text { in. }\end{array}$ & $\begin{array}{l}\text { Length, } \\
\text { in. }\end{array}$ & $\begin{array}{c}\text { Failure } \\
\text { Stress, } \\
\text { psi }\end{array}$ & Remarks \\
\hline $25-1-1$ & 0.5 & 56 & 1.10 & 0.981 & 795 & High Early Cement-Vac. mix \\
\hline$-1-2$ & 0.5 & 56 & 1.10 & 0.921 & 1055 & $"$ \\
\hline$-1-3$ & 0.5 & 56 & 1.10 & 0.920 & 955 & $"$ \\
\hline$-1-4$ & 0.5 & 56 & 1.10 & 0.904 & 735 & $"$ \\
\hline$-1-5$ & 0.5 & 56 & 1.10 & 0.919 & 760 & $"$ \\
\hline$-2-1$ & 0.5 & 56 & 1.10 & 0.918 & 770 & Ditto \& loaded at $0.01 \mathrm{in} /$ \\
\hline$-2-2$ & 0.5 & 56 & 1.10 & 0.944 & 705 & $"$ " " 0.5 min. \\
\hline$-2-3$ & 0.5 & 56 & 1.10 & 0.922 & 515 & $" 0.5 "$ \\
\hline$-2-4$ & 0.5 & 56 & 1.10 & 0.931 & 1170 & $" 0.5$ \\
\hline$-2-5$ & 0.5 & 56 & 1.10 & 0.914 & 875 & $" 0.5 "$ \\
\hline$-2-6$ & 0.5 & 56 & 1.10 & 0.861 & 740 & $" \quad " \quad 0.01 "$ \\
\hline $27-1$ & 0.6 & 42 & 0.50 & 1.103 & 405 & High Early Cement-Vac. mix \\
\hline-2 & 0.6 & 42 & 0.50 & 0.972 & 720 & $"$ " " " \\
\hline-3 & 0.6 & 42 & 0.50 & 1.312 & 730 & $"$ \\
\hline-4 & 0.6 & 42 & 0.50 & 0.919 & 430 & $"$ \\
\hline $28-1$ & 0.6 & 41 & 1.00 & 1.844 & 600 & $"$ \\
\hline-2 & 0.6 & 41 & 1.00 & 1.868 & 505 & $"$ \\
\hline-3 & 0.6 & 41 & 1.00 & 1.904 & 520 & $"$ \\
\hline 29-IA & 0.4 & 28 & 0.50 & 1.087 & 1125 & Vac. Mix \\
\hline$-2 A$ & 0.4 & 28 & 0.50 & 0.839 & 1250 & Vac. Mix \\
\hline$-3 B$ & 0.4 & 28 & 0.50 & 1.035 & 1340 & Vac. Mix \\
\hline$-4 B$ & 0.4 & 28 & 0.50 & 0.811 & 1620 & Vac. Mix \\
\hline $30-1$ & 0.4 & 28 & 1.00 & 1.904 & 600 & Vac. Mix \\
\hline-2 & 0.4 & 28 & 1.00 & 1.934 & 1250 & Vac. Mix \\
\hline-3 & 0.4 & 28 & 1.00 & 1.895 & 1260 & Vac. Mic 3000 Ib. preload \\
\hline-4 & 0.4 & 28 & 1.00 & 1.863 & 855 & Vac. Mix \\
\hline-5 & 0.4 & 28 & 1.00 & 1.955 & 1105 & Vac. Mix 3000 1b. preload \\
\hline $31-1$ & 0.4 & 28 & 1.00 & 1.906 & 1240 & No Vac. \\
\hline-2 & 0.4 & 28 & 1.00 & 1.876 & 1190 & No Vac. \\
\hline-3 & 0.4 & 28 & 1.00 & 1.877 & 1240 & No Vac. 2750 Ib. preload \\
\hline-4 & 0.4 & 28 & 1.00 & 1.845 & 690 & No Vac. 2750 lb. preload \\
\hline $32-1$ & 0.4 & 37 & 1.00 & 1.845 & 1210 & Vac. Mix \\
\hline-2 & 0.4 & 37 & 1.00 & 1.846 & 590 & Vac. Mix \\
\hline-3 & 0.4 & 37 & 1.00 & 1.841 & 710 & Vac. Mix \\
\hline $33-1$ & 0.4 & 37 & 1.00 & 1.836 & 990 & No Vac. \\
\hline-2 & 0.4 & 37 & 1.00 & 1.863 & 1315 & No Vac. \\
\hline-3 & 0.4 & 37 & 1.00 & 1.817 & 1070 & No Vac. \\
\hline $34-4$ & 0.4 & 36 & 1.00 & 1.830 & 990 & Vac. Mix \\
\hline-5 & 0.4 & 36 & 1.00 & 1.863 & 975 & Vac. Mix \\
\hline-6 & 0.4 & 36 & 1.00 & 1.892 & 1075 & Vac. Mix \\
\hline $35-1$ & 0.4 & 36 & 1.00 & 1.827 & 975 & No Vac. \\
\hline-2 & 0.4 & 36 & 1.00 & 1.866 & 905 & No Vac. \\
\hline-3 & 0.4 & 36 & 1.00 & 1.816 & 930 & No Vac. \\
\hline $36-1$ & 0.5 & 22 & 1.00 & - & $-\infty$ & Broken during drilling \\
\hline $\begin{array}{l}-2 \\
-3\end{array}$ & $\begin{array}{l}0.5 \\
0.5\end{array}$ & $\begin{array}{l}22 \\
22\end{array}$ & $\begin{array}{l}1.00 \\
1.00\end{array}$ & $\begin{array}{l}1.768 \\
1.771\end{array}$ & $\begin{array}{l}575 \\
540\end{array}$ & Hole drilled to simulate \\
\hline
\end{tabular}


Table 18, continued

\begin{tabular}{|c|c|c|c|c|c|c|}
\hline $\begin{array}{l}\text { Speci- } \\
\text { men } \\
\text { Number }\end{array}$ & $\mathrm{W} / \mathrm{C}$ & $\begin{array}{l}\text { Age, } \\
\text { days }\end{array}$ & $\begin{array}{l}\text { Diam., } \\
\text { in. }\end{array}$ & $\begin{array}{l}\text { Length, } \\
\text { in. }\end{array}$ & $\begin{array}{c}\text { Failure } \\
\text { Stress, } \\
\text { psi }\end{array}$ & Remarks \\
\hline $36-4$ & 0.5 & 32 & 1.00 & 1.827 & 730 & Vac. Mix on all following \\
\hline-5 & 0.5 & 32 & 1.00 & 1.756 & 815 & \\
\hline-6 & 0.5 & 32 & 1.00 & 1.833 & 850 & \\
\hline $37-1$ & 0.5 & 20 & 1.00 & 1.877 & 990 & \\
\hline-2 & 0.5 & 20 & 1.00 & 1.913 & 700 & \\
\hline-3 & 0.5 & 20 & 1.00 & 1.812 & 695 & \\
\hline-4 & 0.5 & -- & -- & - & -- & Broken during demolding \\
\hline-5 & 0.5 & 32 & 1.00 & 1.817 & 1035 & \\
\hline-6 & 0.5 & 32 & 1.00 & 1.862 & 980 & \\
\hline $38-4$ & 0.5 & 32 & 1.00 & 1.923 & 830 & \\
\hline-5 & 0.5 & 32 & 1.00 & 1.946 & 895 & \\
\hline-6 & 0.5 & 32 & 1.00 & 1.857 & 910 & \\
\hline $39-1$ & 0.5 & 27 & 1.00 & 2.020 & 930 & \\
\hline-2 & 0.5 & 27 & 1.00 & 2.045 & 755 & \\
\hline-3 & 0.5 & 27 & 1.00 & 2.078 & 795 & \\
\hline-4 & 0.5 & 27 & 1.00 & 2.140 & 340 & 0.09 in. dia. hole thru \\
\hline-5 & 0.5 & 27 & 1.00 & 2.078 & 350 & " " " center \\
\hline-6 & 0.5 & 27 & 1.00 & 0.481 & 465 & " " " \\
\hline $40-1$ & 0.5 & 28 & 1.00 & 2.139 & 885 & \\
\hline-2 & 0.5 & 28 & 1.00 & 2.148 & 890 & \\
\hline-3 & 0.5 & 28 & 1.00 & 2.139 & 945 & \\
\hline $41-1$ & 0.5 & 28 & 1.00 & 1.976 & 830 & \\
\hline-2 & 0.5 & 28 & 1.00 & 1.950 & 890 & \\
\hline-3 & 0.5 & 28 & 1.00 & 2.138 & 895 & \\
\hline $42-1$ & 0.5 & 28 & 1.00 & 2.133 & 810 & Bottom bearing strip off \\
\hline-2 & 0.5 & 28 & 1.00 & 2.111 & 880 & \\
\hline-3 & 0.5 & 28 & 1.00 & 2.086 & 840 & \\
\hline $42 A-1-1$ & 0.5 & 28 & 1.10 & 2.005 & 675 & \\
\hline$-1-2$ & 0.5 & 28 & 1.10 & 0.920 & 770 & \\
\hline$-1-3$ & 0.5 & 28 & 1.10 & 0.431 & 1020 & \\
\hline$-1-4$ & 0.5 & 28 & 1.10 & 0.431 & 1050 & \\
\hline$-1-5$ & 0.5 & 28 & 1.10 & 0.411 & 920 & \\
\hline$-1-6$ & 0.5 & 28 & 1.10 & 0.195 & 860 & \\
\hline$-1-7$ & 0.5 & 28 & 1.10 & 0.209 & 890 & \\
\hline$-2-1$ & 0.5 & 28 & 1.10 & 1.998 & 520 & Bad break - off center \\
\hline$-2-2$ & 0.5 & 28 & 1.10 & 0.918 & 660 & \\
\hline$-2-3$ & 0.5 & 28 & 1.10 & 0.449 & 1140 & \\
\hline$-2-4$ & 0.5 & 28 & 1.10 & 0.448 & 740 & \\
\hline$-2-5$ & 0.5 & 28 & 1.10 & 0.300 & 1190 & \\
\hline$-3-1$ & 0.5 & 28 & 1.10 & 1.646 & 360 & 0.09 in. Dia. hole thm \\
\hline$-3-2$ & 0.5 & 28 & 1.10 & 0.980 & 380 & " center \\
\hline$-3-3$ & 0.5 & 28 & 1.10 & 0.428 & 530 & " " \\
\hline$-3-4$ & 0.5 & 28 & 1.10 & 0.245 & 400 & $" \quad "$ \\
\hline $43-1-1$ & 0.5 & 29 & 0.50 & 1.022 & 710 & \\
\hline$-1-2$ & 0.5 & 29 & 0.50 & 0.557 & 570 & \\
\hline-2 & 0.5 & 29 & 0.50 & 2.125 & 720 & \\
\hline
\end{tabular}


Table 18, continued

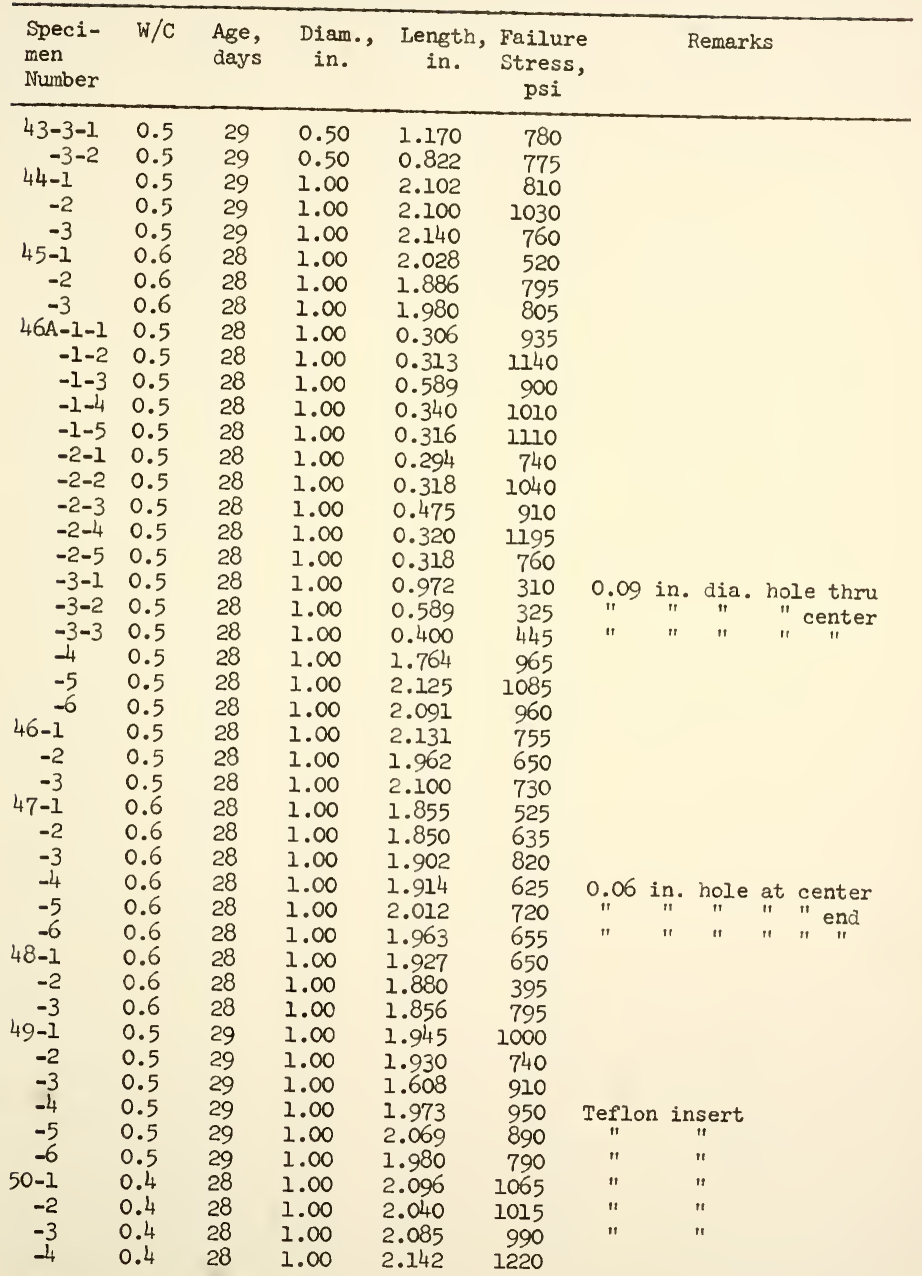


Table 18, continued

\begin{tabular}{|c|c|c|c|c|c|c|c|}
\hline $\begin{array}{l}\text { Speci- } \\
\text { men } \\
\text { Number }\end{array}$ & $\mathrm{W} / \mathrm{C}$ & $\begin{array}{l}\text { Age, } \\
\text { days }\end{array}$ & $\begin{array}{c}\text { Diam., } \\
\text { in. }\end{array}$ & $\begin{array}{l}\text { Length, } \\
\text { in. }\end{array}$ & $\begin{array}{c}\text { Fallure } \\
\text { Stress } \\
\text { psi }\end{array}$ & & Remarks \\
\hline $50-5$ & 0.4 & 28 & 1.00 & 2.110 & 1115 & & \\
\hline-6 & 0.4 & 28 & 1.00 & 1.574 & 690 & & \\
\hline $51-1$ & 0.5 & 28 & 1.00 & 1.843 & 810 & & \\
\hline-2 & 0.5 & 28 & 1.00 & 1.816 & 1120 & & \\
\hline-3 & 0.5 & 28 & 1.00 & 1.806 & 1110 & & \\
\hline $52-1$ & 0.4 & 28 & 1.00 & 2.131 & 1105 & Teflon & insert \\
\hline-2 & 0.4 & 28 & 1.00 & 2.142 & 1010 & $"$ & " \\
\hline-3 & 0.4 & 28 & 1.00 & 2.163 & 970 & $"$ & $"$ \\
\hline-4 & 0.4 & 28 & 1.00 & 2.252 & 860 & & \\
\hline-5 & 0.4 & 28 & 1.00 & 2.132 & 1285 & & \\
\hline-6 & 0.4 & 28 & 1.00 & 2.084 & 1270 & & \\
\hline $53-1$ & 0.6 & 34 & 1.00 & 1.447 & 625 & & \\
\hline-2 & 0.6 & 34 & 1.00 & 1.519 & 585 & & \\
\hline-3 & 0.6 & 34 & 1.00 & 1.746 & 730 & & \\
\hline-4 & 0.6 & 34 & 0.50 & 1.927 & 905 & & \\
\hline-5 & 0.6 & 34 & 0.50 & 1.965 & 970 & & \\
\hline-6 & 0.6 & 34 & 0.50 & 1.988 & 885 & & \\
\hline $54-1$ & 0.5 & 28 & 1.00 & 2.063 & 800 & Teflon & insert \\
\hline-2 & 0.5 & 28 & 1.00 & 2.057 & 820 & & $"$ \\
\hline-3 & 0.5 & 28 & 1.00 & 1.958 & 665 & $"$ & $"$ \\
\hline-4 & 0.5 & 28 & 1.00 & 1.996 & 685 & & \\
\hline-5 & 0.5 & 28 & 1.00 & 1.975 & 1000 & & \\
\hline-6 & 0.5 & 28 & 1.00 & 2.010 & 980 & & \\
\hline $57-1$ & 0.4 & 100 & 1.00 & 1.762 & 590 & Teflon? & \\
\hline-2 & 0.4 & 100 & 1.00 & 1.929 & 695 & $"$ & \\
\hline-3 & 0.4 & 100 & 1.00 & 1.968 & 640 & $"$ & \\
\hline-4 & 0.4 & 180 & 1.00 & 1.792 & 800 & $"$ & \\
\hline-5 & 0.4 & 180 & 1.00 & 1.830 & 765 & $"$ & \\
\hline-6 & 0.4 & 180 & 1.00 & 1.832 & 575 & $"$ & \\
\hline $58-1$ & 0.5 & 87 & 1.00 & 2.48 & 900 & & \\
\hline-2 & 0.5 & 87 & 1.00 & 2.50 & 1005 & & \\
\hline-3 & 0.5 & 87 & 1.00 & 2.32 & 1045 & & \\
\hline-4 & 0.5 & 167 & 1.00 & 1.988 & 1210 & & \\
\hline-5 & 0.5 & 167 & 1.00 & 1.918 & 930 & & \\
\hline-6 & 0.5 & 167 & 1.00 & 1.890 & 875 & & \\
\hline $59-1$ & 0.4 & 71 & 1.00 & 1.926 & 825 & & \\
\hline-2 & 0.4 & 71 & 1.00 & 1.945 & 980 & & \\
\hline-3 & 0.4 & 71 & 1.00 & 2.018 & 790 & & \\
\hline-5 & 0.4 & 71 & 1.00 & 1.973 & 725 & Tested & at $40^{\circ} \mathrm{F}$ \\
\hline-5 & 0.4 & 71 & 1.00 & 1.970 & 955 & " & $" \quad "$ \\
\hline-6 & 0.4 & 71 & 1.00 & 1.937 & 1120 & $"$ & " $"$ \\
\hline-7 & 0.4 & 71 & 1.00 & 2.083 & 450 & $"$ & $" 184^{\circ} \mathrm{F}$ \\
\hline-8 & 0.4 & 71 & 1.00 & 2.094 & 640 & $"$ & " \\
\hline-9 & 0.4 & 71 & 1.00 & 2.069 & 410 & $n$ & $"$ \\
\hline $60-1$ & 0.5 & 67 & 1.00 & 1.931 & 785 & & \\
\hline-2 & 0.5 & 67 & 1.00 & 1.933 & 920 & & . \\
\hline
\end{tabular}


Table 18, continued

\begin{tabular}{|c|c|c|c|c|c|c|}
\hline $\begin{array}{l}\text { Spec1- } \\
\text { men } \\
\text { Number }\end{array}$ & W/C & $\begin{array}{l}\text { Age, } \\
\text { days }\end{array}$ & $\begin{array}{l}\text { Diam., } \\
\text { in. }\end{array}$ & $\begin{array}{l}\text { Length, } \\
\text { in. }\end{array}$ & $\begin{array}{c}\text { Failure } \\
\text { Stress, } \\
\text { psi }\end{array}$ & Remarks \\
\hline $60-3$ & 0.5 & 67 & 1.00 & 1.919 & 910 & \\
\hline-4 & 0.5 & 147 & 1.00 & 1.903 & 985 & \\
\hline-5 & 0.5 & 147 & 1.00 & 1.950 & 945 & \\
\hline-6 & 0.5 & 147 & 1.00 & 1.863 & 1095 & \\
\hline $61-1$ & 0.6 & 66 & 1.00 & 1.905 & 835 & \\
\hline-2 & 0.6 & 66 & 1.00 & 1.924 & 695 & \\
\hline-3 & 0.6 & 66 & 1.00 & 1.905 & 745 & \\
\hline-4 & 0.6 & 66 & 1.00 & 1.589 & 880 & Tested at $40^{\circ} \mathrm{F}$ \\
\hline-5 & 0.6 & 66 & 1.00 & 1.950 & 730 & $"$ \\
\hline-6 & 0.6 & 66 & 1.00 & 1.922 & 540 & " " \\
\hline-7 & 0.6 & 66 & 1.00 & 1.935 & 280 & $" 184^{\circ} \mathrm{F}$ \\
\hline-8 & 0.6 & 66 & 1.00 & 1.719 & 730 & $" 1 "$ \\
\hline-9 & 0.6 & 66 & 1.00 & 1.577 & 695 & $"$ \\
\hline $62-1$ & 0.4 & 65 & 1.00 & 1.943 & 900 & \\
\hline-2 & 0.4 & 65 & 1.00 & 1.966 & 1010 & \\
\hline-3 & 0.4 & 65 & 1.00 & 1.989 & 960 & \\
\hline-4 & 0.4 & 146 & 1.00 & 1.925 & 1025 & \\
\hline-5 & 0.4 & 146 & 1.00 & 1.893 & 990 & \\
\hline-6 & 0.4 & 146 & 1.00 & 1.909 & 1065 & \\
\hline $63-1$ & 0.5 & 59 & 1.00 & 1.902 & 830 & \\
\hline-2 & 0.5 & 59 & 1.00 & 1.919 & 755 & \\
\hline-3 & 0.5 & 59 & 1.00 & 1.932 & $\cdots$ & Bad test \\
\hline-4 & 0.5 & 140 & 1.00 & 1.924 & 710 & \\
\hline-5 & 0.5 & 140 & 1.00 & 1.951 & 1095 & \\
\hline-6 & 0.5 & 140 & 1.00 & 1.939 & 970 & \\
\hline $66-1$ & 0.4 & 45 & 1.00 & 1.972 & 855 & \\
\hline-2 & 0.4 & 45 & 2.00 & 1.978 & 965 & \\
\hline-3 & 0.4 & 45 & 1.00 & 1.679 & 665 & \\
\hline-4 & 0.4 & 45 & 1.00 & 1.917 & 1280 & Tested at $40^{\circ} \mathrm{F}$ \\
\hline-5 & 0.4 & 45 & 1.00 & 1.963 & 2130 & " " " \\
\hline-6 & 0.4 & 45 & 1.00 & 1.921 & 1130 & " " \\
\hline-7 & 0.4 & 45 & 1.00 & 1.953 & 540 & $" 184^{\circ} \mathrm{F}$ \\
\hline-8 & 0.4 & 45 & 1.00 & 1.977 & 835 & $"$ " \\
\hline-9 & 0.4 & 45 & 1.00 & 1.938 & 590 & $"$ \\
\hline $67-1$ & 0.5 & 43 & 1.00 & 1.890 & 825 & \\
\hline-2 & 0.5 & 43 & 1.00 & 2.036 & $=-$ & Bad test \\
\hline-3 & 0.5 & 43 & 1.00 & 1.971 & 760 & \\
\hline 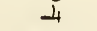 & 0.5 & 123 & 1.00 & 1.933 & 955 & \\
\hline-5 & 0.5 & 123 & 1.00 & 1.958 & 780 & \\
\hline-6 & 0.5 & 123 & 1.00 & 1.901 & 990 & \\
\hline $69-1$ & 0.4 & 31 & 1.00 & 2.001 & 1100 & \\
\hline-2 & 0.4 & 31 & 1.00 & 1.942 & 1245 & \\
\hline-3 & 0.4 & 31 & 1.00 & 1.937 & 970 & \\
\hline-4 & 0.4 & 112 & 1.00 & 1.875 & 1070 & \\
\hline-5 & 0.4 & 112 & 1.00 & 1.854 & 1185 & \\
\hline-6 & 0.4 & 112 & 1.00 & 1.900 & 1390 & \\
\hline
\end{tabular}


Table 18, continued

\begin{tabular}{|c|c|c|c|c|c|c|}
\hline $\begin{array}{l}\text { Speci- } \\
\text { men } \\
\text { Number }\end{array}$ & $\mathrm{W} / \mathrm{C}$ & $\begin{array}{l}\text { Age, } \\
\text { days }\end{array}$ & $\begin{array}{l}\text { Diam., } \\
\text { in. }\end{array}$ & $\begin{array}{l}\text { Length, } \\
\text { in. }\end{array}$ & $\begin{array}{c}\text { Failure } \\
\text { Stress } \\
\text { psi }\end{array}$ & Remarks \\
\hline $71-1$ & 0.5 & 18 & 1.00 & 1.951 & 655 & \\
\hline-2 & 0.5 & 18 & 1.00 & 1.900 & 820 & \\
\hline-3 & 0.5 & 18 & 1.00 & 1.961 & 715 & \\
\hline-4 & 0.5 & 98 & 1.00 & 1.893 & 640 & \\
\hline-5 & 0.5 & 98 & 1.00 & 1.872 & 935 & \\
\hline-6 & 0.5 & 98 & 1.00 & 1.893 & 1245 & \\
\hline $72-1$ & 0.6 & 17 & 1.00 & 1.915 & 780 & \\
\hline-2 & 0.6 & 17 & 1.00 & 1.964 & 695 & \\
\hline-3 & 0.6 & 17 & 1.00 & 1.876 & 595 & \\
\hline-4 & 0.6 & 98 & 1.00 & 1.852 & $-\infty$ & NG off center \\
\hline-5 & 0.6 & 98 & 1.00 & 1.905 & 785 & \\
\hline-6 & 0.6 & 98 & 1.00 & - & $-\infty$ & Lost \\
\hline $73-1$ & 0.4 & 16 & 1.00 & 1.940 & 920 & \\
\hline-2 & 0.4 & 16 & 1.00 & 1.896 & 875 & \\
\hline-3 & 0.4 & 16 & 1.00 & 1.872 & 800 & \\
\hline-4 & 0.4 & 97 & 1.00 & 1.964 & 1085 & \\
\hline-5 & 0.4 & 97 & 1.00 & 1.937 & 1165 & \\
\hline-6 & 0.4 & 97 & 1.00 & 1.935 & 1035 & \\
\hline $74-1$ & 0.5 & 100 & 1.00 & 1.809 & 650 & No bearing strips \\
\hline-2 & 0.5 & 100 & 1.00 & 1.865 & 710 & $"$ \\
\hline-3 & 0.5 & 100 & 1.00 & 1.836 & 650 & $"$ \\
\hline-4 & 0.5 & 100 & 1.00 & 1.793 & 815 & \\
\hline-5 & 0.5 & 100 & 1.00 & 1.804 & 1175 & \\
\hline-6 & 0.5 & 100 & 1.00 & 1.973 & 1130 & \\
\hline $76-1$ & 0.4 & 89 & 1.00 & 1.770 & 1205 & Loaded at $0.05 \mathrm{in} / \mathrm{min}$ \\
\hline-2 & 0.4 & 89 & 1.00 & 1.760 & 1155 & " \\
\hline-3 & 0.4 & 89 & 1.00 & 1.650 & 810 & $" \quad "$ \\
\hline-5 & 0.4 & 89 & 1.00 & 1.695 & 1260 & $" 5$ \\
\hline-5 & 0.4 & 89 & 1.00 & 1.842 & 1105 & " 5 \\
\hline-6 & 0.4 & 89 & 1.00 & 1.858 & 1370 & " 5 \\
\hline-7 & 0.4 & 89 & 1.00 & 1.905 & 1255 & $" 50$ \\
\hline-8 & 0.4 & 89 & 1.00 & 1.786 & 1105 & $" 50$ \\
\hline-9 & 0.4 & 89 & 1.00 & 1.828 & 1060 & $\begin{array}{c}0.05 \mathrm{in} / \mathrm{min} \text { - no bearing } \\
\text { strip }\end{array}$ \\
\hline $77-1$ & 0.5 & 89 & 1.00 & 1.699 & 730 & No bearing strips \\
\hline-2 & 0.5 & 89 & 1.00 & 1.782 & 465 & $"$ \\
\hline-3 & 0.5 & 89 & 1.00 & 1.833 & 555 & $"$ \\
\hline-5 & 0.5 & 89 & 1.00 & 1.890 & 740 & \\
\hline-5 & 0.5 & 89 & 1.00 & 1.554 & 735 & \\
\hline-6 & 0.5 & 89 & 1.00 & 1.908 & 1070 & \\
\hline-7 & 0.5 & 89 & 1.00 & 1.784 & 535 & No bearing st.-holding \\
\hline-8 & 0.5 & 89 & 1.00 & 1.438 & 620 & " " " load \\
\hline-9 & 0.5 & 89 & 1.00 & 1.369 & 475 & " $" 11$ \\
\hline $79-1$ & 0.4 & 84 & 1.00 & 1.836 & 1060 & \\
\hline-2 & 0.4 & 84 & 1.00 & 1.837 & 1230 & \\
\hline-3 & 0.4 & 84 & 1.00 & 2.005 & 1110 & \\
\hline-4 & 0.4 & 84 & 1.00 & 1.966 & 460 & No bearingst.-holding Ioa \\
\hline
\end{tabular}


Table 18, continued

\begin{tabular}{|c|c|c|c|c|c|c|c|}
\hline $\begin{array}{l}\text { Speci- } \\
\text { men } \\
\text { Number }\end{array}$ & $\mathrm{W} / \mathrm{C}$ & $\begin{array}{l}\text { Age, } \\
\text { days }\end{array}$ & $\begin{array}{l}\text { Diam., } \\
\text { in. }\end{array}$ & $\begin{array}{l}\text { Length, } \\
\text { in. }\end{array}$ & $\begin{array}{l}\text { Failure } \\
\text { Stress } \\
\text { psi }\end{array}$ & & Remarks \\
\hline $80-1$ & 0.5 & 77 & 1.00 & 1.854 & 875 & & \\
\hline-2 & 0.5 & 77 & 1.00 & $\ldots$ & $-\infty$ & \multicolumn{2}{|c|}{ Not aligned properly } \\
\hline-3 & 0.5 & 77 & 1.00 & 1.819 & 1030 & & \\
\hline-4 & 0.5 & 77 & 1.00 & 1.843 & 770 & & \\
\hline-5 & 0.5 & 77 & 1.00 & 1.852 & 1170 & & \\
\hline-6 & 0.5 & 77 & 1.00 & 1.957 & 1040 & & \\
\hline $84-1$ & 0.5 & 33 & 1.00 & 1.848 & 750 & & \\
\hline-2 & 0.5 & 33 & 1.00 & 1.877 & 815 & & \\
\hline-3 & 0.5 & 33 & 1.00 & 1.884 & 710 & & \\
\hline-4 & 0.5 & 33 & 1.00 & 1.930 & 660 & \multirow{2}{*}{\multicolumn{2}{|c|}{$\begin{array}{r}\text { Loaded at } 0.005 \mathrm{in} / \mathrm{min} \\
\text { Hand load in stops for } \\
90 \mathrm{~min} .\end{array}$}} \\
\hline-5 & 0.5 & 33 & 1.00 & 1.905 & 785 & & \\
\hline-6 & 0.5 & 33 & 1.00 & 1.915 & 750 & \multicolumn{2}{|c|}{$\begin{array}{l}\text { Hand load in stops for } \\
\qquad 41 / 2 \mathrm{hrs} .\end{array}$} \\
\hline-7 & 0.5 & 33 & 1.00 & 1.716 & 740 & \multirow{2}{*}{\multicolumn{2}{|c|}{${ }_{1 "}^{\text {Loaded at }} 0_{1} 5 \mathrm{in} / \mathrm{min}$}} \\
\hline-8 & 0.5 & 33 & 1.00 & 1.655 & 690 & & \\
\hline-9 & 0.5 & 33 & 1.00 & $\ldots$ & $-\infty$ & \multicolumn{2}{|c|}{ Specimen lost } \\
\hline $87-1$ & 0.6 & 59 & 1.00 & 1.902 & 955 & & \\
\hline-2 & 0.6 & 59 & 1.00 & 1.873 & 715 & & \\
\hline-3 & 0.6 & 59 & 1.00 & 1.857 & 825 & & \\
\hline-4 & 0.6 & 59 & 1.00 & +- & -- & \multicolumn{2}{|c|}{$\begin{array}{c}\text { One inch bearing strip } \\
\text { in center }\end{array}$} \\
\hline-5 & 0.6 & 59 & 1.00 & -.. & $-\infty$ & $" \quad "$ & " " \\
\hline-6 & 0.6 & 59 & 1.00 & -- & $-\infty$ & \multicolumn{2}{|l|}{$" \quad "$} \\
\hline $92-1$ & 0.4 & 28 & 1.00 & 0.980 & 830 & & \\
\hline-2 & 0.4 & 28 & 1.00 & 0.940 & 1340 & & \\
\hline-3 & 0.4 & 28 & 1.00 & 0.941 & 1250 & & \\
\hline $93-1$ & 0.5 & 23 & 1.00 & 0.267 & 980 & & \\
\hline-2 & 0.5 & 28 & 1.00 & 0.266 & 1055 & & \\
\hline-3 & 0.5 & 28 & 1.00 & 0.304 & 1090 & \multirow{2}{*}{\multicolumn{2}{|c|}{ Tested at $160^{\circ} \mathrm{F}$}} \\
\hline $94-1$ & 0.6 & 28 & 1.00 & 1.768 & 595 & & \\
\hline-2 & 0.6 & 28 & 1.00 & 1.851 & 380 & $"$ & " " \\
\hline-3 & 0.6 & 28 & 1.00 & 1.891 & 490 & $"$ & " " \\
\hline $95-1$ & 0.4 & 28 & 1.00 & 1.014 & 880 & \multirow{2}{*}{\multicolumn{2}{|c|}{$\underset{\|}{\text { Tested }}{ }_{\|}^{\text {at }} \underset{11}{160^{\circ} \mathrm{F}}$}} \\
\hline-2 & 0.4 & 28 & 1.00 & 0.959 & 565 & & \\
\hline-3 & 0.4 & 28 & 1.00 & 0.964 & 530 & $"$ & " " \\
\hline $96-1$ & 0.5 & 28 & 1.00 & 0.258 & 1160 & \multicolumn{2}{|c|}{ Tested at ${ }_{\|}^{40} 0^{\circ} \mathrm{F}$} \\
\hline-2 & 0.5 & 28 & 1.00 & 0.292 & 1155 & 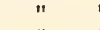 & $" 1$ \\
\hline-3 & 0.5 & 28 & 1.00 & 0.256 & 980 & $"$ & " $"$ \\
\hline $97-1$ & 0.6 & 28 & 1.00 & 0.940 & 490 & \multicolumn{2}{|c|}{$\underset{\|}{\text { Tested }} \underset{\|}{\text { at }} 72^{\circ} \mathrm{F}$} \\
\hline-2 & 0.6 & 28 & 1.00 & 1.004 & 680 & & \\
\hline-3 & 0.6 & 28 & 1.00 & 0.972 & 690 & $"$ & $" n$ \\
\hline $98-1$ & 0.5 & 29 & 1.00 & 1.913 & 600 & \multirow{2}{*}{\multicolumn{2}{|c|}{$\underset{\|}{\text { Tested }}{ }_{\|}^{\text {at }} 160^{\circ} \mathrm{F}$}} \\
\hline-2 & 0.5 & 29 & 1.00 & 1.978 & 465 & & \\
\hline-3 & 0.5 & 29 & 1.00 & 1.963 & 290 & \multirow{3}{*}{\multicolumn{2}{|c|}{$" \quad "$}} \\
\hline $99-1$ & 0.6 & 29 & 1.00 & 1.829 & 565 & & \\
\hline-2 & 0.6 & 29 & 1.00 & 1.853 & 745 & & \\
\hline
\end{tabular}


Table 18, continued

\begin{tabular}{|c|c|c|c|c|c|c|c|}
\hline $\begin{array}{l}\text { Speci- } \\
\text { men } \\
\text { Number }\end{array}$ & W/C & $\begin{array}{l}\text { Age, } \\
\text { days }\end{array}$ & $\begin{array}{l}\text { Diam., } \\
\text { in. }\end{array}$ & $\begin{array}{l}\text { Length, } \\
\text { in. }\end{array}$ & $\begin{array}{c}\text { Failure } \\
\text { Stress } \\
\text { psi }\end{array}$ & & Remarks \\
\hline $99-3$ & 0.6 & 29 & 1.00 & 1.758 & 505 & & \\
\hline-4 & 0.6 & 29 & 1.00 & 1.808 & 625 & & \\
\hline-5 & 0.6 & 29 & 1.00 & 1.757 & 680 & & \\
\hline $101-1$ & 0.4 & 28 & 1.00 & 1.909 & 1135 & Tested & at $40^{\circ} \mathrm{F}$ \\
\hline-2 & 0.4 & 28 & 1.00 & 1.894 & 890 & & \\
\hline-3 & 0.4 & 28 & 1.00 & 1.922 & 1390 & " & " \\
\hline $104-1$ & 0.50 & 28 & 1.00 & 0.959 & 1060 & & \\
\hline-2 & 0.5 & 28 & 1.00 & 0.916 & 905 & & \\
\hline-3 & 0.5 & 28 & 1.00 & 1.020 & 875 & & \\
\hline-4 & 0.5 & 28 & 1.00 & 1.023 & 700 & & \\
\hline $106-1$ & 0.4 & 29 & 1.00 & 0.957 & 1100 & Tested & at $40^{\circ} \mathrm{F}$ \\
\hline-2 & 0.4 & 29 & 1.00 & 0.972 & 965 & & - \\
\hline-3 & 0.4 & 29 & 1.00 & 0.979 & 895 & $"$ & " " \\
\hline $108-1$ & 0.4 & 28 & 1.00 & 0.304 & 2050 & Tested & at $40^{\circ} \mathrm{F}$ \\
\hline-2 & 0.4 & 28 & 1.00 & 0.301 & 1585 & i1 & $" \quad "$ \\
\hline-3 & 0.4 & 28 & 1.00 & 0.281 & 1810 & $"$ & " $"$ \\
\hline $109-1$ & 0.5 & 28 & 1.00 & 0.939 & 595 & Tested & at $40^{\circ} \mathrm{F}$ \\
\hline-2 & 0.5 & 28 & 1.00 & 1.001 & 1020 & " & $"$ \\
\hline-3 & 0.5 & 28 & 1.00 & 0.998 & 640 & $"$ & $"$ \\
\hline $110-1$ & 0.4 & 27 & 1.00 & 1.921 & 1110 & & \\
\hline-2 & 0.4 & 27 & 1.00 & 1.885 & 860 & & \\
\hline-3 & 0.4 & 27 & 1.00 & 1.918 & 1080 & & \\
\hline-4 & 0.4 & 27 & 1.00 & 1.919 & 880 & & \\
\hline $114-1$ & 0.6 & 31 & 1.00 & 0.988 & 485 & Tested & at $160^{\circ} \mathrm{F}$ \\
\hline-2 & 0.6 & 31 & 1.00 & 0.952 & 670 & tosucu & $" 1 "$ \\
\hline-3 & 0.6 & 31 & 1.00 & 1.003 & 525 & " & $" \quad "$ \\
\hline $215-1$ & 0.4 & 31 & 1.00 & 1.829 & 1055 & Tested & at $160^{\circ} \mathrm{F}$ \\
\hline-2 & 0.4 & 31 & 1.00 & 1.801 & 595 & " & $"$ \\
\hline-3 & 0.4 & 31 & 1.00 & 1.862 & 425 & $"$ & " " \\
\hline $136-1$ & 0.5 & 30 & 1.00 & 0.998 & 720 & Tested & at $160^{\circ} \mathrm{F}$ \\
\hline-2 & 0.5 & 30 & 1.00 & 1.052 & 755 & " & \\
\hline-3 & 0.5 & 30 & 1.00 & 0.993 & 320 & $"$ & " " \\
\hline $118-4$ & 0.5 & 30 & 1.00 & 1.875 & 780 & Tested & at $40^{\circ} \mathrm{F}$ \\
\hline-5 & 0.5 & 30 & 1.00 & 1.850 & 910 & & " \\
\hline-6 & 0.5 & 30 & 1.00 & 1.839 & 985 & $"$ & $"$ \\
\hline $119-4$ & 0.4 & 31 & 1.00 & 0.322 & 1235 & & \\
\hline-5 & 0.4 & 31 & 1.00 & 0.291 & 1530 & & \\
\hline-6 & 0.4 & 31 & 1.00 & 0.276 & 1390 & & \\
\hline$-4 T$ & 0.4 & 31 & 1.00 & 0.630 & 1010 & & \\
\hline$-4 B$ & 0.4 & 31 & 1.00 & 0.763 & 980 & & \\
\hline$-5 T$ & 0.4 & 31 & 1.00 & 0.736 & 1040 & & \\
\hline$-5 B$ & 0.4 & 31 & 1.00 & 0.721 & 1080 & & \\
\hline$-6 T$ & 0.4 & 31 & 1.00 & 0.674 & 875 & & \\
\hline$-6 B$ & 0.4 & 31 & 1.00 & 0.996 & 800 & & \\
\hline $121-1$ & 0.6 & 29 & 1.00 & 1.838 & 710 & Tested & at $40^{\circ} \mathrm{F}$ \\
\hline-2 & 0.6 & 29 & 1.00 & 1.805 & 635 & 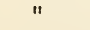 & $" \quad "$ \\
\hline-3 & 0.6 & 29 & 1.00 & 1.840 & 530 & " & $"$ \\
\hline
\end{tabular}


Table 18, continued

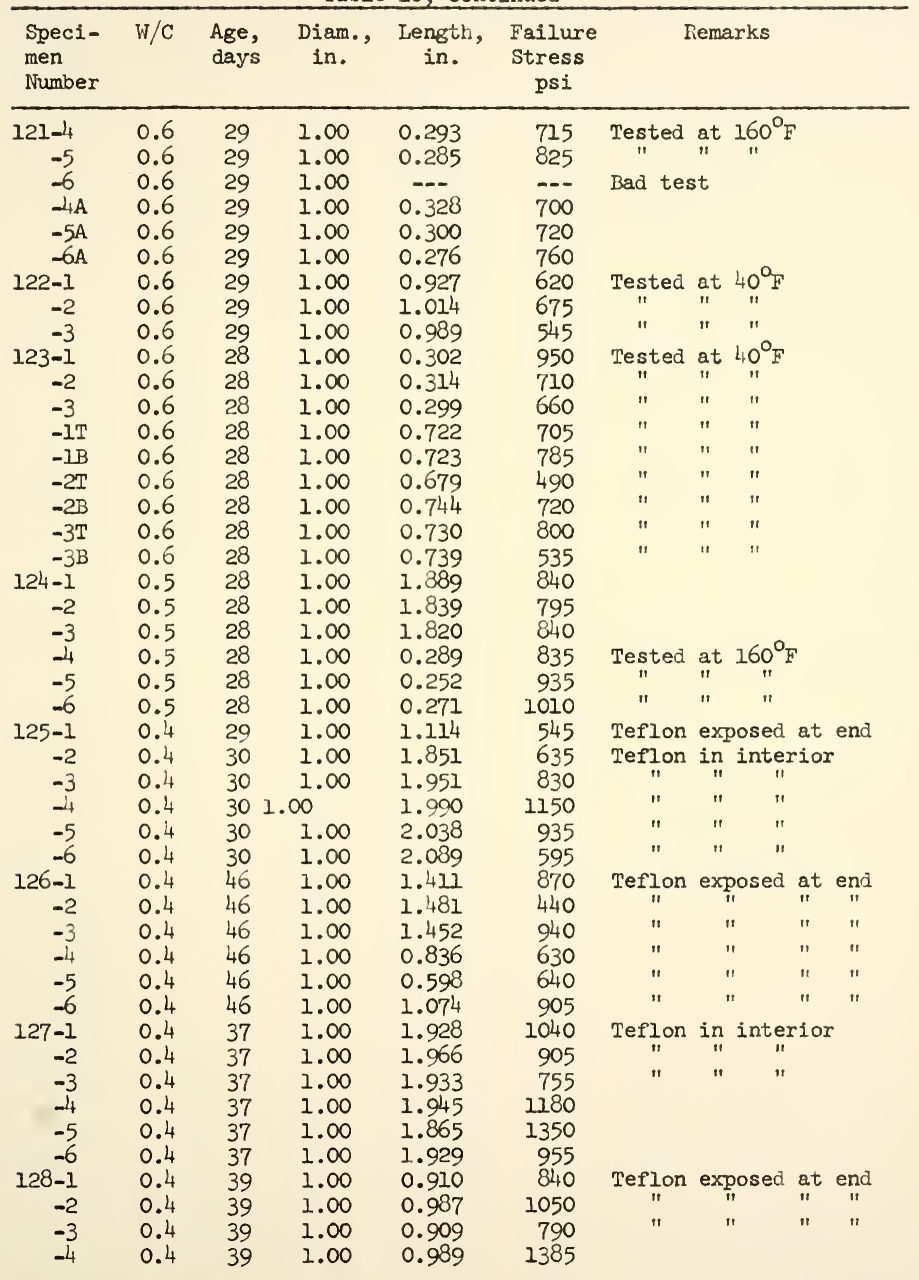


Table 18, continued

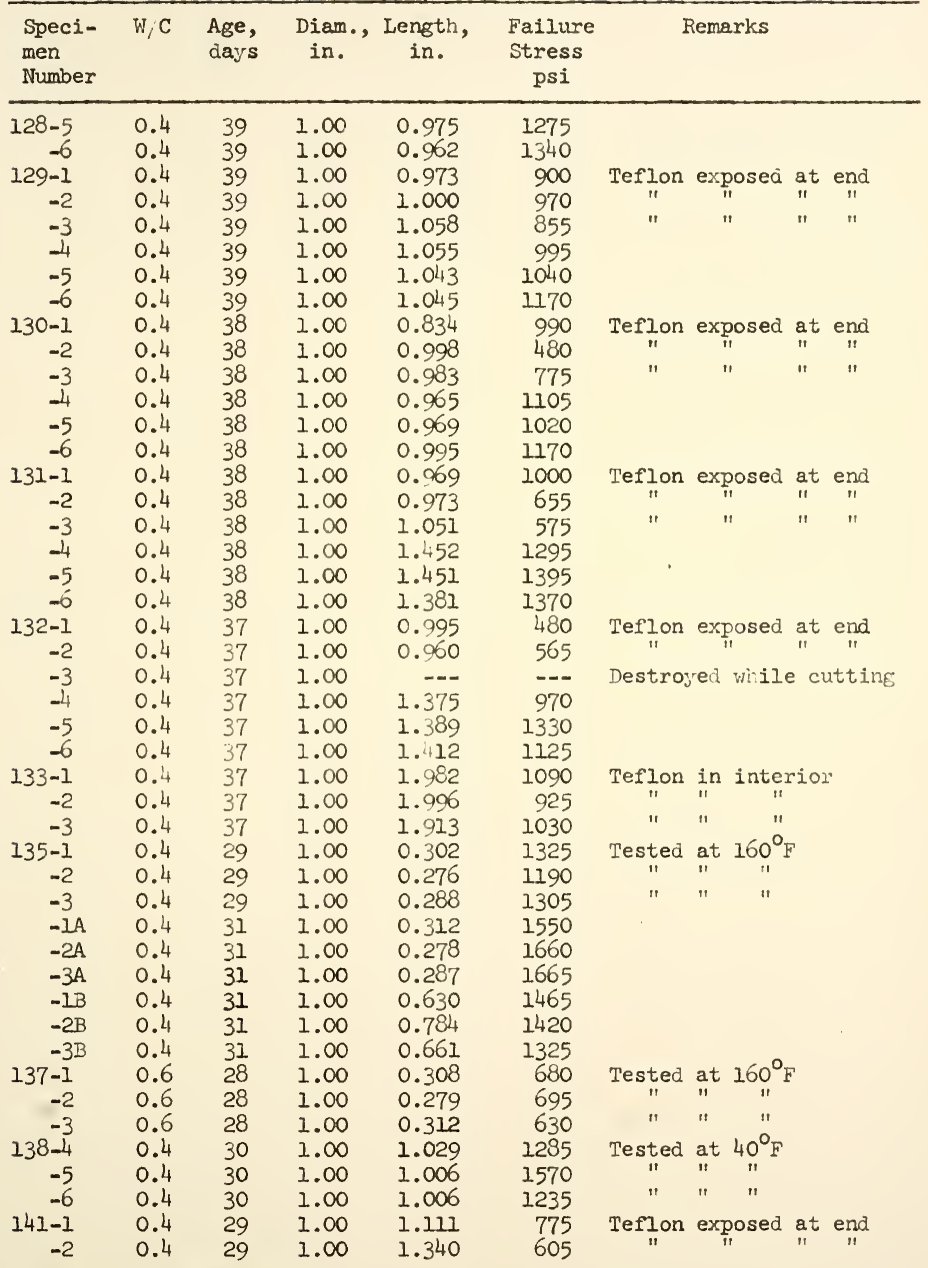


Table 18, continued

\begin{tabular}{ccccccc}
\hline $\begin{array}{l}\text { Speci- } \\
\text { men } \\
\text { Number }\end{array}$ & W/C & $\begin{array}{c}\text { Age, } \\
\text { days }\end{array}$ & $\begin{array}{c}\text { Diam., Length, } \\
\text { in. }\end{array}$ & $\begin{array}{c}\text { Failure } \\
\text { in. }\end{array}$ & $\begin{array}{c}\text { Stress } \\
\text { psi }\end{array}$ & Remarks \\
\hline $141-3$ & 0.4 & 29 & 1.00 & 1.081 & 605 & Teflon exposed at end \\
-4 & 0.4 & 29 & 1.00 & 1.405 & 1290 & \\
-5 & 0.4 & 29 & 1.00 & 1.562 & 1290 & \\
-6 & 0.4 & 29 & 1.00 & 1.516 & 1290 & \\
\hline
\end{tabular}


APPEIVIX B 
APPEIDIX B

STATISTICAL AIALYSIS OF THETA TEST RESULTS FOR $W / C=0.4$ (from Table 6)

$$
\begin{aligned}
\Sigma \mathrm{x}_{i} & =21,640 \\
\mathrm{n} & =14 \\
\overline{\mathrm{X}} & =1550 \mathrm{psi} \\
\mathrm{R} & =2170-800=1370 \mathrm{psi}
\end{aligned}
$$

The two specimens with the lowest values have large flaws present in the fracture zone which make the stress values calculated questionable. Dropping the two low values:

$$
\begin{aligned}
& \Sigma x_{i}=19,920 \\
& n=12 \\
& \bar{X}=1660 \mathrm{psi} \\
& \mathrm{R}=2170-1170=1000 \mathrm{psi} \\
& \Sigma x_{i}^{2}=34,197,850 \\
&\left(\Sigma x_{i}\right)^{2}=396,806,400 \\
& s^{2}=(34,197,850-396,806,400 / 12) / 11=102,786 \\
& s=321 \text { psi } \\
& \text { Coefficient of Variation }=\frac{321}{1660} \cdot 100=19 \%
\end{aligned}
$$


STATISTICAL ANALYSIS OF THETA I'EST RESUTTS FOR W/C $=0.5$ (from Table 7)

$$
\begin{aligned}
\Sigma \mathrm{x}_{\mathrm{i}} & =37,125 \\
\mathrm{n} & =27 \\
\overline{\mathrm{X}} & =1370 \mathrm{psi} \\
\mathrm{R} & =1825-705=1120 \mathrm{psi}
\end{aligned}
$$

The microscopic examination of the one test result with the very low value indicated that the break was not typical for theta specimens tested under normal conditions. Dropping the one low value:

$$
\begin{aligned}
& \Sigma \mathrm{x}_{i}=36,420 \\
& \mathrm{n}=26 \\
& \overline{\mathrm{x}}=1400 \mathrm{psi} \\
& \mathrm{R}=1825-1020=805 \mathrm{psi} \\
& \Sigma \mathrm{x}_{\mathrm{i}}^{2}=52,855,450 \\
&\left(\Sigma \mathrm{x}_{i}\right)^{2}=1,326,416,400 \\
& \mathrm{~s}^{2}=(52,855,450-1,326,416,400 / 26) / 25=73,561 \\
& \mathrm{~s}=271 \\
& \text { Coefficient of Variation }=\frac{271}{1400} \cdot 100=19 \%
\end{aligned}
$$


STATISTICAL AIALYSIS OF THETA TEST RESULMS FOR $\mathrm{W} / \mathrm{C}=0.6$ (from Table 8)

$$
\begin{aligned}
\Sigma x_{i} & =13,740 \\
n & =12 \\
\bar{X} & =1150 \mathrm{psi} \\
R & =1400-730=670 \mathrm{psi}
\end{aligned}
$$

Microscopical examination of the fractured surfaces of the one specimen with the low failure stress showed that the break was not typical for a theta specimen tested under normal conditions. Dropping the one low value:

$$
\begin{aligned}
& \Sigma \mathrm{x}_{\mathrm{i}}=13,010 \\
& \mathrm{n}=11 \\
& \overline{\mathrm{x}}=1180 \mathrm{psi} \\
& \mathrm{R}=1400-925=475 \mathrm{psi} \\
& \Sigma \mathrm{x}_{i}^{2}=15,623,150 \\
&\left(\Sigma \mathrm{x}_{i}\right)^{2}=169,260,100 \\
& \mathrm{~s}^{2}=(15,623,150-169,260,100 / 11) / 10=23,587 \\
& \mathrm{~s}=154 \text { psi } \\
& \text { Coefficient of Variation }=\frac{154}{1180} \cdot 100=13
\end{aligned}
$$


STATISTICAL ANALYSIS OF DIAMETRAL-COMPRESSION RESULTS WITH $W / C=0.4$

$$
\begin{aligned}
\Sigma x_{i} & =14,660 \quad \text { Data from Table } 9 . \\
n & =14 \\
\bar{X} & =1040 \mathrm{psi} \\
\mathrm{R} & =1285-600=685 \mathrm{psi}
\end{aligned}
$$

The two specimens with the very low stress values have large flaws present in the fracture zone and are not typical of the uniform specimens tested. If the two low values are dropped:

$$
\begin{aligned}
& \Sigma \mathrm{x}_{\mathrm{i}}=13,370 \\
& \mathrm{n}=12 \\
& \overline{\mathrm{x}}=1115 \mathrm{psi} \\
& \mathrm{R}=1285-855=430 \mathrm{psi} \\
& \Sigma \mathrm{x}_{\mathrm{i}}^{2}=15,164,600 \\
&\left(\Sigma \mathrm{x}_{1}\right)^{2}=178,756,900 \\
& \mathrm{~s}^{2}=(15,164,600-178,756,900 / 12) / 11=24,381 \\
& \mathrm{~s}=156 \mathrm{psi} \\
& \text { Coefficient of variation }=\frac{156}{1115} \cdot 100=14 \%
\end{aligned}
$$


STATISTICAL ANALYSIS OF DIAMETRAL-COMPRESSION RESULTS WITH $\mathrm{W} / \mathrm{C}=0.5$

$$
\begin{array}{rlr}
\Sigma x_{i} & =25,720 \quad \text { Data from Table } 10 . \\
\mathbf{n} & =30 \\
\bar{x} & =855 \mathrm{psi} \\
R & =1120-650=470 \\
\Sigma x_{i}^{2} & =22,476,000 \\
\left(\Sigma x_{i}\right)^{2} & =661,518,400 \\
s^{2} & =(22,476,000-661,518,400 / 30) / 29=14,669 \\
s & =121 \text { psi } \\
\text { Coefficient of Variation }=\frac{121}{855} \cdot 100=14 \%
\end{array}
$$


STATISTICAL ANALYSIS OF DIAMETRAL-COMPRESSION RESULTS WITH $\mathrm{W} / \mathrm{C}=0.6$

$$
\begin{aligned}
& \Sigma x_{i}=7870 \\
& \text { Data from Table } 11 . \\
& \mathrm{n}=12 \\
& \bar{X}=655 \\
& R=820-395=425
\end{aligned}
$$

The specimen with the very low failure stress value has a pattern present on the fractured surface which is not typical of specimens failed in diametral-compression under normal testing conditions. Dropping the one low value:

$$
\begin{aligned}
& \Sigma x_{i}=7475 \\
& n=11 \\
& \bar{x}=680 \\
& R=820-520=300 \\
& \Sigma x_{i}^{2}=5,206,175 \\
&\left(\Sigma x_{i}\right)^{2}=(5,206,175-55,875,625 / 11) / 10=12,657 \\
& s=112 \text { psi } \\
& \text { Coefficient of Variation }=\frac{112}{680} \cdot 100=16 \%
\end{aligned}
$$




\section{STATISTICAL ANALYSIS OF MIXING TECHNIQUES}

As the vacuum mixing technique was being investigated as a method of reducing the incidence of entrapped air voids, a series of mixes were made using both vacuum and mechanical mixing. This series of mixes (Mixes 32, 33, 34 and 35) was used to test the hypothesis that the mixing procedure does not influence the average tensile strength at failure as measured by the diametral-compression test. A summary of the statistical analysis follows.

$$
\begin{aligned}
& \text { Mechanical Mixing } \\
& \overline{\mathrm{X}}_{\mathrm{M}}=1031 \mathrm{psi} \\
& \mathrm{s}_{\mathrm{M}}=151 \mathrm{psi} \\
& \mathrm{n}=6 \\
& \text { Vacuum Mixing } \\
& \overline{\mathrm{x}}_{\mathrm{V}}=925 \mathrm{psi} \\
& \mathrm{s}_{\mathrm{V}}=232 \mathrm{psi} \\
& \mathrm{n}=6 \\
& \frac{s_{V}^{2}}{s_{M}^{2}}=2.38, \quad F_{0.05}=5.05 \text { Therefore accept } s_{V}^{2}=s_{M}^{2} \\
& s_{d}^{2}=\frac{53,780}{6}+\frac{22,614}{6}=12,732 \text { and } s_{d}=113 \\
& u=\frac{1031-925}{113}=0.94 \text {, Therefore accept } \bar{x}_{V}=\bar{x}_{M}
\end{aligned}
$$


STATISTICAL EVALUATION OF THE EFFECT OF ARTIFICIAL FLAWS

To determine the effect of artificial flaws on the failure stress of specimens tested in diametral-compression, a series of mixes were made with specimens containing artificial flaws and those without. All procedures were the same for mixing and placing of the companion specimen. Three specimens from each mix had teflon disks as artificial flaws and three specimens contained no artificial flaw. A summary of the statistical evaluation of the data follows.

$$
\begin{array}{lr}
\text { Without Flaw } & \text { With Flaw } \\
\bar{x}_{1}=1200 \mathrm{psi} & \bar{x}_{2}=780 \mathrm{psi} \\
\mathrm{s}=152 \mathrm{psi} & \mathrm{s}=198 \mathrm{psi} \\
\mathrm{n}=15 & \mathrm{n}=14 \\
\mathrm{~s}_{\mathrm{d}}^{2}=\frac{39,163}{14}+\frac{22,976}{15}=4329 \text { and } \mathrm{s}=66 & \\
\mathrm{u}=\frac{1200-780}{66}=6.35 & \\
\text { Since } t_{0.05,27}=1.70 \text { then } \bar{x}_{1} \neq \bar{x}_{2}
\end{array}
$$

The statistical evaluation shows that the hypothesis that the means are equal is not accepted. 
Table 19

ANOVA TABLE FOR DIAMETRAL-COMPRESSION RESULTS

\begin{tabular}{lcrrrr}
\hline Source of variation & df & SS & MS & F & F 0.05 \\
& & & & & \\
\hline Specimen Size & 2 & $1,948,090$ & 974,045 & 41.3 & 3.15 \\
Test Temperature & 2 & $1,440,363$ & 720,182 & 30.5 & 3.15 \\
Water-Cement Ratio & 2 & $4,253,813$ & $2,126,906$ & 90.1 & 3.15 \\
Size - Temperature Interaction & 4 & 46,891 & 11,723 & 0.5 & 2.53 \\
Size - W/C Interaction & 4 & 626,419 & 156,605 & 6.6 & 2.53 \\
Temperature - W/C Interaction & 4 & 532,379 & 133,095 & 5.6 & 2.53 \\
Size - Temp. - W/C Interaction & 8 & 160,800 & 20,100 & 0.9 & 2.10 \\
Error & 54 & $1,274,917$ & 23,610 & & \\
Totals & 80 & $10,283,672$ & & & \\
\hline
\end{tabular}




\section{REGFESSION ANALYSIS OF THETA SPECIMEN - FLAW DATA}

The data analyzed is from tests performed on theta specimens with a $\mathrm{W} / \mathrm{C}=0.4$ at age approximately 28 days. The specimens were examined microscopically and the presence of air voids was determined. The air voids were considered as flaws with edge flaws considered to be of depth $c$ and interior voils as flaws with a radius of $c$. The data are summarized along with other test results in Table 17. A logarithmic transfornation of the data was made.

$$
\begin{aligned}
& \text { Logarithmic Failure Stress }=Y \\
& \text { Logarithmic Flaw Size } c=X \\
& n=24 \\
& \Sigma X=-40.2829 \quad \Sigma Y=74.9467 \\
& \bar{X}=-1.6785 \quad \bar{Y}=3.1228 \\
& \Sigma X^{2}=69.0325 \quad \Sigma Y^{2}=234.3791 \quad \Sigma X Y=-126.4124 \\
& (\Sigma X)^{2} / n=67.6130 \quad(\Sigma Y)^{2} / n=234.0420(\Sigma X)(\Sigma Y) / n=-125.7946 \\
& \Sigma x^{2}=1.4195 \quad \Sigma y^{2}=0.3317 \quad \Sigma x y=-0.6178 \\
& b_{1}=\Sigma x y / \Sigma x^{2}=-0.4352 \\
& b_{0}=\bar{Y}-b_{1} \bar{X}=2.3923 \\
& Y=b_{0}+b_{1} X=2.3923-0.4352 x \text { or } \sigma c^{0.44}=2468 \\
& r^{2}=(\Sigma x y)^{2} /\left(\Sigma x^{2}\right)\left(\Sigma y^{2}\right)=0.798 \quad r=0.894
\end{aligned}
$$


APPENDIX C 
APPENDIX C

\section{DERIVATION OF FRACTURE EQUATION}

Assume in the medium a disc-shaped flaw of radius $c$ and oriented with its plane normal to a tensile stress field. Assume all the strain energy has been relieved in a sphere that is concentric with the disc and also of radius c. Assume, further, a linear stress-strain curve for the material so that the strain energy per unit volume is $\sigma^{2} / 2 E$. The relieved strain energy, $U_{E}$ will then be

$$
U_{E}=\frac{2 \pi \sigma^{2} c^{3}}{3 E}
$$

where

$$
\begin{aligned}
& \sigma=\text { tensile stress } \\
& \mathrm{E}=\text { Young's modulus }
\end{aligned}
$$

The total surface free energy $U_{S}$ present in the surfaces of the flaw will be

$$
U_{s}=2 \pi c^{2} \gamma
$$

where

$$
\gamma=\text { unit surface free energy of material }
$$

If now the crack grows slightly larger by an amount dc, the changes in these two energies will be

$$
d U_{E}=\frac{2 \pi \sigma^{2} c^{2} d c}{E}
$$

and

$$
\mathrm{dU}_{\mathrm{S}}=4 \pi \gamma \mathrm{cdc}
$$


Since $\mathrm{dU}_{E}$ is given up by the system and $\mathrm{dU}_{\mathrm{S}}$ is consumed by it, thermodynamic instability, or the point where the crack can propagate spontaneously, because the net free energy of the system will thereby be lowered, is

$$
\mathrm{dU}_{\mathrm{E}}=\mathrm{dU}_{\mathrm{S}}
$$

or

$$
\sigma^{2} c=2 \gamma E
$$

Equation (36) can be compared with Sack's equation (2) for a discshaped flaw

$$
\sigma^{2} c=\left(\frac{\pi}{2}\right) \mathrm{E} \gamma
$$

and Griffith's equation (1) for a slit in a thin plate

$$
\sigma^{2} c=\left(\frac{2}{\pi}\right) E \gamma
$$

The above formulations refer to plane stress conditions. To convert to plane strain conditions, for Mode I (normal stress) deformation, the right hand side of these equations must be divided by $I-v^{2}$, where $v$ is Poisson's ratio (102). Equation (38) then becomes, for plane strain

$$
\sigma^{2} c=\frac{2 E y}{1-v^{2}}
$$

If the flaw is considered spherical and the crack as a plane through the sphere then the same equation results. 
APPENDIX D 


\section{APPEIDIX D}

\section{CALCULATION OF EFFECTIVE SURTACE EISGRGY OF FARDEIED CER ETIT PASTE}

The chemical analysis in Table 1 shovs 51.2 percent of the cement to be Tricalcium Silicate, $\mathrm{C}_{3} \mathrm{~S}$, and 23.8 percent Dicalcium Silicate, $\mathrm{C}_{2} \mathrm{~S}$. The reaction of these constituents with water will, on complete hydration, produce tobermorite gel, $\mathrm{C}_{3} \mathrm{~S}_{2} \mathrm{H}_{3}$, and lime, $\mathrm{CH}$. The reactions are

$$
\begin{aligned}
& 2 \mathrm{C}_{3} \mathrm{~S}+6 \mathrm{H} \rightarrow \mathrm{C}_{3} \mathrm{~S}_{2} \mathrm{H}_{3}+3 \mathrm{CH} \\
& 2 \mathrm{C}_{2} \mathrm{~S}+4 \mathrm{H} \rightarrow \mathrm{C}_{3} \mathrm{~S}_{2} \mathrm{H}_{3}+\mathrm{CH}
\end{aligned}
$$

Assuming one gram of $\mathrm{C}_{2} \mathrm{~S}$, the reactions yield the following products.

$2.15 \mathrm{gm} \mathrm{C}_{3} \mathrm{~S} \rightarrow 1.61 \mathrm{gm}$ tobermorite $+1.265 \mathrm{gm}$ lime $1.0 \mathrm{gm} \mathrm{C}_{2} \mathrm{~S} \rightarrow 1.0 \mathrm{gm}$ tobermorite $+0.215 \mathrm{gm}$ lime or a total of $3.875 \mathrm{gm}$ of products.

By assuming that complete hydration has occurred and that tobermorite and lime are the only reaction products, on estimate of an effective surface energy time can be made. Using the results of density tests on the pastes (Table 3 ) and the densities of tobermorite and lime, an estimate of the volume of each and hence the area of a cross section can easily be made. A summary of the data is tabulated below. 
Dry Evaporable Lime Tob. $\%$ by Volume W/C Density
g/cc vater $\%$ by sp. gr. sp. gr. Water Tob. Lime

\begin{tabular}{llllllll}
\hline 0.4 & 1.65 & 36.1 & 2.23 & 2.85 & 36 & 40 & 24 \\
0.5 & 1.49 & 43.0 & 2.23 & 2.85 & 43 & 35 & 22 \\
0.6 & 1.35 & 48.5 & 2.23 & 2.85 & 48.5 & 32 & 19.5 \\
\hline
\end{tabular}

Previous studies (49) have shown that the surface free energy is approximately 90 percent of the total free energy for Magnesium Oxide. Assuming this ratio is applicable to the cement reaction products and that the tobermorite and lime along with the pore water are the constituents which must be separated as the fracture crack propagates, an erfective surface free energy value can be estimated using $90 \%$ of the total free energies of the constituents, partitioned on the volume percentages determined. Brunauer in a paper entitled "Surface Energies of Solids", presented at the Second International Congress of Surface Activity, reported values of surface energies of $1180 \mathrm{ergs} / \mathrm{cm}^{2}$ for lime and 390 ergs $/ \mathrm{cm}^{2}$ for tobermorite. This calculation yields a value of approximately $420 \mathrm{ergs} / \mathrm{cm}^{2}$ for the 0.4 water-cement ratio paste, approximately $385 \mathrm{ergs} / \mathrm{cm}^{2}$, and approximately $350 \mathrm{ergs} / \mathrm{cm}^{2}$ for the 0.5 and 0.6 watercement ratio pastes, respectively. 
VITA 
VITA

Steven John Ilanna was born in Indianapolis, Indiana on December 24, 1937. He received his primary education in public schools at Fortville, Indians and Oaklandon, Indiana. He received his secondary education in the Marion County, Indiana public school system and was graduated from Lawrence Central High School in 1955.

Mr. Hanna attended Purdue University, where he participated in the Purdue-Industrial Cooperative Program with the Indiana State Highway Commission, and received the BSCE degree from Purdue University in 1960. He was employed as an assistant project engineer with the Indiana State Highway Commission until he returned to Purdue University in September, 1960. He received the MSCE degree from Purdue University in 1962.

Mr. Hanna served as a research assistant with the Joint Highway Research Project from 1960 until January, 1967 and as an instructor in the School of Civil Engineering from 1961 until January 1967. In January, 1967, Mr. Hanna accepted a position as Assistant Professor of Civil Engineering at the University of Wyoming.

Mr. Hanna is a member of the American Society of Testing and Naterials, the American Society of Civil Engineers, the American Society of Engineering Education, Chi Epsilon and Sigma Xi. 

